Piero Luigi Fernandes Mazzini

\title{
Correntes Subinerciais na Plataforma Continental Interna entre Peruíbe e São Sebastião: Observações
}

Dissertação apresentada ao Instituto Oceanográfico da Universidade de São Paulo, como parte dos requisitos para obtenção do título de Mestre em Ciências, área de Oceanografia Física.

Orientador:

Prof. Dr. Belmiro Mendes de Castro Filho

São Paulo

2009 


\title{
UNIVERSIDADE DE SÃO PAULO INSTITUTO OCEANOGRÁFICO
}

\section{Correntes Subinerciais na Plataforma Continental Interna entre Peruíbe e São Sebastião: Observações}

\author{
Piero Luigi Fernandes Mazzini
}

Dissertação apresentada ao Instituto Oceanográfico da Universidade de São Paulo, como parte dos requisitos para obtenção do título de Mestre em Ciências, área de Oceanografia Física.

Julgada em $1+$ 


\section{Sumário}

Agradecimentos

Resumo

Abstract

vii

Lista de Figuras

XV

Lista de Tabelas

xvii

1 Introdução 1

1.1 A Plataforma Continental Sudeste . . . . . . . . . . . . . . . 5

1.1 .1 Massas de Água . . . . . . . . . . . . . . . . . . . 5

1.1 .2 Frentes . . . . . . . . . . . . . . . . . 6

1.1.3 Sistema Atmosférico . . . . . . . . . . . . . . . . . 9

1.1 .4 Circulação . . . . . . . . . . . . . . . . . . . 14

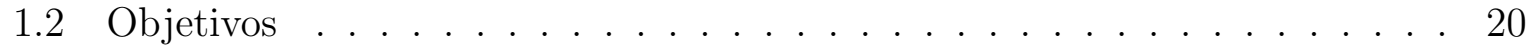

2 Dados e Métodos de Análise $\quad 21$

2.1 Conjunto de Dados . . . . . . . . . . . . . . . . . . . 21

2.2 Métodos de Análise . . . . . . . . . . . . . . . . . . . . . . 27

3 Resultados $\quad 32$

3.1 Ventos . . . . . . . . . . . . . . . . . . . . 32

3.1 .1 Correlações entre Estações Meteorológicas . . . . . . . . . . . . 36

3.1 .2 Autoespectros . . . . . . . . . . . . . . . 38

3.1.3 Espectros Cruzados entre Estações Meteorológicas . . . . . . . . . . 39 


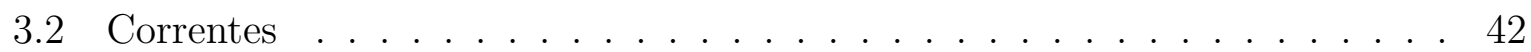

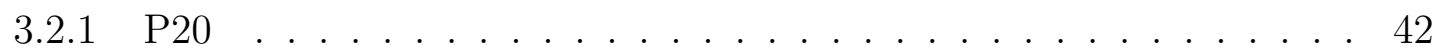

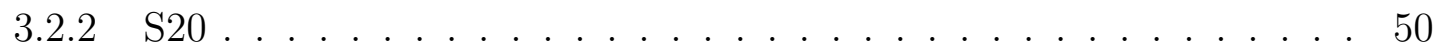

$3.2 .3 \mathrm{M} 20 \ldots \ldots \ldots \ldots \ldots \ldots \ldots \ldots$

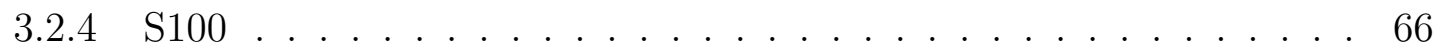

3.2 .5 Correlações entre Fundeios . . . . . . . . . . . . . . . . . . 80

3.2.6 Espectros Cruzados entre Fundeios . . . . . . . . . . . . . . . . 86

4 Discussão $r 9$

4.1 Ventos . . . . . . . . . . . . . . . . . . . . . . 89

4.2 Correntes na PCI . . . . . . . . . . . . . . . . . . . . . . . 93

4.3 Correntes na $\mathrm{PCM} \ldots \ldots \ldots \ldots$

4.4 Resposta da PCI às forçantes . . . . . . . . . . . . . . . . . . . . 99

4.5 Influência da PCM na PCI . . . . . . . . . . . . . . . . . . 105

5 Conclusão $\quad 106$

Referências Bibliográficas . . . . . . . . . . . . . 108 


\section{Agradecimentos}

Ao meu orientador Prof. Belmiro Mendes de Castro Filho, pela oportunidade, confiança e grandes ensinamentos ao longo do mestrado.

A todos os professores que contribuiram enormemente para minha aprendizagem através das disciplinas.

Ao Prof. Miranda, pela grande amizade e ensinamentos durante minha estadia no IO.

Ao Prof. Eduardo Siegle, Cláudia Yuki Omachi, Guto Schettini e Nani Truccolo, pela grande amizade e apoio, que nunca esquecerei.

Ao Prof. Pollete, pelo curtos porém intensos momentos de força, inspiração, e otimismo acima de tudo.

Ao Prof. Ílson Silveira e Prof. Paulo Polito, pela grande amizade, e pelas longas e interessantes conversas sobre dinâmica e análise de dados, assim com também bate-papos não acadêmicos.

A Profa. Sueli Susana de Godoi pela amizade, e pelas longas conversas descontraídas.

A todos os funcionários do LIO - Laboratório de Instrumentação Oceanográfica, especialmente Luiz Nonato, Franciso Vicentini, e Wilson Natal, que sempre estiveram presentes e dispostos ao auxílio.

Ao CNPQ, pelo financiamento de minha bolsa de mestrado, à FAPESP, que financiou o projeto ECOSAN, e ao Instituto Oceanográfico da Universidade de São Paulo, que forneceu infraestrutura para a realização deste trabalho.

A todos os colegas que me acompanharam ao longo do mestrado: Ana Amélia, André Schmit, B.H., Bruno, Camila, Cayo, Daniel, Déia, Fabíola, Fabrício, Fernando, Filipe \& Juliana, Francisco, Gabi, Giu, Hebe, Hélvio, Janini, José Roberto, Juliana, Jussara, 
Maanape, Márcio, Marcos, Marê, Mari, Marina, Melissa, Leandro, Leo, Luciana, Luis Felipe, Paquito, Paulo, Rafael, Raquel, República, Roga, Ruth, Sandro, Saulo, Sebastian, Tom, Vitor, Wandrey, Wellington, Zezinha.

Aos meus amigos de república Hermes e Naty, pela grande paz no convívio, e pela confiança e amizade.

Aos meus amigos e colegas dos bons tempos de graduação, que jamais esquecerei: Alexandre dos Reis, Amandita, Amaro, Ana Banana, Aninha Fátima, Bá, Baiana, Baila, Bauru, Bella, Bia, Cabelo, Cacá, Calouro F., Carol Mussi, Camilla, Capitão, Carine, Casa de Orates, Chris, Christropher, Churisba, Claudinha, Dai, Dani K., Deise, Diana, Diva, Duda, Elizandra, Ernani, Evandro, Fofurinha, Fred Schmit, Gabriel, Garça, Garibaldi, Gi, Gian \& Lela, Gordo \& Luana, Gui Pierri, Guigs, Humberto, Israel, James, Janis, Jeane, Jesus, Joice, Leopoldo C., Leticiaà, Lobato, Los Pepes \& Ella, Louri, Luis, Lú Kurita, Luluzinha, Manú, Maraba, Marçal, Marcião, Marcinho, Mari, Mato, Mel, Mendigo, Mú, Naty, Nayara, Nihues, Nil, Pai, Pânico, Paty, Paula, Pedro Escamoso, Rafa Boy, Regina, Rey, Richard, Rodrigo C., Rondônia, Sandrinha, Schroeder, Simãozinho, Tarrafa Elétrica, Tatinha, Tatuí, Tia Lú, Tiago Mineiro, Tiemi, Tio Chico, Titita, Tiozão, Tomás, Tozza, Vânia, Vinny, Vivi, Zaleski, Zeca e Zica.

Aos meus amigos de infância, os quais espero que tenham compreendido minha ausência durante esse tempo de grande dedicação ao meu trabalho: Chico, Lester, Mindú, Nara, Oscar, Rafa, Régis, Renato, Roy, Tanaka.

A minha namorada Cássia, que tem sido sempre uma grande companheira em todos os momentos, e sempre dedicada, sincera e amorosa.

E finalmente aos meus pais, Décio e Sônia, por sempre terem me amado, apoiado, e acreditado em mim durante toda minha vida, aos meus avós, Dedé, Isa, e Wanda, pelo grande amor e carinho que sempre tem me dado. Ao meu irmão Rodrigo, e todos os meus primos, tios, e quase-familiares. 


\section{Resumo}

A região costeira do Estado de São Paulo, entre Peruíbe (2424'30"S, 46 54'00” W) e São Sebastião (2350'30"S, 4540'00"W) faz parte da Plataforma Continental Sudeste do Brasil (PCSE). A região possui grande importância econômica e social devido ao turismo, indústria de óleo e gás, e ao porto de Santos, o maior do país. Correntes sobre a plataforma continental interna (PCI) dessa região foram pouco estudadas antes do projeto ECOSAN.

Durante o ECOSAN, dados de correntes foram obtidos por aproximadamente 10 meses (2005-2006), através de 4 fundeios: 3 localizados na PCI, próximo à isóbata de 20 m: em frente à Peruíbe (P20) (24²4'30"S, 46 54'00"W), em frente à Santos (S20) (2403'30"S, 46¹7’30"W), e próximo à ilha Montão de Trigo (M20) (2350"30’S, $\left.45^{\circ} 40^{\prime \prime} 00^{\prime} \mathrm{W}\right)$; e 1 localizado na plataforma continental média (PCM), próximo à isóbata de 100 m, em frente à Santos (S100) (2505’00"S, 4542’00”W). Medições de ventos foram feitas durante o mesmo período através de 2 bóias meteorológicas, localizadas junto à P20 e M20, e na Lage de Santos (L30) (2419'48"S, 46'11'20,4"W).

Os dados foram analisados no domínio do tempo e da freqüência para estudar as características das correntes bem como a importância relativa das forçantes da circulação, principalmente: tensão de cisalhamento do vento, gradientes de pressão baroclínicos e troca de momentum entre a Corrente do Brasil (CB) e as águas mais internas da plataforma continental.

Resultados mostraram que as componentes de corrente paralelas à topografia foram as mais energéticas, sendo aparentemente geostróficas. Correntes forçadas pelo vento na PCI foram observadas em P20 durante o verão e em M20. Já em S20, o vento não foi capaz de suplantar os efeitos baroclínicos causados pela descarga fluvial do sistema estuarino de Santos. Em períodos de ventos fracos M20 é forçada por efeitos baroclínicos, aparentemente sofrendo também influência do sistema estuarino de Santos. Em P20 du- 
rante o inverno foi constatada a presença de forçantes baroclínicas, sendo estas atribuídas às águas provenientes do sul, com influência do Rio da Prata, as quais possivelmente influenciam também a dinâmica da PCM.

Durante o período amostrado não foi verificado nenhuma influência direta da Corrente do Brasil sobre a PCM, e tampouco sobre a PCI, demonstrando que essas regiões possuem dinâmica distinta da plataforma continental externa.

A circulação na plataforma continental estudada não é homogênea, apresentando um sistema complexo de fluxos e contra-fluxos, havendo uma tendência das correntes sobre a PCM e a PCI apresentarem sentidos opostos. Há também tendência das correntes na PCI apresentarem sentido predominante para NE sobretudo entre Santos e São Sebastião, enquanto que na PCM a direção predominante é para SW. 


\section{Abstract}

The São Paulo State coastal region located between the cities of Peruíbe (24²4'

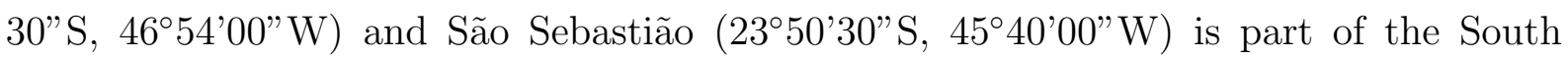
Brazil Bight. This region has great economic and social importance due to the tourism, oil and gas industries and the presence of the largest Brazilian port (Santos). Currents at the region's inner-shelf were poorly sampled before the field work of the ECOSAN project.

During ECOSAN, current meter data was obtained for nearly 10 months (20052006), from 4 moorings: 3 deployed in the inner-shelf, near the $20 \mathrm{~m}$ isobath: in front of

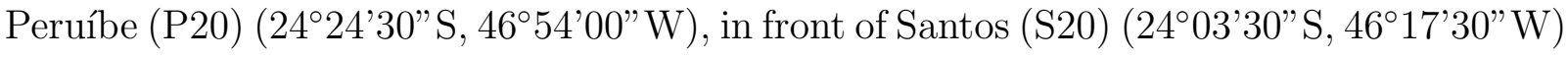
and near Montão de Trigo Island (M20) (2350"30’S, 4540" 00’W); and 1 deployed at the mid-shelf, near the $100 \mathrm{~m}$ isobath, in front of Santos (S100) $\left(25^{\circ} 05^{\prime} 00^{\prime \prime} \mathrm{S}, 45^{\circ} 42^{\prime} 00^{\prime \prime} \mathrm{W}\right)$. Wind time series were measured at the same period, at the two inner shelf moorings, P20 and M20, by a surface met-buoy, and at the Lage de Santos (L30) (24¹9'48"S, $\left.46^{\circ} 11^{\prime} 20,4^{\prime \prime} \mathrm{W}\right)$.

Current and wind data were analyzed in time and frequency domains for describing currents characteristics and comparing the relative importance of the forcing mechanisms for the inner-shelf circulation, mainly: wind-stress, baroclinic pressure gradients and Brazil Current momentum exchanges.

Results showed that alongshelf current components were the most energetic and nearly geostrophic. Wind driven currents on the inner-shelf were observed on P20 during summer time and on M20, however on S20 the wind wasn't capable of overcoming baroclinic effects caused by river discharge from the Santos estuarine system. Over weak wind periods M20 was forced by baroclinic effects, apparently also influenced by Santos estuarine system. Baroclinic forcing was observed on P20 during winter time, being atributed to waters from the south, under the influence of the Plata River, possibly influencing the 
mid-shelf as well.

During the whole period there was no presence of Brazil Current eddies or meanders, showing that neither inner-shelf nor mid-shelf are influenced by the outer-shelf dynamics.

The continental shelf circulation is not homogeneous, with a complex pattern of fluxes and counter-fluxes, where currents have tendency to flow on opposite directions between mid and inner-shelf. There is also a tendency for currents on the inner-shelf to flow towards NE, speccialy between Santos and São Sebastião, and towards SW on the mid-shelf. 


\section{Lista de Figuras}

1.1 Plataforma Continental Sudeste do Brasil (PCSE). Batimetria extraída do conjunto de dados ETOPO1 (Amante E Eakins, 2008). . . . . . . . . . . . 2

1.2 Área de estudo e posições dos fundeios correntográficos e estações meteorológicas utilizados neste trabalho. A batimetria foi digitalizada segundo as cartas náuticas de número 21070, 1711, 1701 e 23100, da DHN (2008). .

1.3 Representação esquemática das regiões da Plataforma Continental Norte do Estado de São Paulo durante o verão (superior) e inverno (inferior). FHS significa frente halina superficial; FTP frente térmica profunda; PCI, PCM e PCE as regiões interna, média e externa da plataforma continental, respectivamente; QPC a quebra da plataforma continental; CB a Corrente do Brasil. As profundidades estão expressas em m e as distâncias horizontais em km $($ Castro, 1996) . . . . . . . . . . . . . .

1.4 Tensão de cisalhamento do vento na região oeste do oceano Atlântico Sul que encompassa a plataforma continental sudeste para os meses de janeiro e julho. Figura adaptada de Castro (1996), desenhada com base nos dados interpolados por Samuels \& Cox (1987). Os contornos estão em dinas $/ \mathrm{cm}^{2}$. 10

1.5 Modelo conceitual de frente fria para a plataforma continental sudeste (Stech $\&$ Lorenzzetti, 1992). . . . . . . . . . . . . . . . . . . . . . . . . . . 12

1.6 Modelo de frente fria típica de verão sobre a PCSE, proposto por Coelho

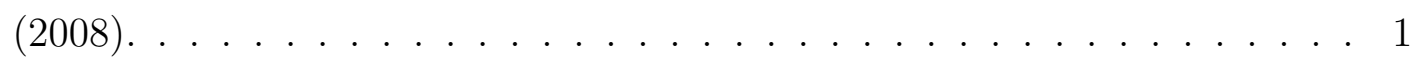

2.1 Esquemas dos fundeios utilizados pelo ECOSAN em P20 e M20. Figura gentilmente cedida pelo Laboratório de Instrumentação Oceanográfica (LIO). 23

2.2 Esquemas dos fundeios utilizados pelo ECOSAN em S100 e S20. Figura gentilmente cedida pelo Laboratório de Instrumentação Oceanográfica (LIO). 24 
2.3 Períodos referentes às observações obtidas nas estações meteorológicas (ventos) e fundeios correntográficos (superfície, meia-água, fundo ou ADCP). $\quad 30$

3.1 Distribuição temporal dos vetores velocidade do vento das séries VM20 no topo, VL30 no meio e VP202 abaixo. As unidades estão em m/s. O vetores $\mathrm{N}$ indicam as orientações do Norte para cada série e à direita estão indicadas as séries.

3.2 Diagramas vetoriais progressivos e rosas de distribuição de ventos (em cm/s) das séries de vento VM20 no topo, VL30 no meio e VP20 abaixo. Os asteríscos indicam o início das séries, as linhas pontilhadas ou tracejadas a orientação do eixo de máxima variância e a barra de cores o número de observações. . . . . . . . . . . . . . . . . . . . .

3.3 Correlação entre as séries de vento, VP202 x VL30. As linhas pontilhadas indicam intervalos de confiança de $95 \% \ldots . . \ldots . . . \ldots 36$

3.4 Correlação entre as séries de vento, VP202 x VM20. As linhas pontilhadas indicam intervalos de confiança de $95 \%$. . . . . . . . . . . . . . . 37

3.5 Correlação entre as séries de vento, VL30 x VM20. As linhas pontilhadas

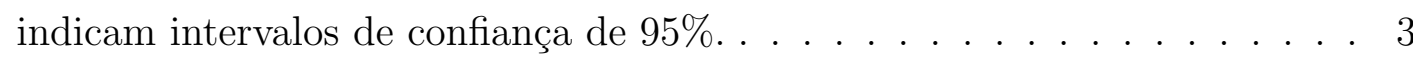

3.6 Autoespectros das séries de vento VM20 no topo, VL30 no meio, e VP202

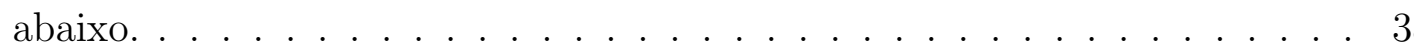

3.7 Espectros de coerência ao quadrado no topo e fase abaixo, entre as séries de vento VP202 X VL30. . . . . . . . . . . . . . . . . 39

3.8 Espectros de coerência ao quadrado no topo e fase abaixo, entre as séries de vento VP202 X VM20.

3.9 Espectros de coerência ao quadrado no topo e fase abaixo, entre as séries de vento VL30 X VM20. . . . . . . . . . . . . . . . . . . . . . . 41

3.10 Distribuição temporal dos vetores tensão de cisalhamento do vento da série VP202 e de velocidade de corrente na superfície da série P20S. As unidades de tensão estão em $\mathrm{mPa}$ e de velocidade em $\mathrm{m} / \mathrm{s}$. O vetor $\mathrm{N}$ indica a orientação do Norte e os números à direita indicam a profundidade das séries obtidas $(\mathrm{m})$ e dados de vento (tensão) . . . . . . . . . . . . . . . 
3.11 Distribuição temporal dos vetores tensão de cisalhamento do vento da série VP201 e de velocidade de corrente no fundo da série P20F. As unidades de tensão estão em $\mathrm{mPa}$ e de velocidade $\mathrm{em} \mathrm{m} / \mathrm{s}$. O vetor $\mathrm{N}$ indica a orientação do Norte e os números à direita indicam a profundidade das séries obtidas (m) e dados de vento (tensão). . . . . . . . . . . . . . . . . . . . 4

3.12 Diagramas vetoriais progressivos e rosas de distribuição de correntes (em $\mathrm{cm} / \mathrm{s}$ ) das séries de superfície P20S no topo e de fundo P20F abaixo. Os asteríscos indicam o início das séries, as linhas pontilhadas ou tracejadas a orientação da isóbata local e a barra de cores o número de observações. . . 45

3.13 Correlações entre as séries de vento e corrente na superfície, VP202 x P20S no topo, e de vento e corrente no fundo, VP201 x P20F abaixo. As linhas pontilhadas indicam intervalos de confiança de $95 \%$. . . . . . . . . . . 46

3.14 Autoespectros das séries de superfície P20S no topo, e de fundo P20F abaixo. 47

3.15 Espectros de coerência ao quadrado no topo e fase abaixo, entre vento e corrente de superfície, das séries VP202 x P20S . . . . . . . . . . . . 49

3.16 Distribuição temporal dos vetores tensão de cisalhamento do vento da série VL30 e de velocidade de corrente na superfície da série S20S1 e no fundo da série S20F1. As unidades de tensão estão em $\mathrm{mPa}$ e de velocidade em $\mathrm{m} / \mathrm{s}$. $\mathrm{O}$ vetor $\mathrm{N}$ indica a orientação do Norte e os números à direita indicam a profundidade das séries obtidas (m) e dados de vento (tensão) . . . . . . . . 52

3.17 Distribuição temporal dos vetores tensão de cisalhamento do vento da série VL30 e de velocidade de corrente na superfície da série S20S2 e fundo da série S20F2. As unidades de tensão estão em $\mathrm{mPa}$ e de velocidade $\mathrm{em} \mathrm{m} / \mathrm{s}$. $\mathrm{O}$ vetor $\mathrm{N}$ indica a orientação do Norte e os números à direita indicam a profundidade das séries obtidas $(\mathrm{m})$ e dados de vento (tensão). . . . . . . . 53

3.18 Diagramas vetoriais progressivos e rosas de distribuição de correntes (em cm/s) das séries de superfície S20S1 no topo, e fundo S20F1 abaixo.Os asteríscos indicam o início das séries, as linhas pontilhadas ou tracejadas a orientação da isóbata local e a barra de cores o número de observações. . 54 
3.19 Diagramas vetoriais progressivos e rosas de distribuição de correntes (em cm/s) das séries de superfície S20S2 no topo, e de fundo S20F2 abaixo. Os asteríscos indicam o início das séries, as linhas pontilhadas ou tracejadas a orientação da isóbata local e a barra de cores o número de observações. . . 55

3.20 Correlações entre as séries de corrente de superfície e fundo, S20S1 x S20F1. As linhas pontilhadas indicam intervalos de confiança de $95 \%$. . . . . . . 56

3.21 Correlações entre as séries de corrente de superfície e fundo, S20S2 x S20F2. As linhas pontilhadas indicam intervalos de confiança de $95 \%$. . . . . . . 56

3.22 Correlações entre as séries de vento e corrente de superfície, VL30 x S20S1 acima, e de vento e corrente de fundo, VL30 x S20F1 abaixo. As linhas pontilhadas indicam intervalos de confiança de $95 \%$. . . . . . . . . 57

3.23 Correlações entre as séries de vento e corrente de superfície, VL30 x S20S2 acima, e de vento e corrente de fundo, VL30 x S20F2 abaixo. As linhas pontilhadas indicam intervalos de confiança de $95 \%$. . . . . . . . . . . . 58

3.24 Distribuição temporal dos vetores tensão de cisalhamento do vento da série VM20 e de velocidade de corrente no fundo da série M20F1. As unidades de tensão estão em $\mathrm{mPa}$ e de velocidade em $\mathrm{m} / \mathrm{s}$. O vetor $\mathrm{N}$ indica a orientação do Norte e os números à direita indicam a profundidade das séries obtidas $(\mathrm{m})$ e dados de vento (tensão). . . . . . . . . . . . . . . . . . 60

3.25 Distribuição temporal dos vetores tensão de cisalhamento do vento da série VM20 e de corrente no fundo da série M20F2. As unidades de tensão estão em $\mathrm{mPa}$ e de velocidade em m/s. O vetor $\mathrm{N}$ indica a orientação do Norte e os números à direita indicam a profundidade das séries obtidas (m) e dados de vento (tensão) . . . . . . . . . . . . . . . . . . . . . . 61

3.26 Diagrama vetorial progressivo e rosa de distribuição de correntes $(\mathrm{em} \mathrm{cm} / \mathrm{s}$ ) da série de fundo M20F1. Os asteríscos indicam o início das séries, as linhas pontilhadas ou tracejadas a orientação da isóbata local e a barra de cores o número de observações. . . . . . . . . . . . . . . . . . . . . . 61 
3.27 Diagrama vetorial progressivo e rosa de distribuição de correntes (em cm/s) da série de fundo M20F2. Os asteríscos indicam o início das séries, as linhas pontilhadas ou tracejadas a orientação da isóbata local e a barra de cores o número de observações. . . . . . . . . . . . . . . . . . . . . . . 62

3.28 Correlação entre as séries de vento e corrente de fundo, VM20 x M20F1. As linhas pontilhadas indicam intervalos de confiança de $95 \%$. . . . . . . 63

3.29 Correlações entre as séries de vento e corrente de fundo VM20 x M20F2. As linhas pontilhadas indicam intervalos de confiança de $95 \%$. . . . . . . 63

3.30 Autoespectros das séries de corrente de fundo M20F1. . . . . . . . . . . . . 64

3.31 Autoespectros das séries de corrente de fundo M20F2 . . . . . . . . . . . . 64

3.32 Espectros de coerência ao quadrado no topo e fase abaixo, entre vento e corrente de fundo, das séries VM20 x M20F1.

3.33 Distribuição temporal dos vetores tensão de cisalhamento do vento da série VL30 e de velocidade de corrente na superfície da série S100S, em meiaágua da série S100M, e no fundo da série S100F. As unidades de tensão estão em $\mathrm{mPa}$ e de velocidade $\mathrm{em} \mathrm{m} / \mathrm{s}$. O vetor $\mathrm{N}$ indica a orientação do Norte e os números à direita indicam a profundidade das séries obtidas (m) e dados de vento (tensão)

3.34 Diagramas vetoriais progressivos e rosas de distribuição de correntes (em $\mathrm{cm} / \mathrm{s}$ ) das séries de corrente de superfície, S100S no topo, de meia-água, S100M no meio, e de fundo, S100F abaixo. Os asteríscos indicam o início das séries, as linhas pontilhadas ou tracejadas a orientação da isóbata local e a barra de cores o número de observações. . . . . . . . . . . . . . . . . .

3.35 Correlações entre as séries de corrente de superfície e meia-água, S100S x S100M no topo, de superfície e fundo, S100S x S100F no meio, e de meia-água e fundo, S100M x S100F abaixo. As linhas pontilhadas indicam intervalos de confiança de $95 \%$. . . . . . . . . . . . . . . . 70

3.36 Correlações entre as séries de vento e corrente de superfície, VL30 x S100S no topo, de vento e corrente de meia-água, VL30 x S100M no meio, e de vento e corrente de fundo, VL30 x S100F abaixo. As linhas pontilhadas indicam intervalos de confiança de $95 \% \ldots \ldots . \ldots . \ldots . \ldots 7$ 
3.37 Autoespectros das séries de corrente de superfície, S100S no topo, de meiaágua, S100M no meio, e de fundo, S100F abaixo. . . . . . . . . . . . . 73

3.38 Espectros de coerência ao quadrado no topo e fase abaixo, entre corrente na superfíe e meia-água, das séries S100S x S100M. . . . . . . . . . . . . 74

3.39 Espectros de coerência ao quadrado no topo e fase abaixo, entre corrente de superfíe e fundo, das séries S100S x S100F. . . . . . . . . . . . . . 75

3.40 Espectros de coerência ao quadrado no topo e fase abaixo, entre corrente de meia-água e fundo, das séries S100M x S100F. . . . . . . . . . . . . 76

3.41 Espectros de coerência ao quadrado no topo e fase abaixo, entre vento e corrente de superfície, das séries VL30 x S100S. . . . . . . . . . . . . . 77

3.42 Espectros de coerência ao quadrado no topo e fase abaixo, entre vento e corrente de meia-água, das séries VL30 x S100M. . . . . . . . . . . . . 78

3.43 Espectros de coerência ao quadrado no topo e fase abaixo, entre vento e corrente de fundo, das séries VL30 x S100F. . . . . . . . . . . . . . . 79

3.44 Correlação entre as séries de corrente de fundo P20F x S20F1. As linhas pontilhadas indicam intervalos de confiança de $95 \%$. . . . . . . . . . . 80

3.45 Correlação entre as séries de corrente de fundo P20F x M20F1. As linhas

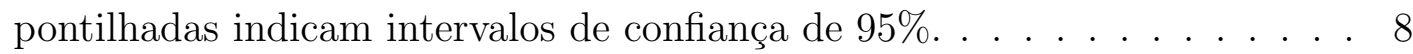

3.46 Correlação entre as séries de corrente de superfície P20S x S100S. As linhas pontilhadas indicam intervalos de confiança de $95 \%$. . . . . . . . . . . 81

3.47 Correlação entre as séries de corrente de fundo S20F1 x M20F1. As linhas pontilhadas indicam intervalos de confiança de $95 \%$. . . . . . . . . . . . 82

3.48 Correlação entre as séries de corrente de fundo S20F2 x M20F2. As linhas pontilhadas indicam intervalos de confiança de $95 \%$. . . . . . . . . . . 82

3.49 Correlação entre as séries de corrente de superfície S20S1 x S100S. As linhas pontilhadas indicam intervalos de confiança de $95 \% \ldots . . . . . . . .83$

3.50 Correlação entre as séries corrente de superfície, S20S2 x S100S, e de fundo S20F2 x S100F. As linhas pontilhadas indicam intervalos de confiança de $95 \%$.

3.51 Correlação entre as séries de corrente de fundo M20F2 x S100F. As linhas pontilhadas indicam intervalos de confiança de $95 \%$. . . . . . . . . . 
3.52 Espectros de coerência ao quadrado no topo e fase abaixo, entre corrente de fundo, das séries P20F X M20F. . . . . . . . . . . . . . 86

3.53 Espectros de coerência ao quadrado no topo e fase abaixo, entre corrente de superfície, das séries P20S X S100S. . . . . . . . . . . . . 87

3.54 Espectros de coerência ao quadrado no topo e fase abaixo, entre corrente de fundo, das séries M20F2 X S100F. . . . . . . . . . . . . . 88

4.1 Climatologia da tensão de cisalhamento do vento sobre a PCSE para o período de verão, elaborada por Coelho (2008) . . . . . . . . . . . . . . 92

4.2 Distribuição superficial de temperatura (em cima) e salinidade (embaixo) climatológica de verão na plataforma continental e talude sudeste, obtida com dados históricos (Rezende, 2003). . . . . . . . . . . . . 100

4.3 Distribuição superficial de temperatura (em cima) e salinidade (embaixo) climatológica de inverno na plataforma continental e talude sudeste, obtida com dados históricos (Castro $\&$ Miranda, 1998) . . . . . . . . . . . . . . 102 


\section{Lista de Tabelas}

2.1 Cruzeiros oceanográficos realizados para instalação, manutenção e recuperação de estações autônomas meteoceanográficas, durante o projeto ECOSAN. 22

2.2 Informações sobre os fundeios oceanográficos do projeto ECOSAN que originaram os dados utilizados neste trabalho. Prof. é profundidade. . . . . . . 25

2.3 Informações sobre as estações meteorológicas do projeto ECOSAN que originaram os dados utilizados neste trabalho. Prof. é a profundidade. . . . . . 26

2.4 Orientação das isóbatas locais na posição dos fundeios correntográficos, medida positivamente no sentido antihorário em relação ao eixo x (Leste). . 28

2.5 Orientação dos eixos de máxima variância das séries de vento filtradas, medida positivamente no sentido antihorário em relação ao eixo x (Leste). . 28

2.6 Séries temporais de corrente editadas e filtradas disponíveis para análise. 29

2.7 Séries temporais de vento editadas e filtradas disponíveis para análise. . . . 30

3.1 Primeiros momentos estatísticos para as séries de vento filtradas. U e V correspondem às componentes de mínima e máxima variância, respectivamente. Dir é a orientação das componentes em graus medida positivamente no sentido antihorário em relação ao eixo x (Leste); Min é o valor mínimo e Max é o valor máximo (em m/s); Amp é a diferença entre Max e Min (em m/s); M. é a média; D.Pad é o desvio padrão da média (em m/s); Var é a variância $\left(\mathrm{m}^{2} / \mathrm{s}^{2}\right)$ e \% é a porcentagem que a variância da série filtrada representa com relação à variância da série original. . . . . . . . . . . . . . 33 
3.2 Primeiros momentos estatísticos para séries correntográficas filtradas para o fundeio P20. U e V correspondem às componentes transversais e paralelas às isóbatas locais, respectivamente. Min é o valor mínimo e Max é o valor máximo (em m/s); Amp é a diferença entre Max e Min (em m/s); M. é a média; D.Pad é o desvio padrão da média (em m/s); Var é a variância $\left(\mathrm{m}^{2} / \mathrm{s}^{2}\right)$ e $\%$ é a porcentagem que a variância da série filtrada representa com relação à variância da série original. . . . . . . . . . . . . . . . . . . . 42

3.3 Primeiros momentos estatísticos para séries correntográficas filtradas para o fundeio S20. U e V correspondem às componentes transversais e paralelas às isóbatas locais, respectivamente. Min é o valor mínimo e Max é o valor máximo (em m/s); Amp é a diferença entre Max e Min (em m/s); M. é a média; D.Pad é o desvio padrão da média (em m/s); Var é a variância $\left(\mathrm{m}^{2} / \mathrm{s}^{2}\right)$ e $\%$ é a porcentagem que a variância da série filtrada representa com relação à variância da série original. . . . . . . . . . . . . . . . . . . . 50

3.4 Primeiros momentos estatísticos para séries correntográficas filtradas para o fundeio M20. U e V correspondem às componentes transversais e paralelas às isóbatas locais, respectivamente. Min é o valor mínimo e Max é o valor máximo (em m/s); Amp é a diferença entre Max e Min (em m/s); M. é a média; D.Pad é o desvio padrão da média (em $\mathrm{m} / \mathrm{s})$; Var é a variância $\left(\mathrm{m}^{2} / \mathrm{s}^{2}\right)$ e $\%$ é a porcentagem que a variância da série filtrada representa com relação à variância da série original. . . . . . . . . . . . . . . . . . . 5

3.5 Primeiros momentos estatísticos para séries correntográficas filtradas para o fundeio S100. U e V correspondem às componentes transversais e paralelas às isóbatas locais, respectivamente. Min é o valor mínimo e Max é o valor máximo (em m/s); Amp é a diferença entre Max e Min (em m/s); M. é a média; D.Pad é o desvio padrão da média (em m/s); Var é a variância $\left(\mathrm{m}^{2} / \mathrm{s}^{2}\right)$ e $\%$ é a porcentagem que a variância da série filtrada representa com relação à variância da série original. . . . . . . . . . . . . . . . . . . 66 


\section{Capítulo 1}

\section{Introdução}

A plataforma continental, ambiente transicional entre o continente e o oceano profundo, vem sofrendo grande impacto das civilizações costeiras que continuamente nela injetam os mais diversos contaminantes, tais como: lixo, esgotos, dejetos industriais, calor proveniente, por exemplo, da operação de usinas nucleares e termoelétricas. Além disso, com o grande crescimento populacional nas áreas costeiras, tem-se observado o aumento de problemas relacionados ao uso e ocupação do espaço marinho, dos quais podem ser destacados a sobre-pesca, maricultura, construção de portos e marinas, operações da indústria de óleo e gás, recifes artificiais, molhes, espigões e emissários submarinos.

Evidentemente, o transporte e dispersão de todas substâncias e materiais presentes no meio marinho são dependentes, primordialmente, das correntes marinhas. Dentro deste contexto, torna-se clara a necessidade da melhor compreensão e do monitoramento contínuo dos processos físicos e das forçantes que controlam a dinâmica da zona mais costeira da plataforma continental. Entretanto, há relativamente poucos esforços nesse sentido, dirigido aos ambientes costeiros, nos países emergentes.

Na costa sudeste brasileira, encontra-se uma das principais feições geomorfológicas da plataforma continental brasileira, o chamado "Embaiamento de São Paulo" (Castro 6 Lee, 1995), também conhecido como "Embaiamento de Santos" (Campos et al., 1995), ou ainda "Plataforma Continental Sudeste" (PCSE) (Castro, 1996). Com o formato de uma lua crescente, a PCSE é delimitada ao norte por Cabo Frio $\left(23^{\circ} \mathrm{S}\right)$ e ao sul pelo Cabo de Santa Marta (28 40' S), com uma extensão de aproximadamente 1100 km (Figura 1.1). 


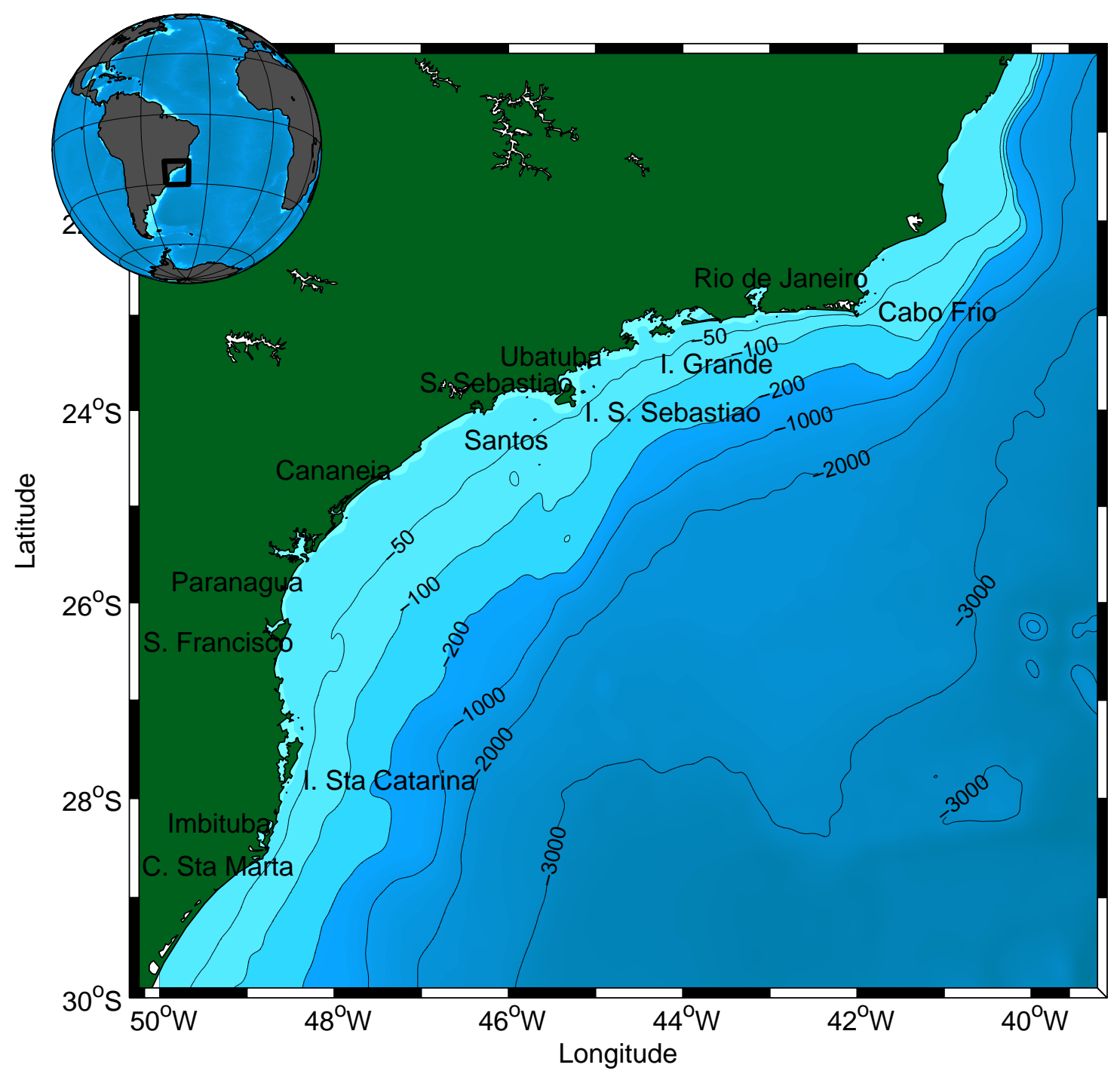

Figura 1.1: Plataforma Continental Sudeste do Brasil (PCSE). Batimetria extraída do conjunto de dados ETOPO1 (Amante 83 Eakins, 2008). 
Segundo Zembruscki (1979), excetuando-se algumas poucas ilhas grandes próximas à costa, como por exemplo: Ilha de Santa Catarina, Ilha de São Francisco, Ilha de São Sebastião e Ilha Grande, a PCSE possui relevo suave e monótono, sendo sua região mais larga em frente a Santos com 230 km, as regiões mais estreitas próximo ao Cabo Frio com $50 \mathrm{~km}$ e Santa Marta com 70 km, abrangendo uma área total de aproximadamente 150.000 $\mathrm{km}^{2}$. Zembruscki (1979), ainda verificou que os contornos batimétricos acompanham o formato da linha de costa e que a quebra da plataforma ocorre entre as isóbatas de 120 e 180 metros.

A PCSE apresenta características dinâmicas típicas de plataformas continentais de latitudes médias, uma vez que está suficientemente longe do Equador para que a rotação da Terra e conseqüentemente o efeito de Coriolis sejam importantes. Assim, apresenta geostrofia em fluxos de escalas temporais maiores que o período inercial e escalas espaciais maiores que o Raio de Deformação de Rossby.

Os movimentos das águas da PCSE são gerados por uma combinação de diferentes forçantes, tais como: a Corrente do Brasil, as marés, os ventos e as descargas fluviais, cada qual atuando em regiões diferentes da PCSE e em distintas escalas espaciais e temporais. A região mais interna da PCSE não sofre, em geral, influência direta da Corrente do Brasil como forçante; as correntes de maré na PCSE são pouco energéticas e não há deságue de grandes rios (Castro, 1996). Assim, supostamente, uma das forçantes mais energéticas da PCSE é o vento.

A área de estudo do presente trabalho compreende a região da plataforma continental interna na porção central da PCSE, entre Peruíbe e São Sebastião (Figura 1.2). Nessa região está localizado o maior porto do Brasil, o porto de Santos, além disso possui uma grande importância turística e na exploração de gás e óleo. 


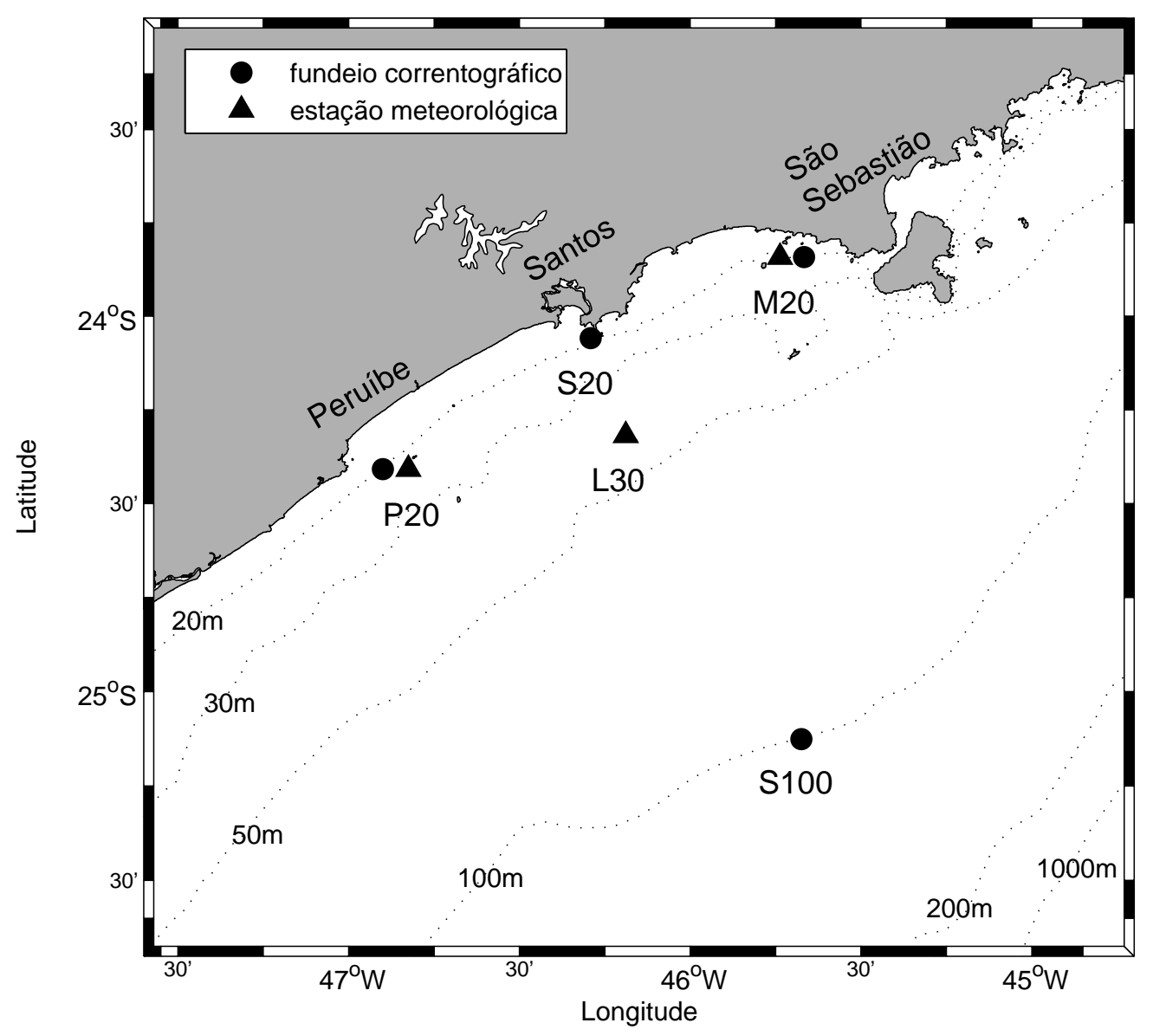

Figura 1.2: Área de estudo e posições dos fundeios correntográficos e estações meteorológicas utilizados neste trabalho. A batimetria foi digitalizada segundo as cartas náuticas de número 21070, 1711, 1701 e 23100, da $D H N(2008)$. 


\subsection{A Plataforma Continental Sudeste}

Para possível compreensão da dinâmica da plataforma continental interna é necessário antes conhecer as principais características oceanográficas (físicas) da PCSE em sua íntegra, uma vez que os processos não ocorrem isoladamente em cada região, mas ao contrário, há trocas de energia e de massa entre elas.

\subsubsection{Massas de Água}

De acordo com Emilson (1961), e posteriormente confirmado por diversos outros autores (Miranda (1982, 1985); Castro et al. (1987); Castro (1996); Miranda \& Katsuragawa (1991)), as massas de água sobre a PCSE são o resultado da mistura entre:

- Água Tropical (AT) (T>20,0 C e S>36,40; Miranda (1982)) transportada na direção sudoeste pela camada superficial da Corrente do Brasil (0-200 m) próxima à quebra da plataforma continental;

- Água Central do Atlântico Sul (ACAS) (T<20,0C e S<36,40; Miranda (1982)) transportada na direção sul pela camada inferior da Corrente do Brasil (200-500 m), ao longo do talude continental, próximo à quebra da plataforma continental;

- Água Costeira (AC), resultante da mistura das águas sobre a plataforma continental com o aporte continental de água doce, possuindo baixa salinidade principalmente devido à presença de pequenos e médios estuários na PCSE.

A região mais interna da PCSE é ocupada principalmente pela AC, com a coluna de água praticamente homogênea devido à mistura causada pela turbulência imposta pela tensão de cisalhamento do vento na superfície e do cisalhamento das correntes de maré com o fundo. Nas regiões mais afastadas da costa, encontra-se próximo à superfície, águas influenciadas principalmente pela AT e, próximo ao fundo, águas influenciadas pela ACAS (Castro, 1996).

Em aspectos gerais, a posição dessas massas de água varia sazonalmente: durante o verão ocorre a penetração da ACAS na camada subsuperficial da região mais costeira da plataforma; já, durante o inverno, há o afastamento da ACAS, aumentando o domínio da AC na porção mais costeira (Castro et al., 1987). 
As propriedades físicas das águas da PCSE são condicionadas por uma série de processos físicos que ocorrem em diversas escalas temporais e espaciais (Castro, 1996):

- Na escala temporal interanual podem ocorrer perturbações sobre o ciclo hidrológico climatológico médio, apresentando dessa forma variações dos índices de pluviosidade que, por fim, têm como consequência variações no campo de salinidade.

- Na escala temporal sazonal, variações da radiação solar incidente sobre a superfície do oceano, assim como diferenças entre precipitação e evaporação influenciam o campo de temperatura e salinidade. Variações do campo de vento médio e do vento de maior frequência incitam mistura por processos turbulentos e também são responsáveis por correntes sazonais.

- Na mesoescala temporal (da ordem de 100 dias), podem ocorrer principalmente penetrações de vórtices frontais e meandros da Corrente do Brasil, transportando energia e massa plataforma a dentro.

- Na escala de tempo subinercial, altamente relacionado à passagem de frentes sinóticas na atmosfera, podem ocorrer fenômenos como ressurgência e subsidência costeira, oscilações de frentes térmicas ou halinas e, principalmente, inversões das correntes geradas pelo vento.

\subsubsection{Frentes}

"Frentes são em geral caracterizadas como zonas em que ocorre a intensificação do gradiente quase-horizontal de uma ou mais propriedades físicas" (Castro, 1996). Segundo Castro (1996), na PCSE há a presença de 2 frentes: a Frente Térmica Profunda (FTP), que separa as regiões interna e média da PCSE e a Frente Halina Superficial (FHS), que separa as regiões média e externa da PCSE.

A FTP é a instersecção da termoclina com o fundo, formada na região de encontro entre águas influenciadas pela ACAS e pela AC, separando no fundo água oceânica relativamente fria (ACAS) de água costeira mais quente (AC), estando associada a intrusões subsuperficiais das águas transportadas pela Corrente do Brasil em direção à costa.

A FHS pode ser caracterizada como sendo uma frente de quebra de plataforma, principalmente durante o verão, apesar de não estar posicionada exatamente sobre a 
quebra da plataforma. Também associada à intrusões da Corrente do Brasil, a FHS separa na camada superficial águas com influências costeiras (AC) e águas oceânicas (AT).

Castro (1996), baseando-se em características termohalinas e dinâmicas, sugeriu divisão da parte norte da PCSE em 3 regiões (Figura 1.3), possuindo variação sazonal:

- Plataforma Continental Interna (PCI), localizada entre a costa e a FTP; durante o verão é mais estreita, com largura variando entre 10-30 km, até as isóbatas de 20-40m e, no inverno, é mais larga, entre 40-80 km, até as isóbatas de 50-70 m. A PCI apresenta uma alta homogeneidade tridimensional de suas características hidrográficas durante todo o ano. No verão as águas são mais quentes e mais salinas quando comparadas ao inverno, com valores de temperatura acima de $21-22^{\circ} \mathrm{C}$, podendo atingir máximos de $27-28^{\circ} \mathrm{C}$, e valores de salinidade variando entre 34,4 e 35,4 . Durante o inverno são observadas temperaturas menores que $22-23^{\circ} \mathrm{C}$, podendo atingir mínimos de $19-20^{\circ} \mathrm{C}$, e a salinidade com maior variação nessa estação, apresentando valores mínimos de 33,4 e máximos de 38,8.

- Plataforma Continental Média (PCM), localizada entre a FTP e a FHS; durante o verão pode variar entre 10-30 km até $60-80 \mathrm{~km}$ da costa, entre as isóbatas de 20-40 m e 70-90 m, enquanto que no inverno ocupa uma faixa estreita entre 40$60 \mathrm{~km}$ e $60-80 \mathrm{~km}$ da costa, podendo muitas vezes colapsar sendo englobada pela PCI. A PCM apresenta uma alta estratificação durante o verão devido à presença da termoclina sazonal, formada pela intrusão da ACAS, processo esse ocasionado pela ação dos ventos com alta persistência temporal provenientes dos quadrantes norte e nordeste. Durante o verão, apresenta na superfície temperaturas entre 22$24^{\circ} \mathrm{C}$, com salinidade entre $35-35,4$ e, no fundo, temperaturas entre $14-15^{\circ} \mathrm{C}$, com salinidade entre 35,6-35,8. Durante o inverno há o enfraquecimento da termoclina sazonal. Observa-se, assim, uma coluna de água com maior homogeneidade de características hidrográficas.

- Plataforma Continental Externa (PCE), com pouca variação espacial durante o ciclo sazonal, localizada entre a FHS e a quebra da plataforma continental; seu limite interno encontra-se entre 60-80 km da costa, sob as isóbatas de 70-90 m. A PCE apresenta acentuada estratificação vertical, porém com pequena variação sazonal. 
Durante o verão apresenta na superfície valores típicos de temperatura de $24,0^{\circ} \mathrm{C}$ e salinidade de 36,2 , já, durante o inverno, valores típicos de temperatura de $22,0^{\circ} \mathrm{C}$ e salinidade de 35,6. No fundo praticamente não há variação sazonal das propriedades hidrográficas, apresentando valores típicos de temperatura de $14,0^{\circ} \mathrm{C}$ com salinidade de 35,4 .
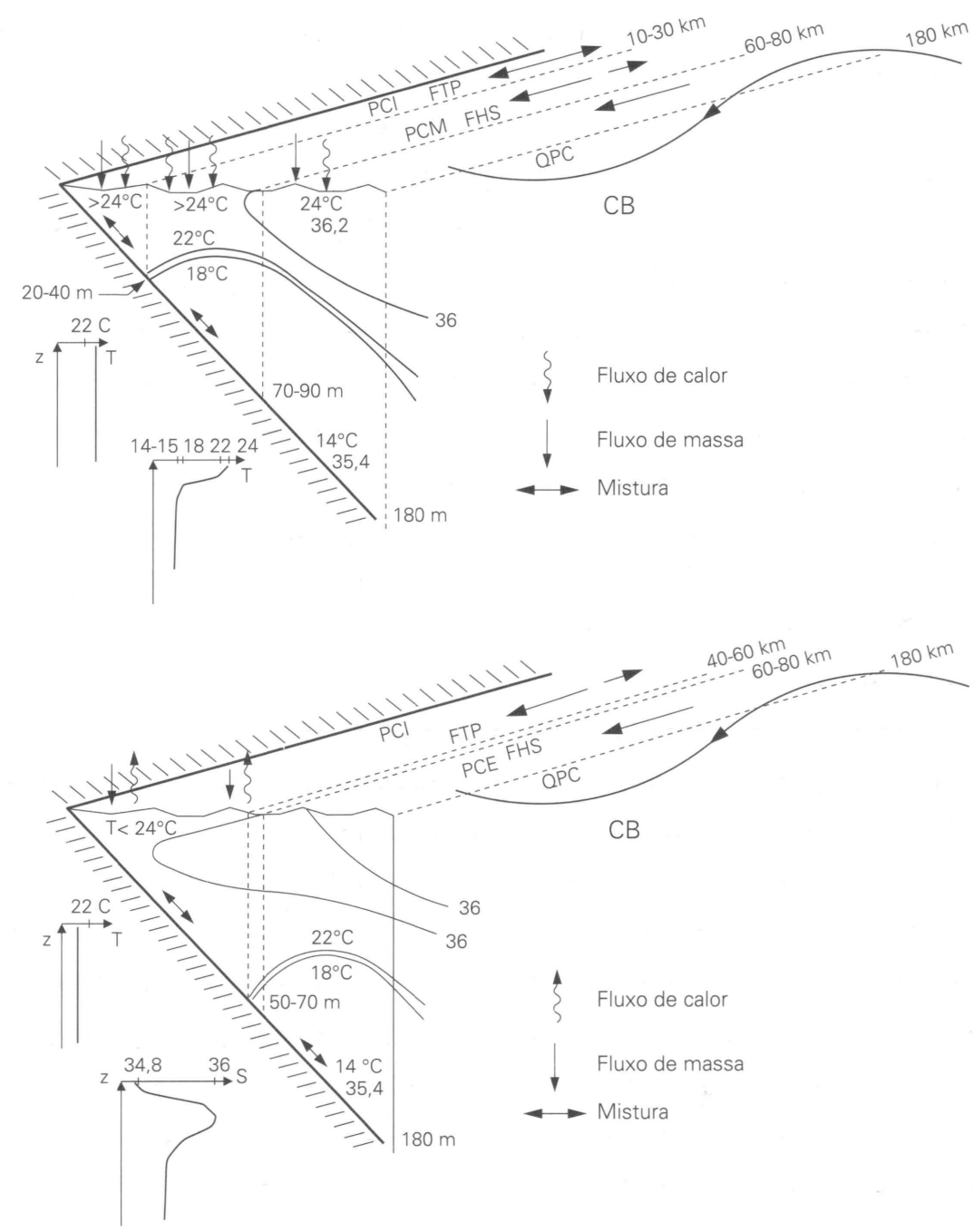

Figura 1.3: Representação esquemática das regiões da Plataforma Continental Norte do Estado de São Paulo durante o verão (superior) e inverno (inferior). FHS significa frente halina superficial; FTP frente térmica profunda; PCI, PCM e PCE as regiões interna, média e externa da plataforma continental, respectivamente; QPC a quebra da plataforma continental; CB a Corrente do Brasil. As profundidades estão expressas em m e as distâncias horizontais em km (Castro, 1996). 


\subsubsection{Sistema Atmosférico}

Diversos estudos demonstram a importância dos sistemas atmosféricos de meso e larga escala para dinâmica de plataformas continentais em escala subinercial e sazonal.

Sob o Atlântico Sul, em latitudes médias, encontra-se na atmosfera um centro de alta pressão, a Alta Subtropical, sendo responsável pela indução do giro subtropical do campo de ventos em larga escala. A Alta Subtropical tem uma grande influência sob o campo de ventos presente na região da PCSE. Sua posição e profundidade oscilam sazonalmente.

Castro (1996) descreveu a climatologia da tensão de cisalhamento do vento na PCSE utilizando dados interpolados por Samuels $\&$ Cox (1987) à partir de dados históricos de Hellerman $\mathscr{G}$ Rosenstein (1983), uma vez que sob a região não há dados observacionais em quantidade suficiente para a caracterização do vento sazonal médio. A Figura 1.4 apresenta os dados da tensão de cisalhamento do vento para os meses de janeiro e julho. 

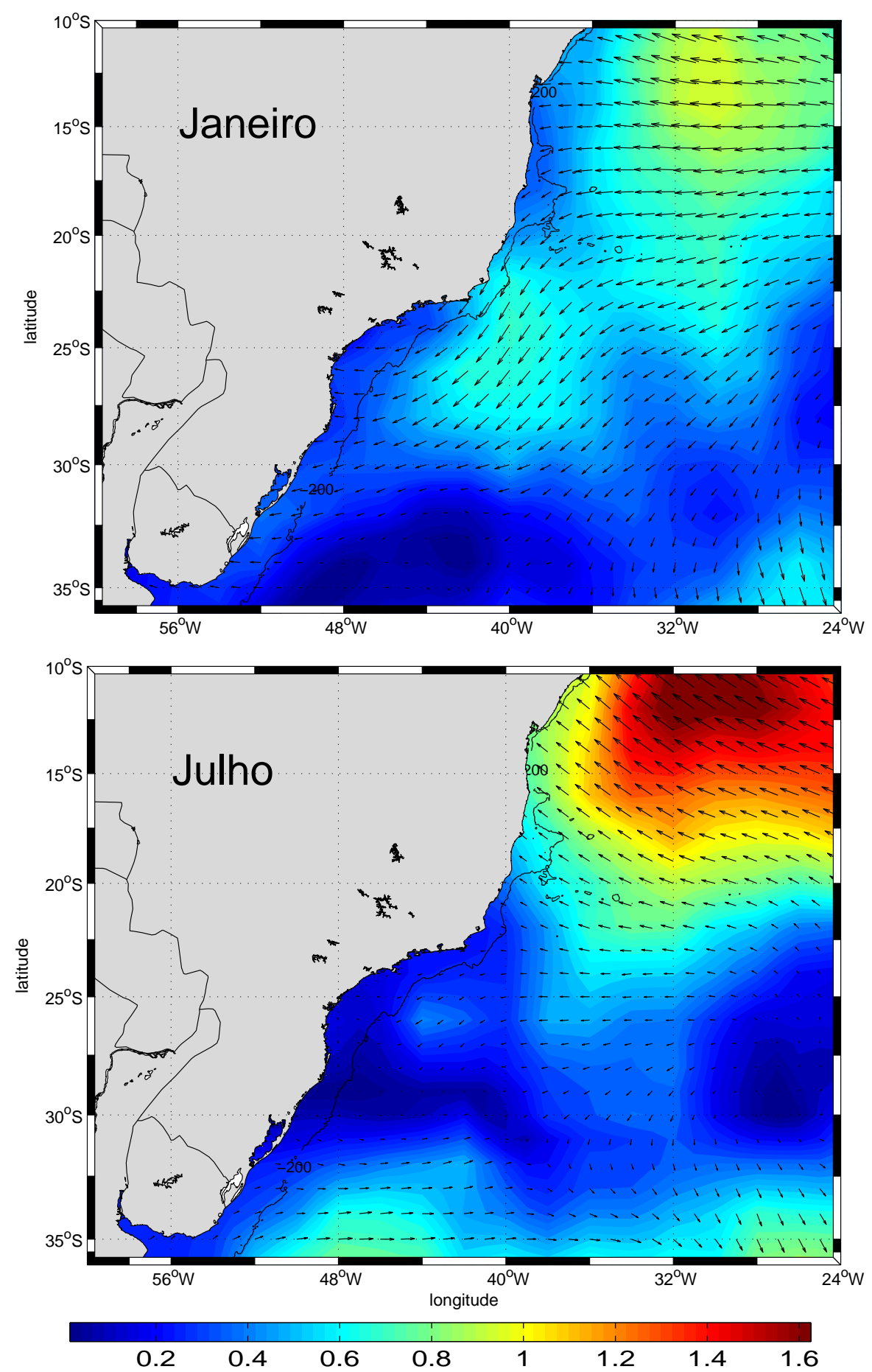

Figura 1.4: Tensão de cisalhamento do vento na região oeste do oceano Atlântico Sul que encompassa a plataforma continental sudeste para os meses de janeiro e julho. Figura adaptada de Castro (1996), desenhada com base nos dados interpolados por Samuels \& Cox (1987). Os contornos estão em dinas $/ \mathrm{cm}^{2}$. 
Pode-se observar a presença marcante da parte oeste do giro subtropical, que durante o verão provê à região da PCSE ventos de leste-nordeste entre $15^{\circ} \mathrm{S}$ e $35^{\circ} \mathrm{S}$. Durante o inverno, os ventos de leste-nordeste presentes no giro subtropical ficam confinados entre $20^{\circ} \mathrm{S}$ e $25^{\circ} \mathrm{S}$, e a região ao sul de $25^{\circ} \mathrm{S}$ é caracterizada por ventos provenientes de oeste-sudoeste.

Em escala sinótica, uma das principais perturbações na atmosfera em latitudes médias é a passagem de sistemas meteorológicos frontais, ou frentes frias. Em geral, essas frentes tem sua gênese associada à ondas baroclínicas presentes nos ventos predominantes de oeste existentes no Oceano Pacífico entre $50^{\circ} \mathrm{S}$ e $60^{\circ} \mathrm{S}$ (Castro, 1996).

Segundo Stech (1990), o campo de ventos na PCSE é altamente influenciado pela passagem de sistemas frontais, principalmente durante o inverno, com intervalos entre 6 e 11 dias. Stech $\&$ Lorenzzetti (1992) elaboraram um modelo conceitual de passagem de frentes frias sob a PCSE (Figura 1.5) baseando-se em cartas meteorológicas sinóticas e imagens termais do satélite GOES. Segundo os autores, o deslocamento típico da frente é de sudoeste para nordeste, com velocidade de aproximadamente $500 \mathrm{~km} /$ dia. No setor quente os ventos têm intensidade média de $5 \mathrm{~m} / \mathrm{s}$, giram de nordeste para noroeste com a aproximação da frente e, no setor frio, os ventos têm intensidade média de $8 \mathrm{~m} / \mathrm{s}$ e direção predominante de sudoeste, com rotação em sentido anti-horário, mudando para direção sudeste cerca de 24 horas após a passagem da frente. 


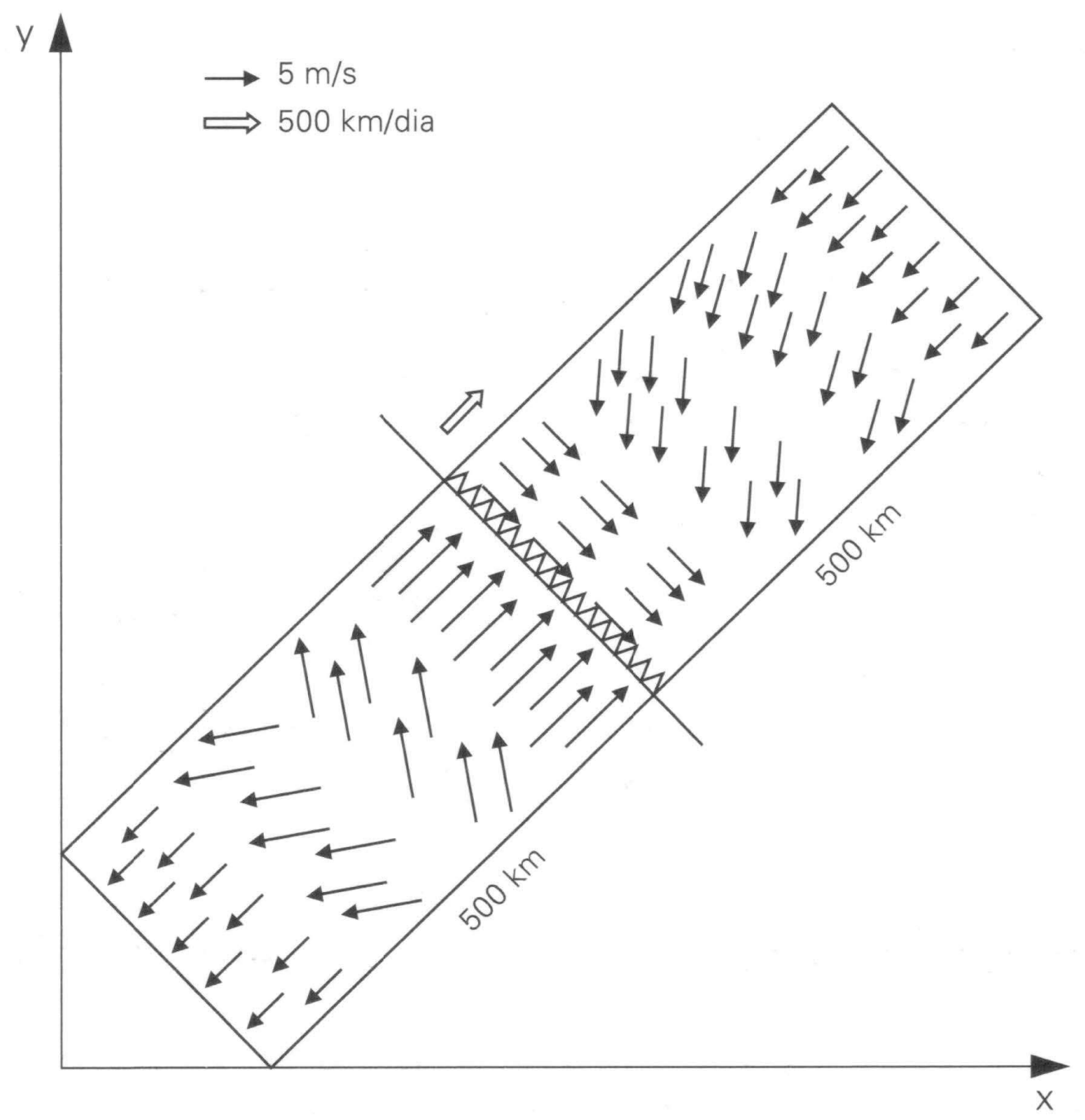

Figura 1.5: Modelo conceitual de frente fria para a plataforma continental sudeste (Stech $\&$ Lorenzzetti, 1992). 
Um modelo mais recente e com maior detalhamento das características transientes da passagem de frentes frias sobre a PCSE foi proposto por Coelho (2008) (Figura 1.6). O autor analisou cartas sinóticas referentes a um período de 8 anos (1998 até 2005) elaboradas pela Diretoria de Hidrografia e Navegação (DHN), identificando frentes que percorreram a PCSE desde o Cabo de Santa Marta até o Cabo de São Tomé. Foram selecionadas 12 frentes frias e suas velocidades de propagação calculadas admitindo-se uma propagação linear de SW para NE. O autor concluíu que a velocidade média de propagação das frentes frias é mais rápida no verão do que no inverno; velocidades típicas das frentes no verão são de $32,8 \mathrm{~km} / \mathrm{h}$ ou $9,1 \mathrm{~m} / \mathrm{s}(787,2 \mathrm{~km} /$ dia $)$, e que em média as frentes atravessam os 1033,4 km da PCSE em 31,5 horas.
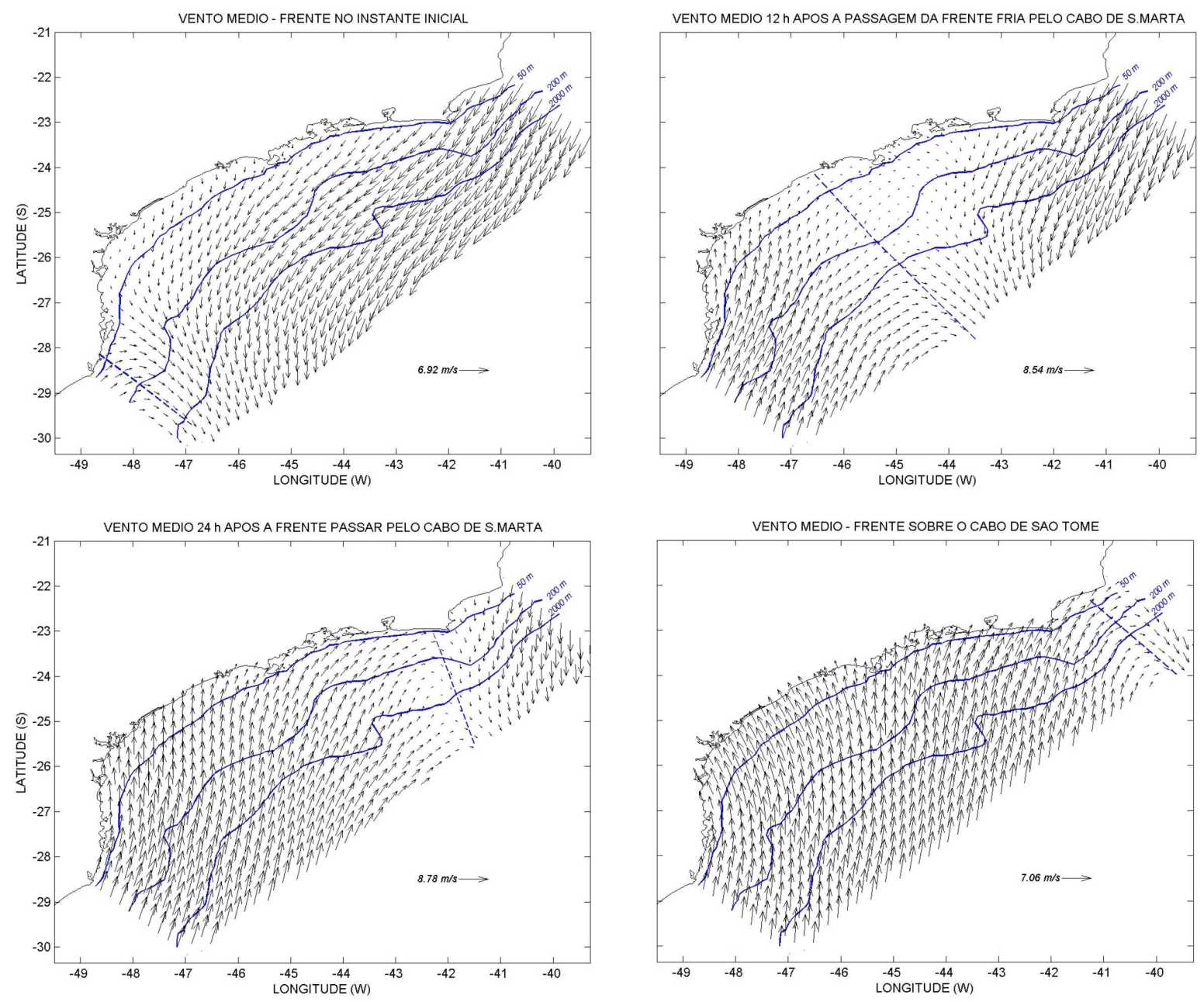

Figura 1.6: Modelo de frente fria típica de verão sobre a PCSE, proposto por Coelho (2008). 


\subsubsection{Circulação}

De acordo com Castro (1996), não existem trabalhos sobre a PCSE que tenham gerado dados em quantidade suficiente e duração adequada para a caracterização da circulação nas freqüências suprainercial, subinercial e sazonal cobrindo toda a região.

Na banda de freqüência sazonal, muito pouco ainda é conhecido sobre a circulação da porção mais interna da PCSE, existindo apenas alguns trabalhos observacionais (Matsuura (1975); Luedemann (1991); Castro Filho et al. (1995)) e outros através de simulações numéricas (Caldas (1978); Rezende (2003); Coelho (2008)). Todos apresentam evidências de que o fluxo predominante é no sentido NE, principalmente nas porções centrais e sul da PCSE.

Grandes esforços amostrais, no entanto, foram realizados no Canal de São Sebastião, situado na zona interna da plataforma continental de São Paulo, gerando muitos trabalhos de diversos autores: Emílson (1962), Kvinge (1967), Castro (1985, 1990), Miranda \& Castro (1995) e Fontes (1995), entre outros. Estes trabalhos demonstraram, em padrões gerais, que as correntes locais são altamente dependentes do vento. Segundo Kvinge (1967), oscilações das correntes devem estar associadas a perturbações no campo de vento devido a sistemas meteorológicos frontais.

Castro (1985) estudou numericamente a resposta da circulação barotrópica da PCSE ao vento típico de inverno. Utilizando em sua simulação tensão de cisalhamento do vento estacionária e uniforme, apontando para NE, obteve que a resposta das correntes à forçante ficou confinada na plataforma continental com escala de decaimento neperiano de 70-120 km da costa. Na direção normal à costa ocorreu balanço geostrófico, ou seja, equilíbrio entre a força de gradiente de pressão normal à costa e a força de Coriolis associada à componente de velocidade paralela à costa. Na direção paralela à costa, ocorreu balanço friccional, ou seja, equilíbrio entre a tensão de cisalhamento do vento e a tensão de cisalhamento com o fundo.

Castro (1985), Stech \& Lorenzzetti (1992), e Coelho (2008) analizaram numericamente a resposta da PCSE, especialmente a porção mais interna, às perturbações sinóticas no campo de ventos. Castro (1985) utilizou como forçante em sua simulação ventos do modelo de circulação geral da atmosfera do "National Meteorological Center (NMC)", dos Estados Unidos da América, referentes ao período de inverno de 1979. Os resultados 
obtidos através das simulações foram coerentes com as observações de oscilações do nível do mar na costa e de correntes próximas à costa. Stech $\&$ Lorenzzetti (1992) utilizaram o modelo conceitual de uma frente fria (Figura 1.5) como forçante em suas simulações. Os autores confirmaram que a passagem desses sistemas é capaz de causar inversões do fluxo de correntes, predominantemente para SW antes da passagem da frente e para NE sob a ação da frente.

Castro (1985) e Castro $\mathscr{G}$ Lee (1995), através de observações de vento e de oscilações do nível do mar durante o inverno na PCSE demonstraram que as oscilações subinerciais do nível do mar na região são manifestações de Ondas de Plataforma Continental, geradas entre Cananéia e o norte do Paraná, com períodos entre seis e doze dias.

Castro (1996), através de estudos observacionais ao largo de Ubatuba (SP), verificou na plataforma interna durante o inverno fluxo predominante para SW em três anos consecutivos, havendo eventos de inversão para NE. Valores típicos obtidos de intensidade para as correntes foram da ordem de $0,20 \mathrm{~m} / \mathrm{s}$ para $\mathrm{SW}$ e de $0,10 \mathrm{~m} / \mathrm{s}$ para NE. Segundo o autor, as componentes paralelas à costa são essencialmente barotrópicas, pois o primeiro modo ortogonal empírico explica mais de $95 \%$ da variância; já para as componentes normais há um aumento da importância do segundo modo ortogonal empírico, que pode ser associado ao primeiro modo baroclínico. Os auto-espectros das correntes paralelas apresentaram picos de energia nas bandas de períodos longos (10-14 dias) e períodos médios (4-10 dias). Na banda de períodos longos houve coerência entre as correntes e a tensão de cisalhamento do vento, sendo o vento liderado pela corrente em aproximadamente $50^{\circ}(50$ horas). Na banda de períodos médios houve correlação significativa com o vento, sendo a liderança do vento de $40^{\circ}$ (18 horas). De acordo com Castro (1996), a coerência entre as correntes normais e a tensão de cisalhamento do vento foi marginalmente significativa para o correntógrafo de superfície nas bandas longa e curta e, para o correntógrafo de fundo na banda média.

Correntes na plataforma média ao largo de Ubatuba, no período de inverno, foram estudadas por Castro (1996). O autor verificou que o fluxo predominante nessa região tem sentido SW, embora inversões para NE sejam freqüêntes, e que as componentes paralelas são essencialmente barotrópicas, pois o primeiro modo ortogonal empírico explica mais 
de $90 \%$ da variância em qualquer profundidade. Já, as componentes normais possuem um grande cisalhamento vertical, tendo uma grande importância dos modos baroclínicos, podendo apresentar uma estrutura em até 3 camadas. Velocidades típicas das correntes foram de 0,20-0,30 m/s para SW e pouco inferiores para NE. Autoespectros da componentes paralelas revelam picos em períodos curtos (3-4 dias) e médios (6-10 dias), e nessas bandas há coerência entre vento e corrente. As maiores coerências são entre os períodos médios, com o vento liderando a corrente em $90^{\circ}$ (42 horas). As componentes normais não apresentaram coerências significativas com o vento.

Segundo Castro (1996), a principal forçante da circulação da plataforma média são os ventos. Há coerência significativa entre a PCM e a PCI em oscilações de períodos médios e curtos; em ambos casos a PCM é liderada pela PCI, com atraso de 30 horas nos períodos médios e 15 horas nos períodos curtos.

Moreira (1997) analisou dados correntográficos obtidos através de fundeios a 100, 200 e 1000 metros de profundidade, junto à quebra da plataforma e talude ao largo de Santos durante o verão de 1993. A circulação observada foi predominantemente paralela à topografia, com fluxos para SW. Segundo o autor o fundeio a 100 metros apresentou velocidades médias de 0,1 e $0,2 \mathrm{~m} / \mathrm{s}$ e máximas da ordem de $0,5 \mathrm{~m} / \mathrm{s}$, estando estas associadas à presença da Corrente do Brasil quando o fluxo foi predominante para SW e às frentes frias quando as correntes se deslocaram para NE. Nos fundeios a 200 e 1000 metros houve a presença marcante da Corrente do Brasil; as intensidades médias foram da ordem de 0,4-0,5 m/s próximo à superfície e valores máximos de 1,0 m/s. Durante o período observado, houve a atuação de dois vórtices da Corrente do Brasil sobre a região, atingindo a isóbata de 100 metros. A influência da Corrente do Brasil foi observada até profundidades superiores a 700 metros.

Fundeios nas mesmas posições que os utilizados pelo trabalho de Moreira (1997), porém amostrando correntes durante períodos mais longos, foram analisados por Souza (2000). De acordo com a autora o fundeio sobre 100 metros de profundidade sofreu grande influência meteorológica: em todas as estações sazonais e profundidades amostradas houve predominância de fluxo para SW entretanto com alta variabilidade devida a sua alternância com o fluxo para NE. Essa variabilidade, com escala subinercial, demonstra que na maior parte do tempo, nessa região a dinâmica é típica de plataforma continental, 
e não de correntes de contorno oeste, sendo a influência da Corrente do Brasil nessa região apenas esporádica. Já entre as isóbatas de 200 e 1000 metros a presença da Corrente do Brasil é marcante: o fluxo nos níveis superiores é intenso, tipicamente de $1 \mathrm{~m} / \mathrm{s}$ e predominante para SW com baixa variabilidade temporal. Um vórtice ciclônico, de núclo frio, com período de 20 dias e escala vertical de aproximadamente 700 metros, foi observado em fevereiro de 1993, com sinais detectados até a isóbata de 100 metros.

Moreira (1998) estudou através de fundeios correntográficos a circulação da PCI no estado de São Paulo: em frente à Praia Grande e também ao norte (Ubatuba), ao sul (Montão de Trigo) e no interior do canal de São Sebastião. A autora concluiu que em toda a área de estudo a circulação sofre grande influência do vento, local ou remoto. Os pontos ao sul e ao norte do canal de São Sebastião apresentaram sentidos predominantes de correntes opostos. Ao sul do canal, houve predominância de corrente fluindo para NE, enquanto que ao norte do canal a predominância foi para SW. Nos períodos médios houve coerência significativa entre corrente e vento, ao sul e ao norte do canal. Ao sul do canal, o vento liderou a componente longitudinal da corrente em todas as estações, com exceção do verão; para a componente normal, houve liderança da corrente sobre o vento. Ao norte do canal, houve coerência significativa em períodos médios e longos. Nos perídos médios, a liderança é da corrente sobre o vento; no verão e primavera a componente transversal lidera o vento, enquanto que a componente longitudinal é liderada pelo vento na banda de períodos curtos; no inverno, a liderança se inverte. Na região da Praia Grande, houve coerências significativas entre o vento e as correntes em todas as bandas de freqüência. O ponto mais ao sul obteve coerências máximas nos períodos curtos com liderança da corrente, e o ponto mais ao norte apresentou coerências máximas nos períodos médios, com liderança da corrente na componente normal, e do vento na componente paralela.

Coelho (2008) estudou através de modelagem numérica a resposta da PCSE a ventos sazonais e sinóticos de verão. Nos experimentos utilizando ventos típicos de verão, obteve o campo de ventos climatológico médio à partir de oito anos (1998 até 2005) de dados do Serviço Meteorológico Alemão ( DWD - Deutcher Wetterdienst) e do European Centre for Médium-Range Weather Forecasts (ECMWF) e, nos experimentos utilizando ventos sinóticos de verão, adotou a frente sinótica já anteriormente descrita na Seção 1.1.3. Nas simulações com ventos típicos de verão, na região central da PCSE, entre Cananéia 
e a Ilha de São Sebastião, foi obtido na superfície entre as isóbatas de 30 e 50 metros escoamento para NE, e entre as isóbatas de 50 e 200 metros para SW, formando uma célula ciclônica entre Cananéia e Santos. A 10 metros de profundidade também foi observado fluxo para NE na PCI e para SW na PCM e PCE. Através de uma seção transversal em frente à Santos, o autor verificou escoamento para SW com intensidade máxima de -0,35 m/s na superfície da PCM, apresentando cizalhamento vertical. Na porção mais externa da PCM houve escoamento para SW em toda a coluna de água, enquanto que na PCI o escoamento foi todo para NE, com intensidade máxima de $0,15 \mathrm{~m} / \mathrm{s}$. Nos experimentos utilizando como forçante a passagem de um sistema frontal típico de verão o autor obteve que a porção da PCSE localizada ao sul da Ilha de São Sebastião foi a que respondeu com maior intensidade à passagem do sistema frontal. Durante a passagem da frente fria, as correntes giram anticiclonicamente conforme as tensões de cisalhamento do vento, invertendo para NE em cerca de seis a nove horas após a passagem do sistema frontal por cada região da PCSE. À partir da análise da estrutura vertical em frente à Santos, foi verificado que com a passagem da frente, as correntes na PCI, predominantemente para NE, adquirem em superfície o dobro da intensidade, $0,25 \mathrm{~m} / \mathrm{s}$, quando comparadas ao estado básico climatológico médio de verão e, também, com um maior cisalhamento vertical. Além disso, na PCM e na PCE, nos 20 metros iniciais o escoamento para SW encontra-se mais fraco. Após a passagem da frente fria o modelo voltou a ser forçado por quatro dias com a climatologia de ventos de verão e, quatro horas e meia após a passagem da frente, a PCSE já se encontrava próxima ao estado básico climatológico de verão. À partir do balanço de momentum, foi obtido que: na direção transversal à costa, predomina o balanço geostrófico, o qual é intensificado após a passagem da frente fria e, na direção paralela à costa, há um desvio do balaço geostrófico durante a passagem da frente fria, causado pela tensão de cisalhamento do vento e pela aceleração local, que sempre estão opostas.

$\mathrm{Na}$ banda de freqüência suprainercial, pode ser destacado o trabalho de Alves (1992), que apresentou o estudo mais completo e detalhado sobre o tema para Ubatuba. O autor comparou a distribuição de energia entre as correntes de maré e as correntes de menor freqüência, verificando que, para as componentes paralelas à topografia, as correntes subinerciais são dominantes, com aproximadamente $80 \%$ da variância; já para as 
componentes perpendiculares à topografia, as correntes de maré contribuem com aproximadamente 40-50\% da variância. Alves (1992), verificou ainda que as correntes das constituintes semidiurnas, $\mathrm{M}_{2}$ e $\mathrm{S}_{2}$, eram essencialmente barotrópicas, enquanto que as correntes das constituintes diurnas, $\mathrm{O}_{1}$ e $\mathrm{K}_{1}$, eram predominantemente baroclínicas.

Ruffato (2007) estudou correntes de maré barotrópica e baroclínica na porção norte da PCSE e quebra do talude continental, mais especificamente na região compreendida entre Ubatuba e Cabo Frio. O autor verificou que as componentes da maré mais energéticas, foram: $\mathrm{M}_{2}, \mathrm{~S}_{2}, \mathrm{~K}_{1}, \mathrm{O}_{1}$ e $\mathrm{M}_{3}$, em ordem decrescente. A velocidade máxima para a componente $\mathrm{M}_{2}$ foi de $5 \mathrm{~cm} / \mathrm{s}$, e a circulação predominantemente anti-horária. Para as marés internas, foram observadas componentes diurnas, $\mathrm{K}_{1}$ e $\mathrm{O}_{1} \mathrm{com} 3 \mathrm{~cm} / \mathrm{s}$, semidiurnas, $\mathrm{M}_{2}$ e $\mathrm{S}_{2} \operatorname{com} 8 \mathrm{~cm} / \mathrm{s}$ e $3 \mathrm{~cm} / \mathrm{s}$ respectivamente, e terdiurna, $\mathrm{M}_{3}$, relativamente menor. 


\subsection{Objetivos}

A hipótese básica do presente trabalho é que as correntes na plataforma continental interna, na região compreendida entre Peruíbe e São Sebastião, no Estado de São Paulo, são forçadas principalmente pelo vento e pela componente baroclínica da força de gradiente de pressão. Assim, o objetivo geral é caracterizar as correntes subinerciais na região de estudo e, especificamente:

- analisar a variabilidade temporal das correntes e ventos nas escalas subinercial e sazonal;

- determinar as forçantes preponderantes para a circulação na região;

- verificar possível influência das correntes da plataforma continental média e externa, incluindo a Corrente do Brasil, sobre a dinâmica da plataforma continental interna. 


\section{Capítulo 2}

\section{Dados e Métodos de Análise}

\subsection{Conjunto de Dados}

Os dados utilizados provêm do projeto multidisciplinar "A Influência do Complexo Estuarino da Baixada Santista sobre o Ecossistema da Plataforma Adjacente (ECOSAN)", realizado entre os anos de 2004 a 2006, reunindo diversos pesquisadores e colaboradores do IOUSP, UFRGS, UNESP (Campus São Vicente) e UNISINOS. O objetivo deste projeto foi avaliar a influência do complexo estuarino da Baixada Santista sobre a plataforma continental situada entre Itanhaém e São Sebastião, estudando o aporte do material orgânico e inorgânico, os mecanismos físicos que possibilitam o aporte e deposição desse material e o impacto desse aporte sobre os processos biológicos e a estrutura do ecossistema da região. Desta forma, em seu quadro de pesquisadores, havia especialistas de diversas áreas da oceanografia, tais como físicos, biólogos, geólogos, químicos e engenheiros, possibilitando inúmeras amostragens com distintos objetivos e metodologias.

Para o presente trabalho foram utilizados apenas dados obtidos pela equipe de oceanografia física do ECOSAN, formada por pesquisadores e técnicos do Laboratório de Hidrodinâmica Costeira (LHICO) e do Laboratório de Instrumentação Oceanográfica (LIO), ambos do IOUSP. Foram analisados os dados coletados nos fundeios correntográficos e de ADCP (Acoustic Doppler Current Profiler - Perfilador de Correntes Acústico por Efeito Doppler), bem como dados de vento (Figura 1.2).

Foram realizados 4 cruzeiros a bordo do N/Oc. Prof. W. Besnard para instalação e recuperação das estações autônomas, instrumentadas com correntógrafos convencionais, 
ADCPs e bóias meteorológicas (Tabela 2.1).

\begin{tabular}{cccc}
\hline Cruzeiro & Início & Fim & Duração (dias) \\
\hline \hline 1 & $26 / 06 / 2005$ & $28 / 06 / 2005$ & 3 \\
2 & $03 / 11 / 2005$ & $07 / 11 / 2005$ & 5 \\
3 & $06 / 02 / 2006$ & $10 / 02 / 2006$ & 5 \\
4 & $18 / 04 / 2006$ & $20 / 04 / 2006$ & 3 \\
\hline
\end{tabular}

Tabela 2.1: Cruzeiros oceanográficos realizados para instalação, manutenção e recuperação de estações autônomas meteoceanográficas, durante o projeto ECOSAN.

Foram obtidas séries temporais correntográficas no estado de São Paulo, através de fundeios, em 3 locais na plataforma interna, sob à isóbata de 20 metros: em frente à Peruíbe (P20), em frente à Santos (S20), próximo à Ilha Montão de Trigo (M20) e, também, na plataforma média sobre à isóbata de 100 metros, em frente à Santos (S100) (Figura 1.2). As posições geográficas, nomenclatura e principais características dos fundeios encontram-se na Tabela 2.2. Os fundeios P20 e M20 foram superficiais, com bóia meteorológica na superfície (Figura 2.1). O fundeio S20 consistiu de um ADCP embutido em carapaça antiarrasto (Figura 2.2). O fundeio S100 foi subsuperficial (Figura 2.2), com bóia de topo no nível de 20 metros. 
Projelo ECOSAN - Fundeios

Pontos Penoibe \& Nondão de Triga

Legenda

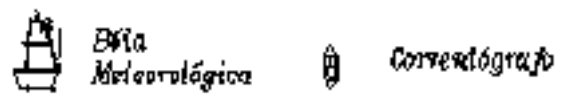

出 Bria

『 Auretar 量 Poritos

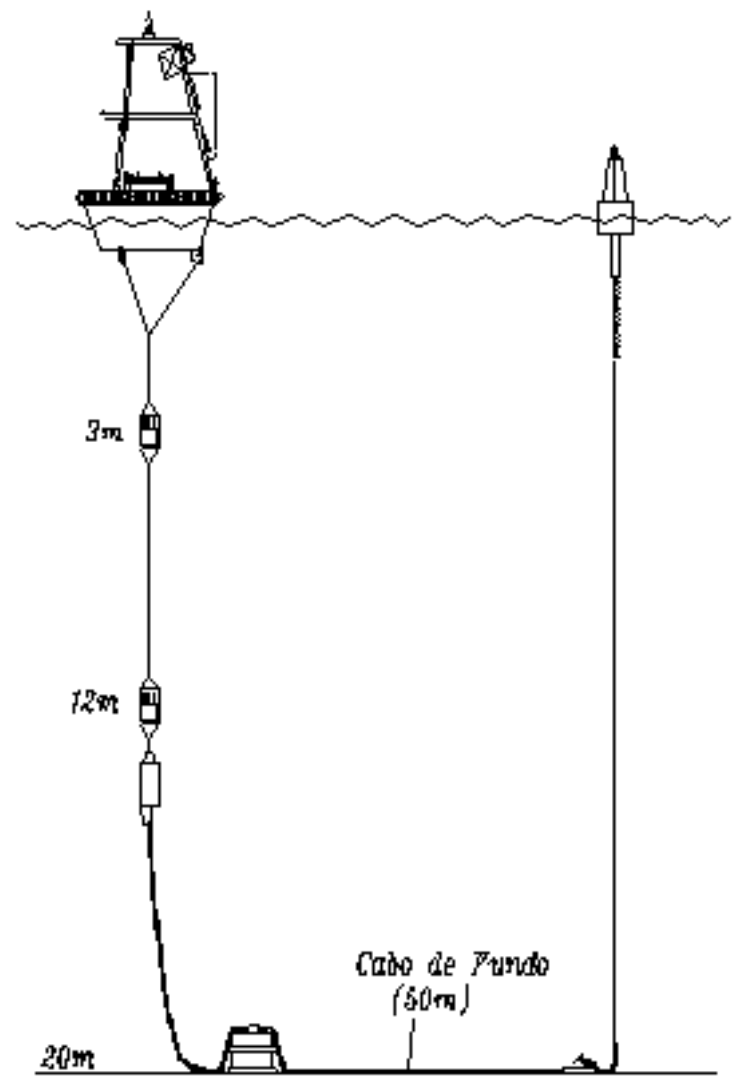

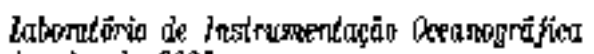
jancior de 2005

Obsideseribo fors de escoin

Figura 2.1: Esquemas dos fundeios utilizados pelo ECOSAN em P20 e M20. Figura gentilmente cedida pelo Laboratório de Instrumentação Oceanográfica (LIO). 


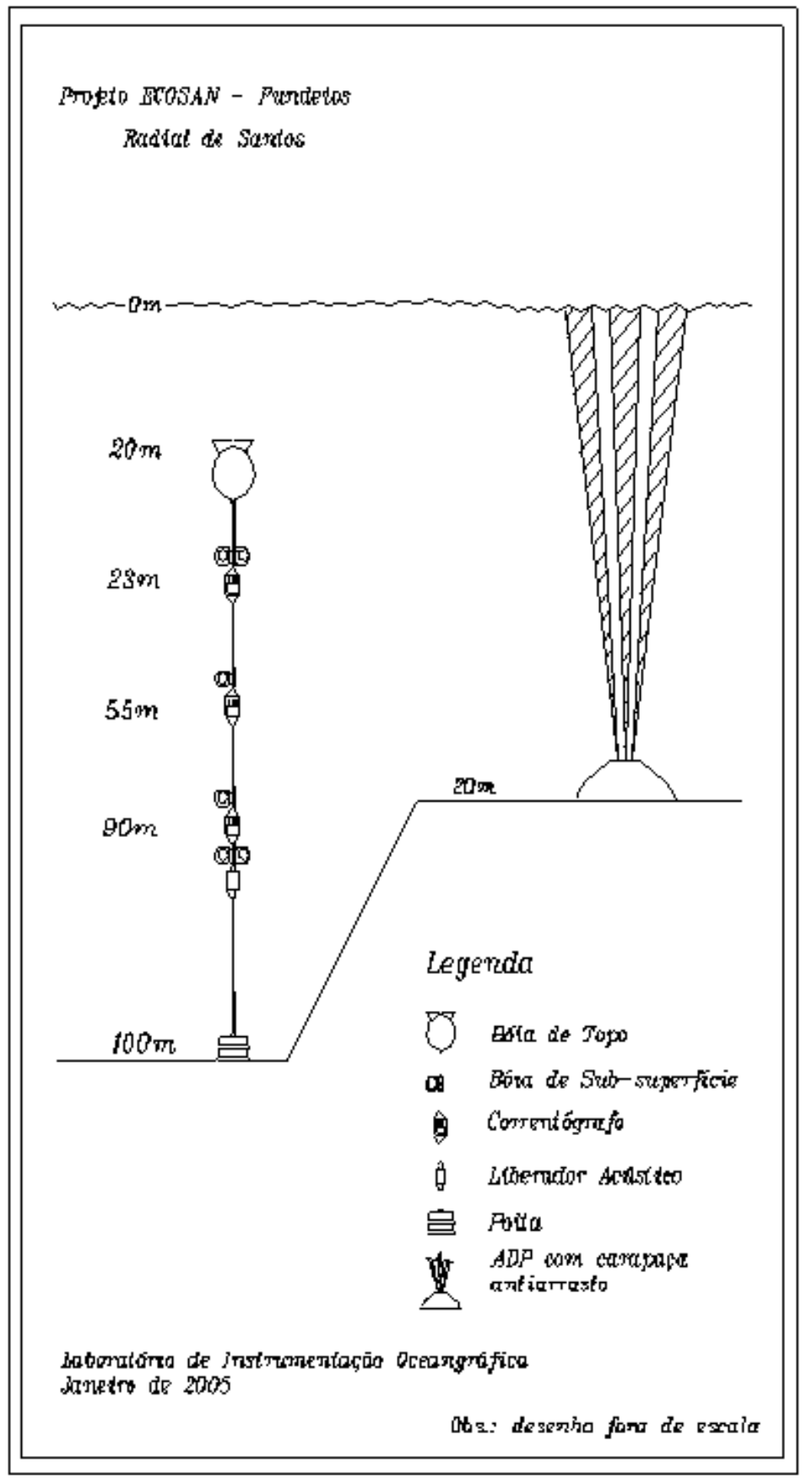

Figura 2.2: Esquemas dos fundeios utilizados pelo ECOSAN em S100 e S20. Figura gentilmente cedida pelo Laboratório de Instrumentação Oceanográfica (LIO). 
Nas estações P20 e M20, foram coletados dados através de correntógrafos próximos à superfície (3 metros), e próximos ao fundo (12 metros); na estação S20 foi utilizado um ADCP fixo ao fundo e em S100 utilizou-se correntógrafos em superfície (23 metros), meiaágua (55 metros), e fundo (90 metros).

\begin{tabular}{lcccc}
\hline Fundeio & $\begin{array}{c}\text { Coordenada } \\
\text { Geográfica }\end{array}$ & $\begin{array}{c}\text { Prof. } \\
\text { Local (m) }\end{array}$ & $\begin{array}{c}\text { Prof. do } \\
\text { Equipamento (m) }\end{array}$ & Equipamentos \\
\hline \hline P20 & $24^{\circ} 24^{\prime} 30^{\prime \prime} \mathrm{S} 46^{\circ} 54^{\prime} 00^{\prime \prime} \mathrm{W}$ & 20 & 03,12 & Correntógrafos \\
S20 & $24^{\circ} 03^{\prime} 30^{\prime \prime} \mathrm{S} 46^{\circ} 17^{\prime} 30^{\prime \prime} \mathrm{W}$ & 20 & 20 & ADCP \\
M20 & $23^{\circ} 50^{\prime} 30^{\prime} \mathrm{S} 45^{\circ} 40^{\prime} 00^{\prime \prime} \mathrm{W}$ & 20 & 03,12 & Correntógrafos \\
S100 & $25^{\circ} 05^{\prime} 00^{\prime} \mathrm{S} 45^{\circ} 42^{\prime} 00^{\prime \prime} \mathrm{W}$ & 100 & $23,55,90$ & Correntógrafos \\
\hline
\end{tabular}

Tabela 2.2: Informações sobre os fundeios oceanográficos do projeto ECOSAN que originaram os dados utilizados neste trabalho. Prof. é profundidade.

Os correntógrafos acústicos utilizados foram fabricados pela Falmouth, modelo 2D-ACM. Possuem bússola interna, medidor de inclinação, e utilizam 4 transdutores equidistantemente espaçados para medição das correntes em 2 dimensões. Possuem precisão para a velocidade de $+/-0,01 \mathrm{~m} / \mathrm{s}$, para a direção de $+/-2^{\circ}$, e para inclinação de $+/-0.5^{\circ}$.

O ADCP de $250 \mathrm{kHz}$ empregado foi fabricado pela SonTek (ADP). Esse aparelho mede correntes através de método acústico utilizando efeito Doppler; apresenta três transdutores orientados a $25^{\circ}$ do eixo vertical e a $120^{\circ}$ entre eles. Possui precisão para a velocidade de $+/-0,005 \mathrm{~m} / \mathrm{s}$, para a direção de $+/-2^{\circ}$, e para inclinação de $+/-1^{\circ}$.

Os correntógrafos e o ADCP foram programados para obtenção de dados por "burst sampling", sendo registradas três médias consecutivas, uma por minuto, a cada meia hora.

Os dados de vento foram obtidos à partir de 2 bóias meteorológicas instaladas nos fundeios P20 e M20, e por uma estação meteorológica fixa, sobre a Lage de Santos (L30), a 38 metros acima do nível do mar. Os equipamentos possuíam sensores de vento (intensidade e direção), temperatura do ar e pressão atmosférica. Os sensores de vento eram posicionados a 3,5 metros acima da superfície do mar e os dados eram coletados a cada hora, armazenados em uma memória interna e, também, transmitidos através de satélite (ARGOS-ID 32007). 
As coordenadas geográficas e principais características das estações meteorológicas estão apresentadas na Tabela 2.3.

\begin{tabular}{lccc}
\hline Estação & $\begin{array}{c}\text { Coordenada } \\
\text { Geográfica }\end{array}$ & $\begin{array}{c}\text { Prof. } \\
\text { Local }(\mathbf{m})\end{array}$ & Equipamentos \\
\hline \hline P20 & $24^{\circ} 24^{\prime} 30^{\prime \prime}$ S $46^{\circ} 54^{\prime} 00^{\prime \prime} \mathrm{W}$ & 20 & bóia meteorológica \\
M20 & $23^{\circ} 50^{\prime} 30^{\prime \prime} \mathrm{S} 45^{\circ} 40^{\prime} 00^{\prime \prime} \mathrm{W}$ & 20 & bóia meteorológica \\
L30 & $24^{\circ} 19^{\prime} 05^{\prime \prime} \mathrm{S} 46^{\circ} 11^{\prime} 20^{\prime \prime} \mathrm{W}$ & 30 & estação fixa \\
\hline
\end{tabular}

Tabela 2.3: Informações sobre as estações meteorológicas do projeto ECOSAN que originaram os dados utilizados neste trabalho. Prof. é a profundidade. 


\section{$2.2 \quad$ Métodos de Análise}

Primeiramente, os dados de corrente foram reduzidos para valores horários, com a finalidade de apresentar intervalos iguais aos dos dados de vento. Cada série de dados de corrente e vento tiveram a declinação magnética corrigida e os vetores decompostos em componentes E-W e N-S de velocidade. Inspeção cuidadosa das séries de tempo, utilizando gráficos x-t e stickplots, permitiu a identificação de períodos que apresentaram problemas por mal funcionamento dos equipamentos ou por incrustações biológicas. Esses dados foram eliminados.

Intervalos sem dados (gaps) de corrente maiores do que 24 horas não foram preenchidos. Alguns gaps de poucas horas ( $<5$ horas) foram preenchidos linearmente.

Nos dados de vento, gaps inferiores a 5 horas, foram interpolados linearmente. A estação meteorológica L30 apresentou um gap de 3 dias e, para preenchê-lo, utilizou-se regressão linear dos dados filtrados (passa-baixa) do NCEP/NCAR Reanalysis (NCEP - National Center For Environmental Prediction / NCAR - National Center For Atmospheric Research), interpolados para o domínio da região de estudo (coordenada 36³9'58"S 4556'15”W). A estação meteorológica M20 apresentou gaps de: 3 dias, 1 dia, 33 horas, 3,5 dias, e 16 dias, sendo todos preenchidos através de regressão linear dos dados de L30 filtrados. O mesmo procedimento foi utilizado à partir dos dados de L30 para preencher dados de P20, que apresentou gaps de: 1 dia, 33 horas, 3,5 dias. Um outro gap de aproximadamente 1 mês na série P20 não foi preenchido: a série foi dividida em duas e cada parte analisada separadamente.

Posteriormente foi efetuada a rotação dos eixos cartesianos dos dados de corrente e de vento. Para os dados de corrente adotou-se a decomposição da velocidade em componente paralela à isóbata local (v) e componente perpendicular à isóbata local (u) e para os dados de vento, adotou-se a decomposição segundo a componente de máxima variância (v) e componente de mínima variância $(u)$, sendo a componente u em ambos casos crescente em direção ao oceano profundo. A orientação das isóbatas locais para cada fundeio correntográfico está apresentada na Tabela 2.4 e a orientação dos eixos de máxima variância para cada estação meteorológica apresentada na Tabela 2.5. 


\begin{tabular}{lc}
\hline Fundeio & $\begin{array}{c}\text { Orientação da } \\
\text { Isóbata Local }\end{array}$ \\
\hline \hline P20 & $53^{\circ}$ \\
S20 & $-15^{\circ}$ \\
M20 & $-4^{\circ}$ \\
S100 & $22^{\circ}$ \\
\hline
\end{tabular}

Tabela 2.4: Orientação das isóbatas locais na posição dos fundeios correntográficos, medida positivamente no sentido antihorário em relação ao eixo x (Leste).

\begin{tabular}{lc}
\hline Estação & $\begin{array}{c}\text { Eixo de Máxima } \\
\text { Variância }\end{array}$ \\
\hline \hline M20 & $26^{\circ}$ \\
L30 & $36^{\circ}$ \\
P20 & $18^{\circ}$ \\
\hline
\end{tabular}

Tabela 2.5: Orientação dos eixos de máxima variância das séries de vento filtradas, medida positivamente no sentido antihorário em relação ao eixo x (Leste).

Com a finalidade de remover os sinais suprainerciais das séries temporais de correntes e ventos, foi aplicado um filtro passa-baixa com resposta impulsiva finita, do tipo Lanczos Quadrático. O método de filtragem utilizado adota um critério de $50 \%$, ou seja, na freqüência de corte a energia do sinal é reduzida pela metade. Segundo Walters $\mathscr{G}$ Heston (1982) esse filtro é eficiente para a remoção do sinal de maré e, ao mesmo tempo, preserva as freqüências subinerciais. A freqüência de corte utilizada foi de $0,6 \mathrm{cpd}$ (período de aproximadamente 40 horas) e os pesos atribuidos ao filtro, obedecem a:

$$
r_{j}=\left\{\frac{\sin [\pi(j-1) / M]}{\pi(j-1) / M}\right\}^{2}
$$

onde M é meia largura do filtro.

Através de uma rápida estimativa, adotando uma latitude típica para a região de estudo de $24,5^{\circ}$, pode-se verificar que o período inercial local é de aproximadamente 29 
horas. Assim, as oscilações inerciais do campo de correntes e do campo de ventos também são removidas através da filtragem dos dados.

Na Tabela 2.6 e na Tabela 2.7 estão apresentadas as séries temporais correntográficas e meteorológicas respectivamente, editadas e filtradas, disponíveis para as análises. Cada série está codificada como:

- V - determinando quando são dados de vento;

- P20, S20, M20, S100 ou L30 - determinando a posição do fundeio ou estação meteorológica;

- S, M ou F - determinando posição da medição de corrente: próximo à superfície, à meia-água ou ao fundo, respectivamente;

- 1 ou 2 - determinando a primeira ou segunda parte da série, respectivamente, caso haja gap.

\begin{tabular}{cccc}
\hline Fundeio & $\begin{array}{c}\text { Inicio da Série } \\
\text { GMT }\end{array}$ & $\begin{array}{c}\text { Fim da Série } \\
\text { GMT }\end{array}$ & $\begin{array}{c}\text { Número de } \\
\text { Pontos }(\Delta \mathbf{t = 1 h})\end{array}$ \\
\hline \hline P20S & 05-Nov-2005 21:00:00 & 08-Fev-2006 10:00:00 & 2270 \\
P20F & 27-Jun-2005 13:00:00 & 19-Set-2005 12:00:00 & 2016 \\
S20S1 & 26-Jun-2005 12:00:00 & 16-Jul-2005 14:00:00 & 483 \\
S20F1 & 26-Jun-2005 12:00:00 & 16-Jul-2005 14:00:00 & 483 \\
S20S2 & 06-Mar-2006 19:00:00 & 18-Abr-2006 12:00:00 & 1026 \\
S20F2 & 06-Mar-2006 19:00:00 & 18-Abr-2006 12:00:00 & 1026 \\
M20F1 & 28-Jun-2005 14:00:00 & 06-Nov-2005 00:00:00 & 3131 \\
M20F2 & 10-Fev-2006 00:00:00 & 19-Abr-2006 18:00:00 & 1651 \\
S100S & 26-Jun-2005 23:00:00 & 19-Abr-2006 08:00:00 & 7114 \\
S100M & 26-Jun-2005 23:00:00 & 19-Abr-2006 08:00:00 & 7114 \\
S100F & 04-Nov-2005 16:00:00 & 19-Abr-2006 08:00:00 & 3977 \\
\hline
\end{tabular}

Tabela 2.6: Séries temporais de corrente editadas e filtradas disponíveis para análise. 


\begin{tabular}{cccc}
\hline Fundeio & $\begin{array}{c}\text { Inicio da Série } \\
\text { GMT }\end{array}$ & $\begin{array}{c}\text { Fim da Série } \\
\text { GMT }\end{array}$ & $\begin{array}{c}\text { Número de } \\
\text { Pontos }(\Delta \mathbf{t}=\mathbf{1 h})\end{array}$ \\
\hline \hline VP201 & 25-Jun-2005 15:00:00 & 12-Jul-2005 06:00:00 & 400 \\
VP202 & 05-Nov-2005 21:00:00 & 05-Fev-2006 12:00:00 & 2200 \\
VM20 & 25-Jun-2005 16:00:00 & 28-Mar-2006 11:00:00 & 6620 \\
VL30 & 31-Mai-2005 13:00:00 & 30-Abr-2006 23:00:00 & 8027 \\
\hline
\end{tabular}

Tabela 2.7: Séries temporais de vento editadas e filtradas disponíveis para análise.

Para facilitar a sintetização e visualização das informações presentes nas Tabelas 2.6 e 2.7, foi elaborada a Figura 2.3.

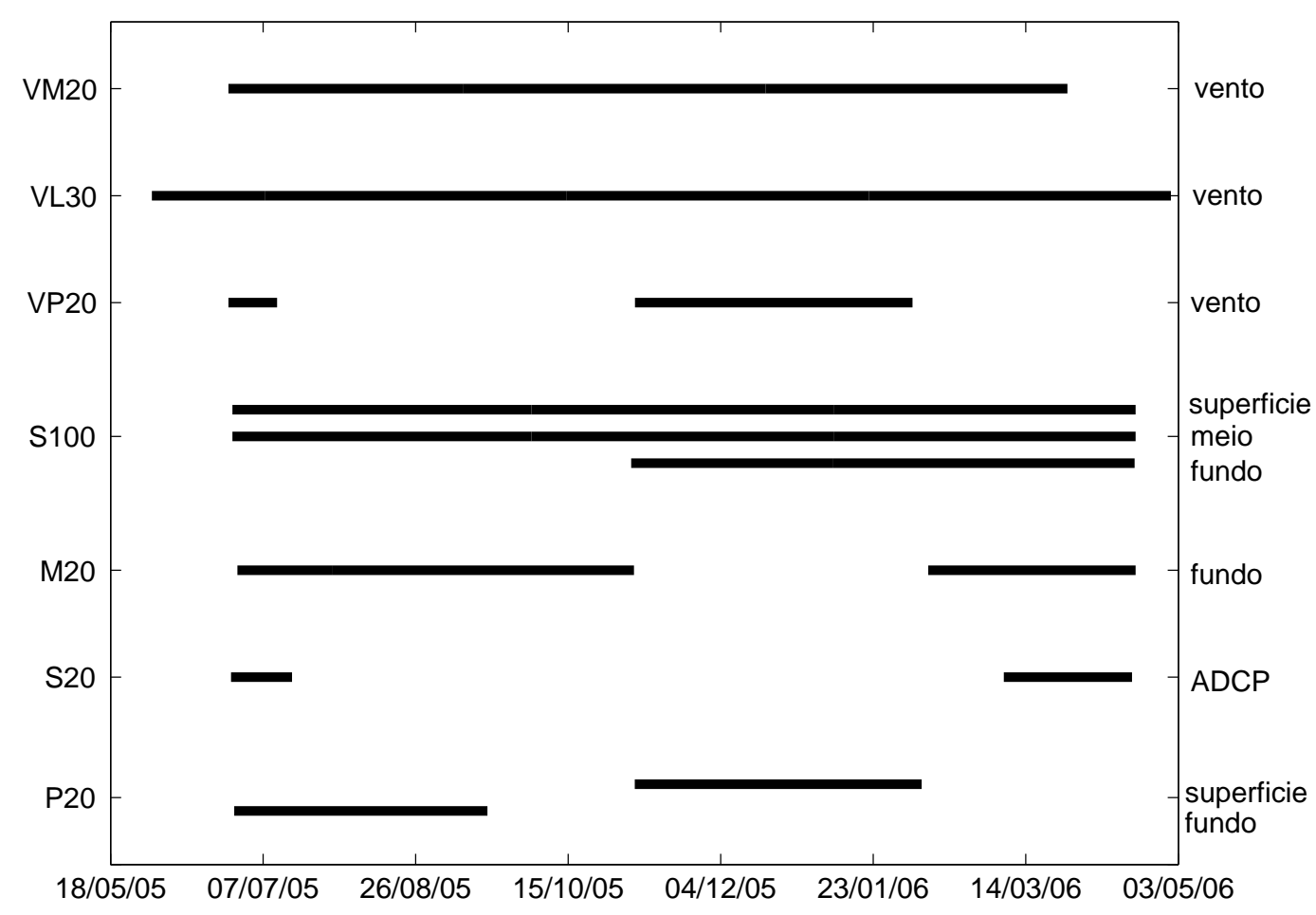

Figura 2.3: Períodos referentes às observações obtidas nas estações meteorológicas (ventos) e fundeios correntográficos (superfície, meia-água, fundo ou ADCP).

Para análise dos dados, os momentos estatísticos e outras grandezas foram calculadas seguindo Jenkins \& Watts (1968). Com a finalidade de facilitar a interpretação dos resultados foram ainda confeccionados gráficos do tipo palito (stickplots), diagramas vetorias progressivos e rosas de correntes.

No domínio do tempo, foram efetuadas correlações cruzadas entre as séries de 
distintos níveis para um mesmo fundeio, entre níveis equivalentes para fundeios distintos, entre vento e correntes em todos os níveis e fundeios, e entre ventos de diferentes estações. Para correlações entre vento e correntes adotou-se o mesmo sistema de coordenadas utilizado para os dados de correntes (Tabela 2.4). Para as estações S20 e S100 utilizaram-se os dados de ventos de L30 nos cálculos de correlação.

A análise de correlação é uma medida do grau de associação linear entre duas variáveis, pressupondo que tratam-se de processos estocásticos, estacionários e discretos. Os intervalos de confiança utilizados foram de 95\%, obedecendo Sciremammano (1979).

No domínio da freqüência foram calculados os autoespectros de cada série, espectros de coerência ao quadrado e fase entre as séries de distintos níveis para um mesmo fundeio, entre níveis equivalentes para fundeios distintos, entre vento e correntes em todos os níveis e fundeios, e entre ventos de diferentes estações. Para espectros de coerência ao quadrado e fase entre vento e correntes adotou-se o mesmo sistema de coordenadas utilizado para os dados de correntes (Tabela 2.4). Para as estações S20 e S100 utilizaram-se os dados de ventos de L30 nos cálculos de espectros de coerência ao quadrado e fase.

A análise espectral particiona a variância em função da freqüência, através da transformada de Fourier, e tem como objetivo buscar oscilações dominantes. O autoespectro tem a finalidade de encontrar as freqüências dominantes em cada série temporal; os espectros de coerência ao quadrado medem a correlação linear entre duas séries em função da freqüência e, uma vez havendo coerência ao quadrado significativa, é possível através do espectro de fase conhecer o atraso temporal das oscilações presentes nas duas séries. Nesse trabalho, espectros de coerência ao quadrado ou coerência, terão o mesmo sentido. O método utilizado para a análise espectral foi o do "Periodograma Modificado de Welch" segundo Emery $\&$ Thomson (1998), utilizando uma janela do tipo "Hamming", com sobreposição de $50 \%$ e adotando intervalo de confiança de $95 \%$. 


\section{Capítulo 3}

\section{Resultados}

\section{$3.1 \quad$ Ventos}

Nesta seção estão apresentados os resultados dos ventos correspondentes ao período entre 05-Nov-2005 às 21:00:00 até 05-Fev-2006 às 12:00:00, quando há dados observados simultaneamente nas três estações meteorológicas. Todos resultados e análises relacionadas aos dados de vento obedecem convenção oceanográfica ao invés de convenção meteorológica, ou seja, as direções apontam para onde o vento vai e não de onde o vento vem.

Os primeiros momentos estatísticos para as séries de ventos são apresentados na Tabela 3.1. As velocidades máximas em módulo são de 10,86, 7,09 e 4,44 m/s em VL30, VP20 e VM20 respectivamente. Nota-se também que os desvios padrões são sempre maiores que as médias, com exceção da componente de máxima variância de VL30. A filtragem dos dados causou uma maior redução da variância para as componentes de mínima variância, sendo de 92\% em VM20, 83\% em VL30, e VP20 em 96\%. As direções de máxima variância, assim como a linha de costa da PCSE, possuem orientação SW-NE e são aproximadamente paralelas às isóbatas locais, sendo os desvios de $30^{\circ} \mathrm{em} \mathrm{M} 20,-2^{\circ}$ em L30 e $-35^{\circ}$ em P20 (medidos positivamente no sentido antihorário). 


\begin{tabular}{cccccccc}
\hline Série & Dir & Min & Max & Amp & M \pm D.Pad & Var & $\%$ \\
\hline \hline UVM20 & $-64^{\circ}$ & $-3,02$ & 2,98 & 5,99 & $-0,16 \pm 0,97$ & 0,9429 & 8 \\
VVM20 & $26^{\circ}$ & $-4,44$ & 2,18 & 6,61 & $-0,89 \pm 1,30$ & 1,6812 & 19 \\
UVL30 & $-54^{\circ}$ & $-5,28$ & 3,36 & 8,64 & $-0,42 \pm 1,62$ & 2,6303 & 17 \\
VVL30 & $36^{\circ}$ & $-10,86$ & 1,73 & 12,59 & $-4,05 \pm 3,08$ & 9,4785 & 37 \\
UVP202 & $-72^{\circ}$ & $-4,03$ & 2,08 & 6,11 & $-0,67 \pm 1,25$ & 1,5551 & 4 \\
VVP202 & $18^{\circ}$ & $-7,09$ & 2,59 & 9,68 & $-1,41 \pm 1,84$ & 3,3859 & 10 \\
\hline
\end{tabular}

Tabela 3.1: Primeiros momentos estatísticos para as séries de vento filtradas. U e V correspondem às componentes de mínima e máxima variância, respectivamente. Dir é a orientação das componentes em graus medida positivamente no sentido antihorário em relação ao eixo x (Leste); Min é o valor mínimo e Max é o valor máximo (em m/s); Amp é a diferença entre Max e Min (em m/s); M. é a média; D.Pad é o desvio padrão da média $(\mathrm{em} \mathrm{m} / \mathrm{s})$; Var é a variância $\left(\mathrm{m}^{2} / \mathrm{s}^{2}\right)$ e \% é a porcentagem que a variância da série filtrada representa com relação à variância da série original. 
A distribuição temporal dos vetores velocidade do vento filtrado é apresentada na Figura 3.1 enquanto que as rosas de distribuição de vento e diagramas vetoriais progressivos são apresentados na Figura 3.2.

É possível verificar uma maior intensidade dos ventos em VL30 em relação à VP20 e VM20. Em todas as séries de vento a direção predominante é SW, seguindo a orientação média da linha de costa da PCSE.
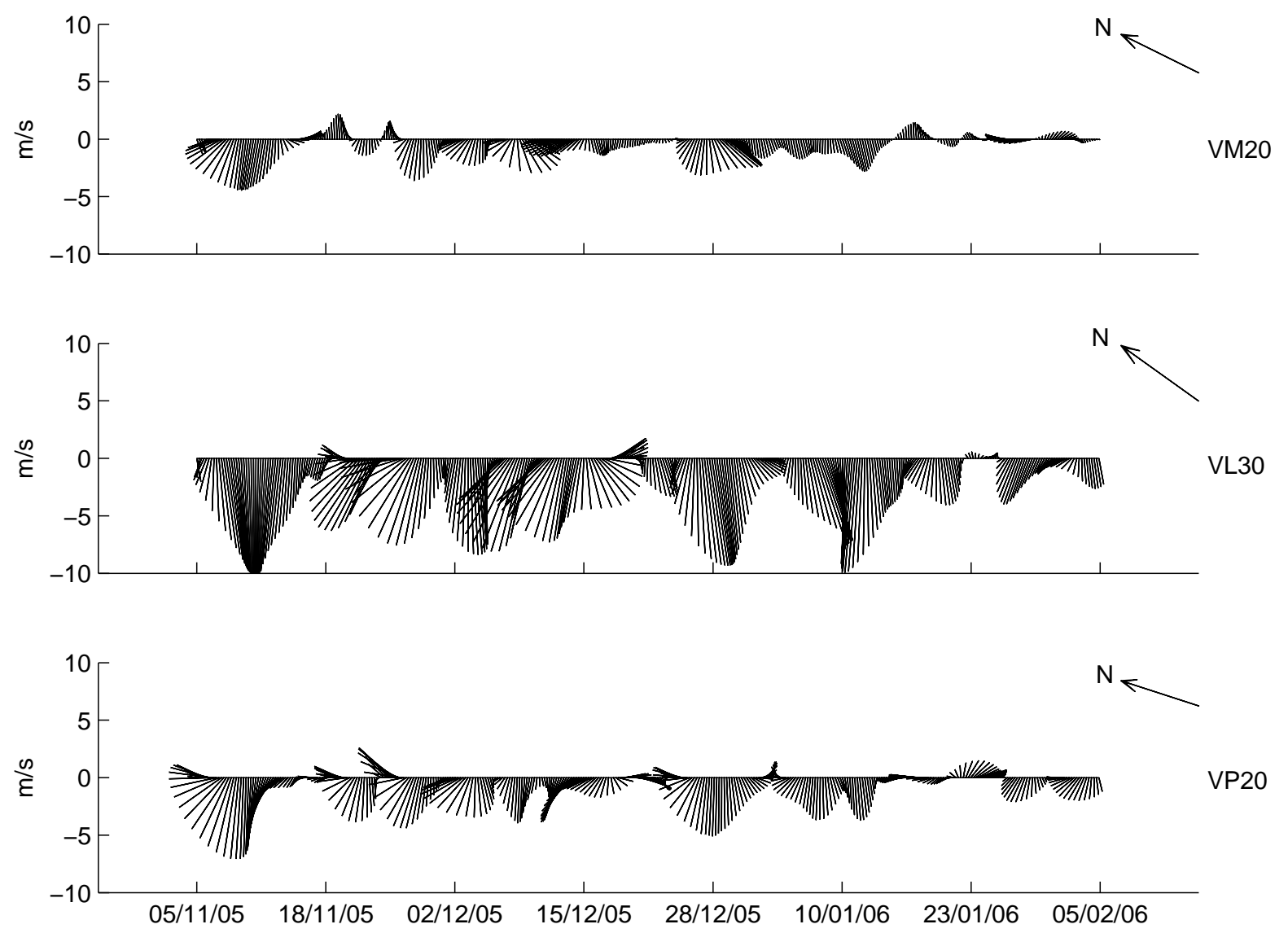

Figura 3.1: Distribuição temporal dos vetores velocidade do vento das séries VM20 no topo, VL30 no meio e VP202 abaixo. As unidades estão em m/s. O vetores $\mathrm{N}$ indicam as orientações do Norte para cada série e à direita estão indicadas as séries. 

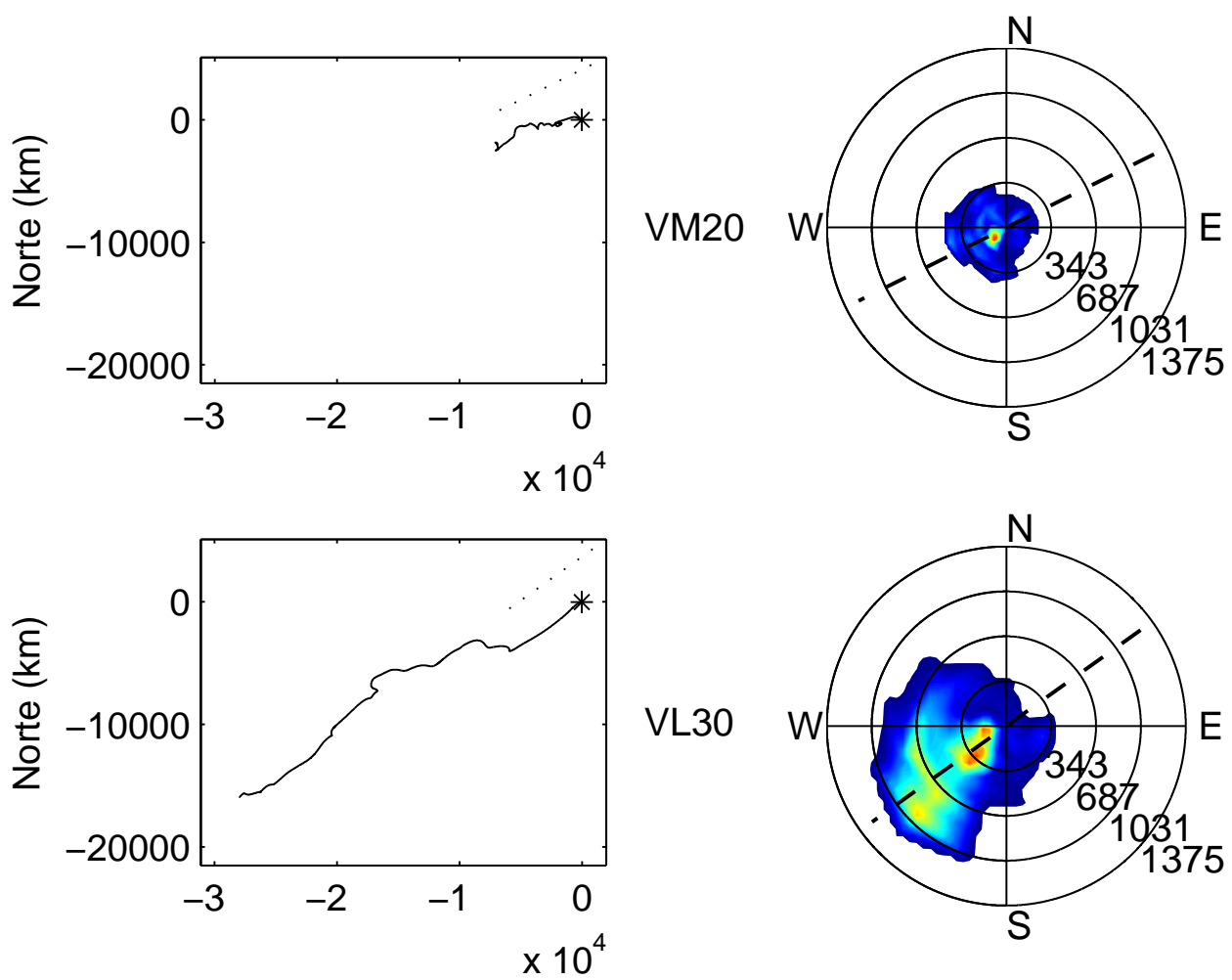

VL30
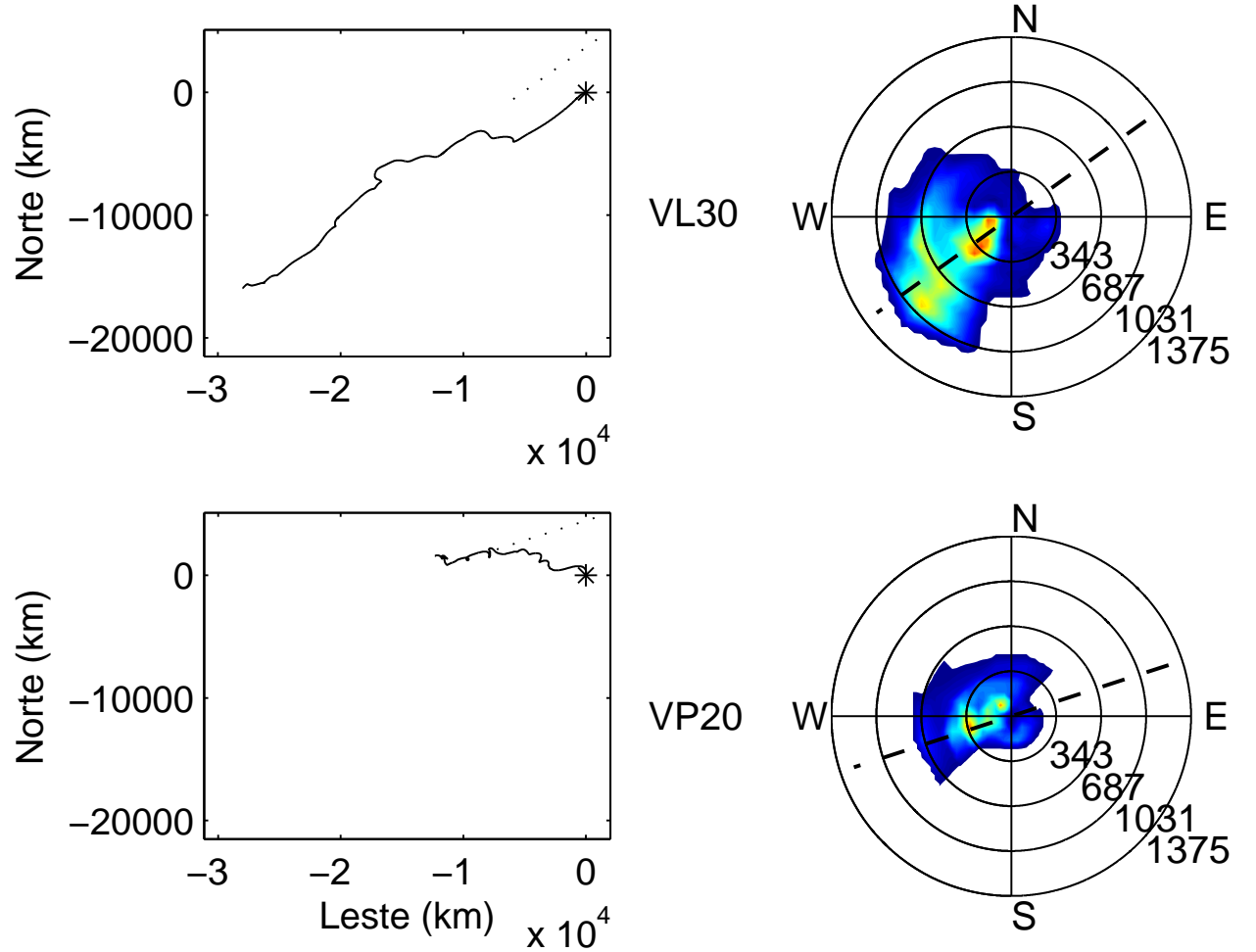

Figura 3.2: Diagramas vetoriais progressivos e rosas de distribuição de ventos $(\mathrm{em} \mathrm{cm} / \mathrm{s})$ das séries de vento VM20 no topo, VL30 no meio e VP20 abaixo. Os asteríscos indicam o início das séries, as linhas pontilhadas ou tracejadas a orientação do eixo de máxima variância e a barra de cores o número de observações. 


\subsubsection{Correlações entre Estações Meteorológicas}

\section{VP20 X VL30}

Correlação entre as séries de vento VP20 e VL30 está apresentada na Figura 3.3, entre VP20 e VM20 está apresentada na Figura 3.4, e entre VL30 e VM20 está apresentada na Figura 3.5. Em todas as séries a correlação é maior para as componentes na direção de máxima variância: a correlação entre VP20 e VL30 é de 0,85 em lag de 0,15 dias, onde VP20 lidera VL30, entre VP20 e VM20 é de 0,84 em lag de 0,19 dias, portanto VP20 lidera VM20 e entre VL30 e VM20 é de 0,8 em lag próximo a zero, não havendo liderança neste caso.

Para as componentes na direção de mínima variância, a correlação entre VP20 e VL30 é de 0,39 em lag de -0,7 dias, ou seja VP20 é liderado por VL30, entre VP20 e VM20 é de 0,38 em lag de 0,06 dias, onde VP20 lidera VM20 e entre VL30 e VM20 é de 0,27 em lag de 0,37 dias, havendo lideranca de VL30 sobre VM20.

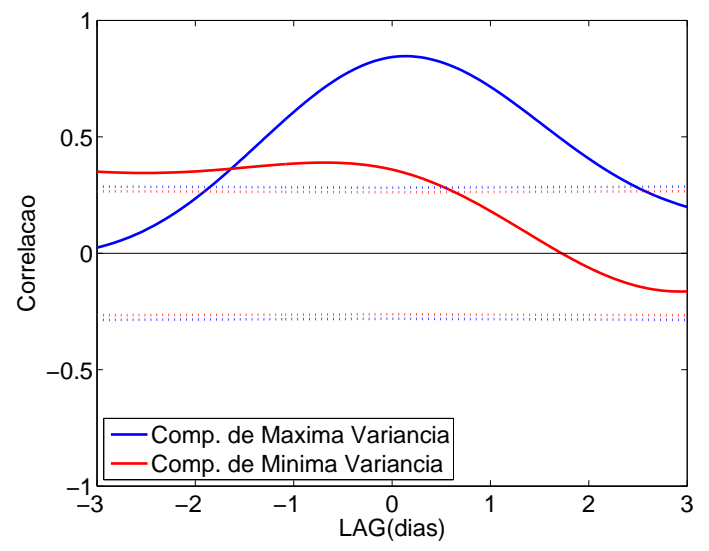

Figura 3.3: Correlação entre as séries de vento, VP202 x VL30. As linhas pontilhadas indicam intervalos de confiança de $95 \%$. 


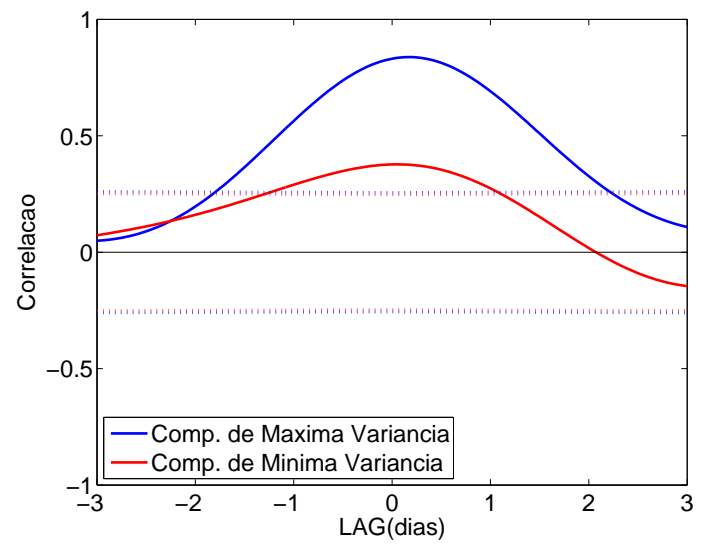

Figura 3.4: Correlação entre as séries de vento, VP202 x VM20. As linhas pontilhadas indicam intervalos de confiança de $95 \%$.

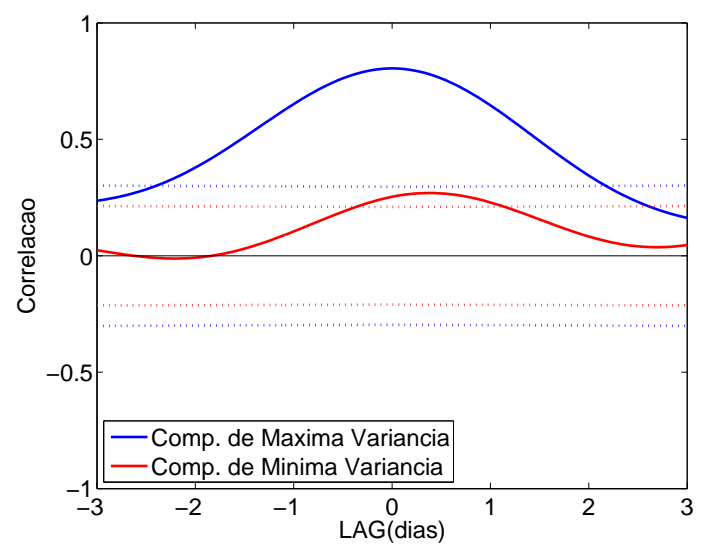

Figura 3.5: Correlação entre as séries de vento, VL30 x VM20. As linhas pontilhadas indicam intervalos de confiança de $95 \%$. 


\subsubsection{Autoespectros}

Os autoespectros para as séries de vento de VM20, VL30 e VP20 são apresentados na Figura 3.6. Há presença marcante de oscilações em freqüencias compreendidas entre 0,20 e 0,15 cpd, correspondendo a períodos entre 5 e 6,7 dias, em todas as séries e componentes. Em VL30 é possível notar maior energia associada à componente na direção de máxima variância quando comparada à outra componente.
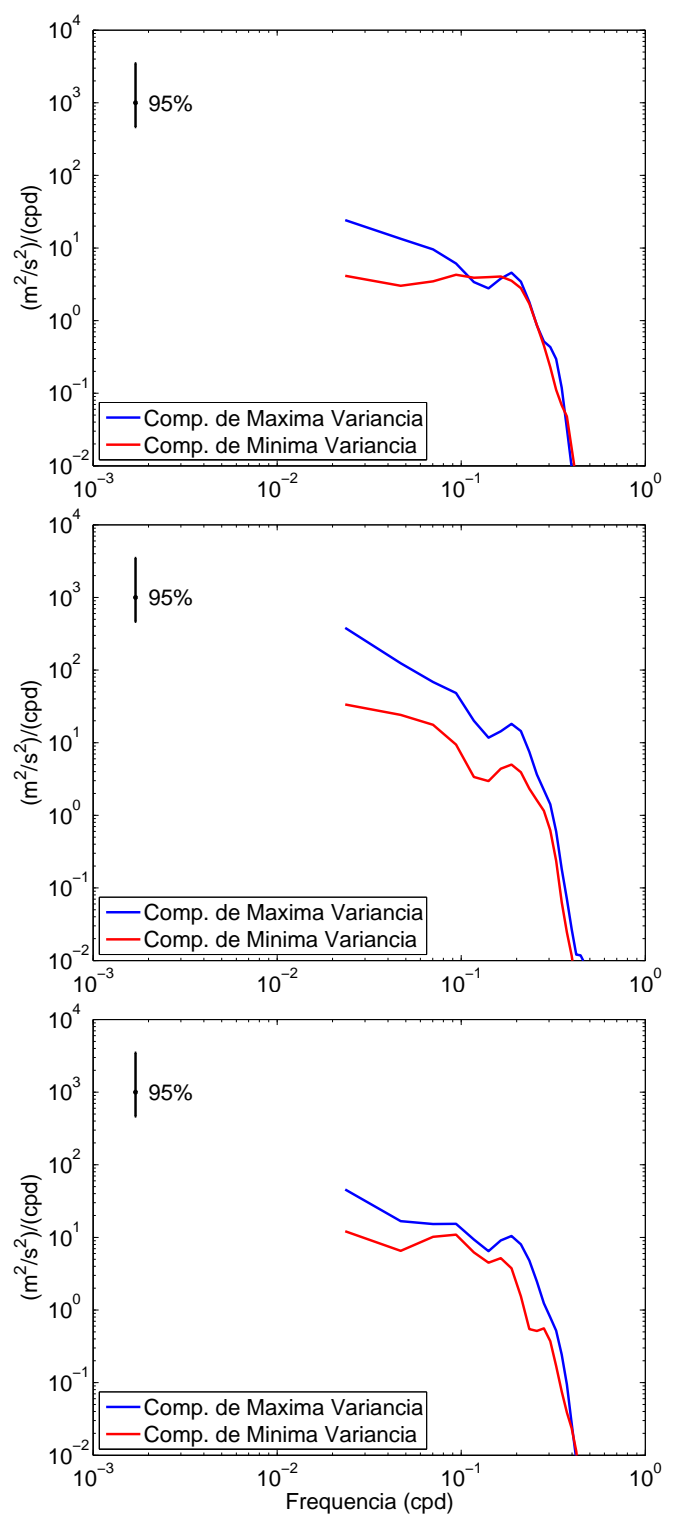

Figura 3.6: Autoespectros das séries de vento VM20 no topo, VL30 no meio, e VP202 abaixo. 


\subsubsection{Espectros Cruzados entre Estações Meteorológicas}

\section{VP20 X VL30}

Espectros de coerência ao quadrado e fase entre as séries de vento de VP20 e VL30 são apresentados na Figura 3.7. Há uma alta coerência, de 0,85, para as componentes na direção de máxima variância na banda $0,2 \mathrm{cpd}$, correspondendo a período de 5 dias, e fase de $10^{\circ}$ (3 horas), sendo VL30 liderada por VP20. Para as componentes na direção de mínima variância, a coerência também é significativa, porém menor, de 0,7, na banda 0,2 cpd, e fase de $10^{\circ}$ (3 horas), sendo VL30 liderada por VP20.
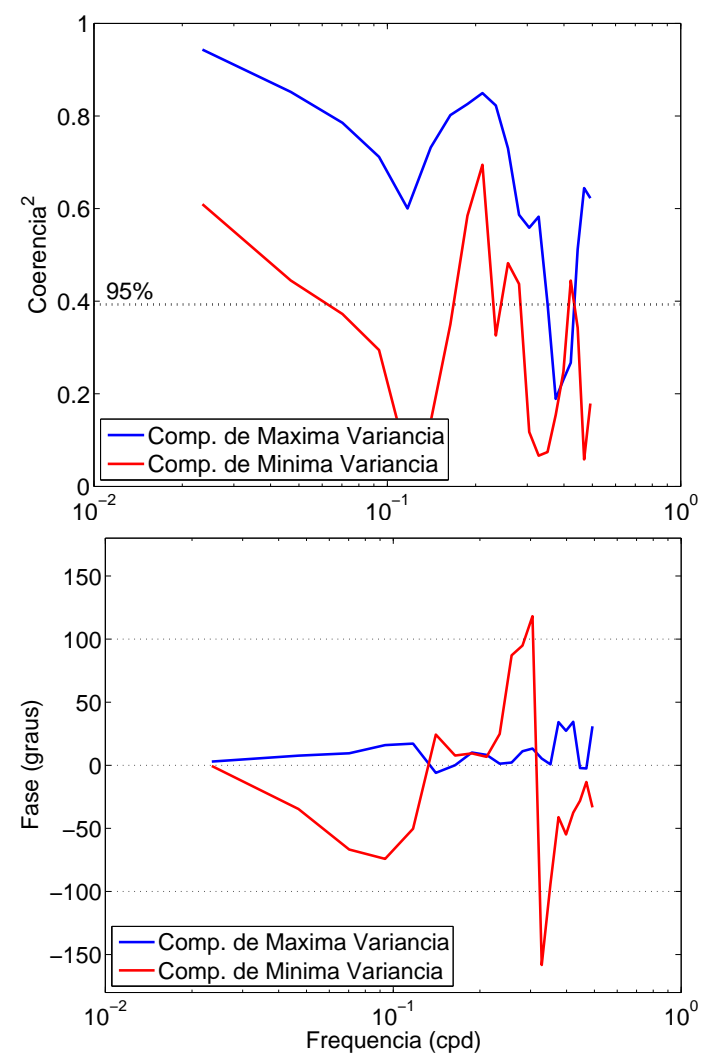

Figura 3.7: Espectros de coerência ao quadrado no topo e fase abaixo, entre as séries de vento VP202 X VL30. 


\section{VP20 X VM20}

Espectros de coerência ao quadrado e fase entre as séries de vento de VP20 e VM20 são apresentados na Figura 3.7. Para as componentes na direção de máxima variância, há coerência de 0,9 na banda $0,2 \mathrm{cpd}$, correspondendo a período de 5 dias, com fase de $10^{\circ}$ (3 horas), sendo VM20 liderada por VP20 e, também, há coerência de 0,85 na banda de 0,3 cpd, correspondendo a período de 3,3 dias, com fase de $15^{\circ}$ (3 horas), sendo também VM20 liderada por VP20.

Para as componentes de mínima variância há coerência muito menor, de 0,45, na banda $0,1 \mathrm{cpd}$, correspondendo a período de 10 dias, com fase de $-40^{\circ}$ (27 horas), sendo VP20 liderada por VM20.

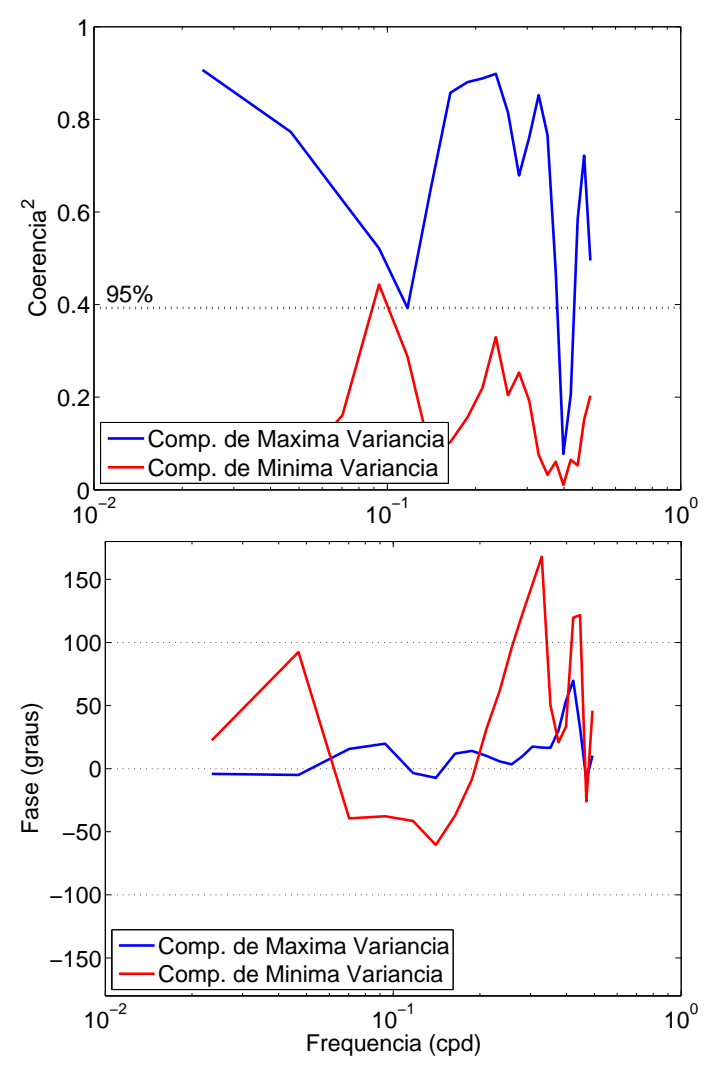

Figura 3.8: Espectros de coerência ao quadrado no topo e fase abaixo, entre as séries de vento VP202 X VM20. 


\section{VL30 X VM20}

Espectros de coerência ao quadrado e fase entre as séries de vento de VL30 e VM20 são apresentados na Figura 3.9. Para as componentes de máxima variância há coerência de 0,94 na banda 0,2 cpd, correspondendo a período de 5 dias, com fase $0^{\circ}$, portanto não havendo liderança.

Para as componentes de mínima variância, há coerência de 0,94 entre as bandas 0,3 e 0,2 cpd, correspondendo a período entre 3,3-5 dias, com fase $40^{\circ}$ (12 horas), havendo liderança de VL30 sobre VM20.
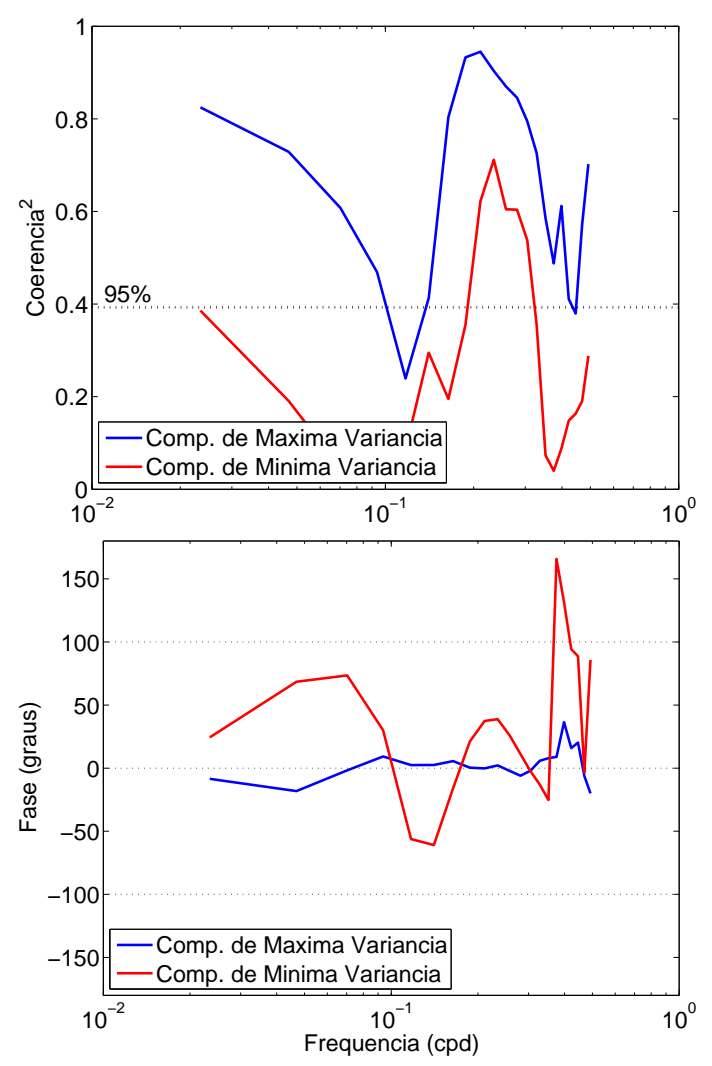

Figura 3.9: Espectros de coerência ao quadrado no topo e fase abaixo, entre as séries de vento VL30 X VM20. 


\subsection{Correntes}

\subsubsection{P20}

Os primeiros momentos estatísticos para as séries de corrente do fundeio P20 são apresentados na Tabela 3.2. As correntes observadas próximo à superfície são mais intensas que as próximas ao fundo, com valores mínimos de -0,38 e - -0,08 m/s respectivamente. Pode-se observar que as componentes paralelas à batimetria apresentam valores mais intensos, e com maior variância, quando comparadas às componentes normais. Nota-se também que os desvios padrões são maiores que as médias.

A filtragem dos dados causou uma maior redução da variância para as componentes normais à batimetria, em $73 \%$ na superfície, e $65 \%$ no fundo, enquanto que, para as componentes paralelas às isóbatas, a redução foi de apenas $38 \%$ em superfícies e $35 \%$ no fundo.

\begin{tabular}{ccccccc}
\hline Série & Min & Max & Amp & M \pm D.Pad & Var & \% \\
\hline \hline UP20S & $-0,35$ & 0,05 & 0,41 & $-0,03 \pm 0,05$ & 0,0027 & 27 \\
VP20S & $-0,38$ & 0,51 & 0,89 & $0,01 \pm 0,15$ & 0,0237 & 62 \\
UP20F & $-0,06$ & 0,05 & 0,11 & $-0,00 \pm 0,02$ & 0,0005 & 35 \\
VP20F & $-0,08$ & 0,08 & 0,17 & $-0,03 \pm 0,05$ & 0,0025 & 65 \\
\hline
\end{tabular}

Tabela 3.2: Primeiros momentos estatísticos para séries correntográficas filtradas para o fundeio P20. $\mathrm{U}$ e V correspondem às componentes transversais e paralelas às isóbatas locais, respectivamente. Min é o valor mínimo e Max é o valor máximo (em m/s); Amp é a diferença entre Max e Min (em m/s); M. é a média; D.Pad é o desvio padrão da média $(\mathrm{em} \mathrm{m} / \mathrm{s})$; Var é a variância $\left(\mathrm{m}^{2} / \mathrm{s}^{2}\right)$ e \% é a porcentagem que a variância da série filtrada representa com relação à variância da série original. 
A distribuição temporal dos vetores velocidade de corrente é apresentada na Figura 3.10 e na Figura 3.11. As rosas de distribuição de correntes e diagramas vetorias progressivos são apresentados na Figura 3.12. Novamente, é possível verificar uma menor intensidade das correntes no fundo, em relação às correntes de superfície. É importante ressaltar que em ambas profundidades a direção predominante das correntes encontra-se no eixo NE-SW, ou seja, quase paralela à isóbata local.

As correntes de fundo têm sentido predominante SW, com poucas inversões para NE. Já as correntes de superfície apresentam um grande número de inversões na direção NE-SW, não demonstrando um sentido predominante.
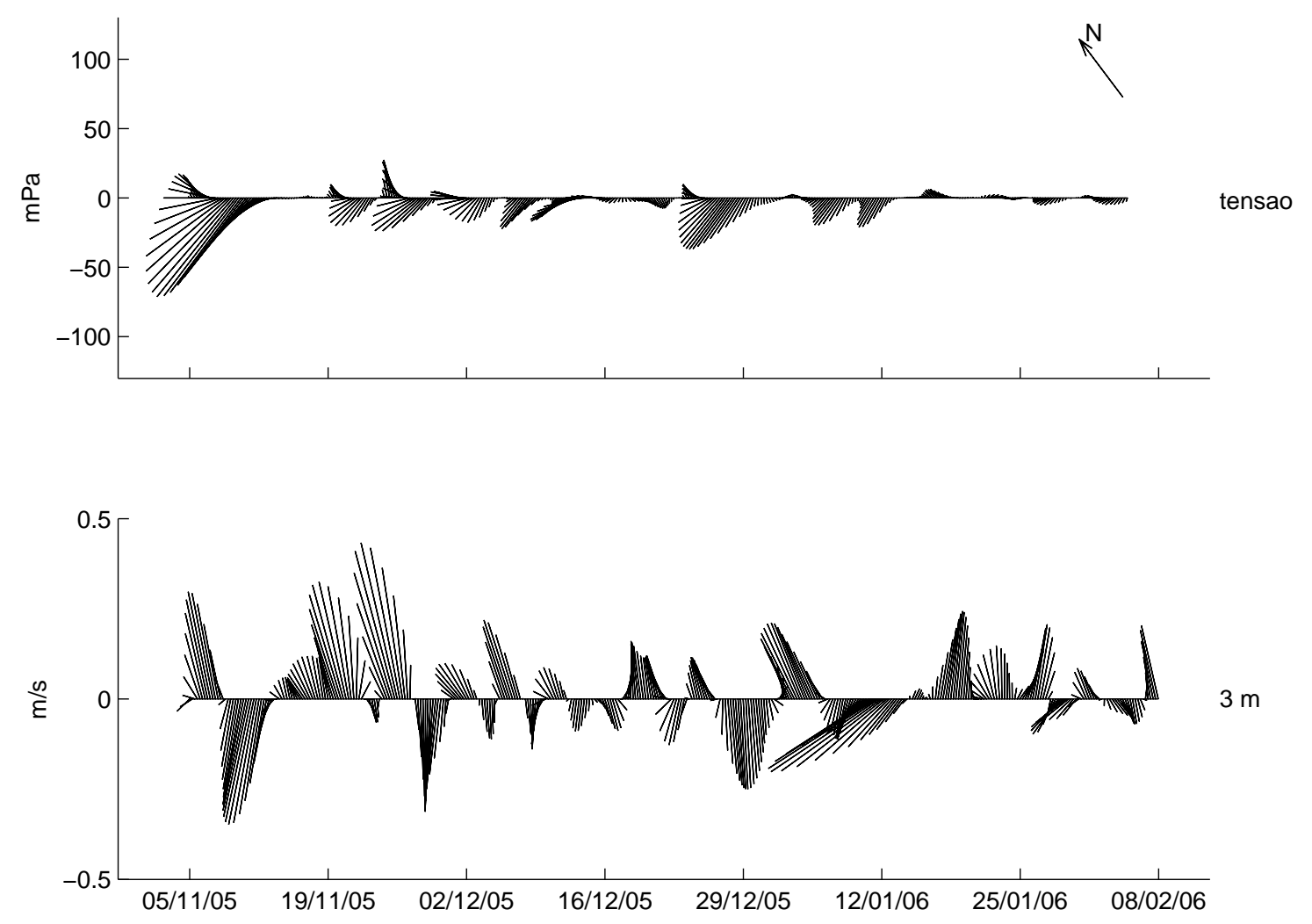

Figura 3.10: Distribuição temporal dos vetores tensão de cisalhamento do vento da série VP202 e de velocidade de corrente na superfície da série P20S. As unidades de tensão estão em mPa e de velocidade $\mathrm{em} \mathrm{m} / \mathrm{s}$. O vetor $\mathrm{N}$ indica a orientação do Norte e os números à direita indicam a profundidade das séries obtidas $(m)$ e dados de vento (tensão). 


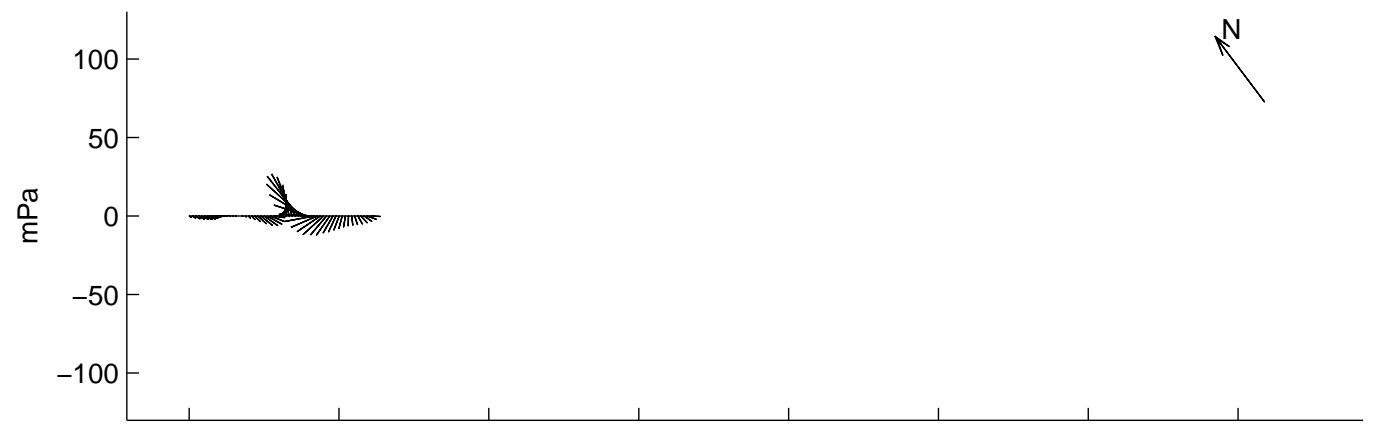

tensao

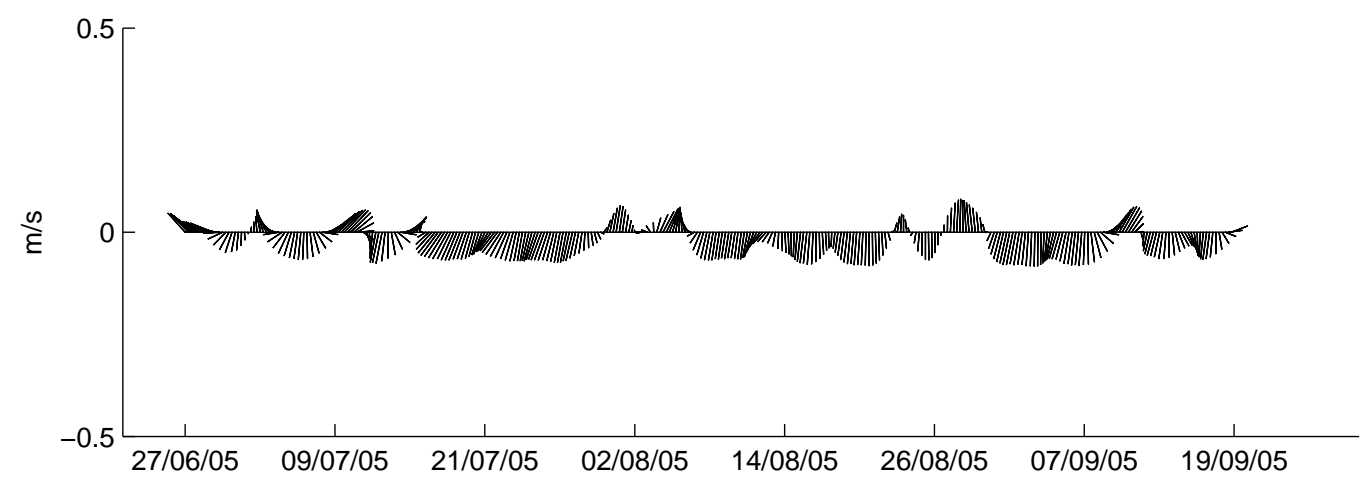

Figura 3.11: Distribuição temporal dos vetores tensão de cisalhamento do vento da série VP201 e de velocidade de corrente no fundo da série P20F. As unidades de tensão estão em mPa e de velocidade em $\mathrm{m} / \mathrm{s}$. O vetor $\mathrm{N}$ indica a orientação do Norte e os números à direita indicam a profundidade das séries obtidas (m) e dados de vento (tensão). 

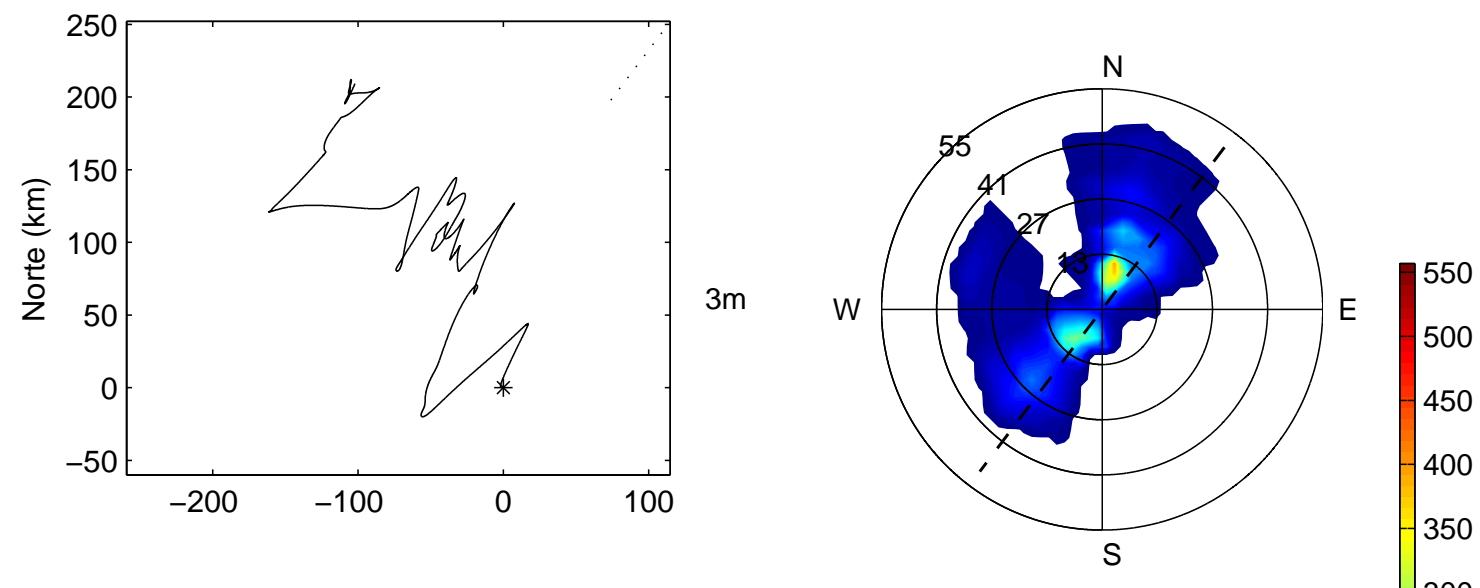

500

450

400

350
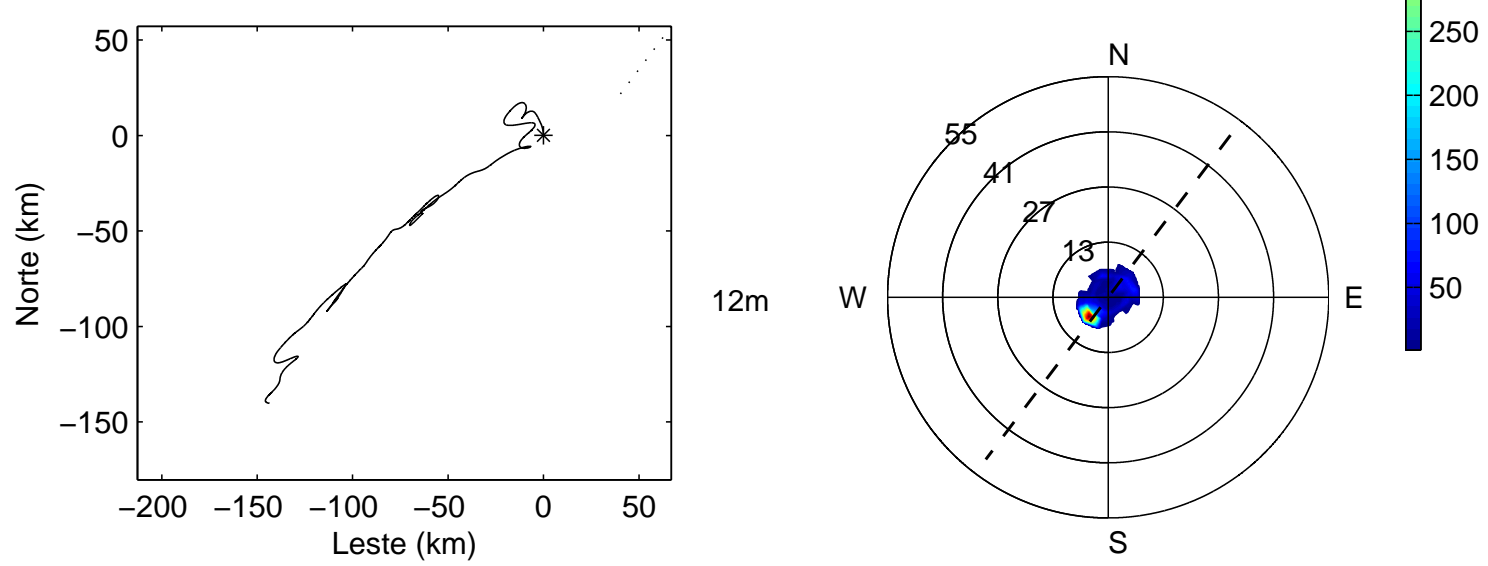

Figura 3.12: Diagramas vetoriais progressivos e rosas de distribuição de correntes $(\mathrm{em} \mathrm{cm} / \mathrm{s})$ das séries de superfície P20S no topo e de fundo P20F abaixo. Os asteríscos indicam o início das séries, as linhas pontilhadas ou tracejadas a orientação da isóbata local e a barra de cores o número de observações. 


\section{Correlações}

As correlações entre as séries de vento e corrente na superfície, e entre vento e corrente no fundo, são apresentadas na Figura 3.13. Correlações entre superfície e fundo não foram obtidas, pois as medições disponíveis eram referentes a períodos distintos.

Em superfície há alta correlação para as componentes paralelas à topografia, maior que 0,8 , no lag de 0,75 dias (18 horas), indicando liderança do vento sobre a corrente. Para as componentes normais, a correlação é muito menor, abaixo de 0,3, e há liderança da corrente, apresentando lag negativo de 2 dias.

No fundo, as correlações são negativas, -0,8 para as componentes paralelas e -0,75 para as componentes normais aproximadamente. A maior correlação em módulo ocorre com lag 0,8 dias para as componentes paralelas, e entre o lag de 1,5 e 2 dias para as componentes normais, sendo ambas lideradas pelo vento.
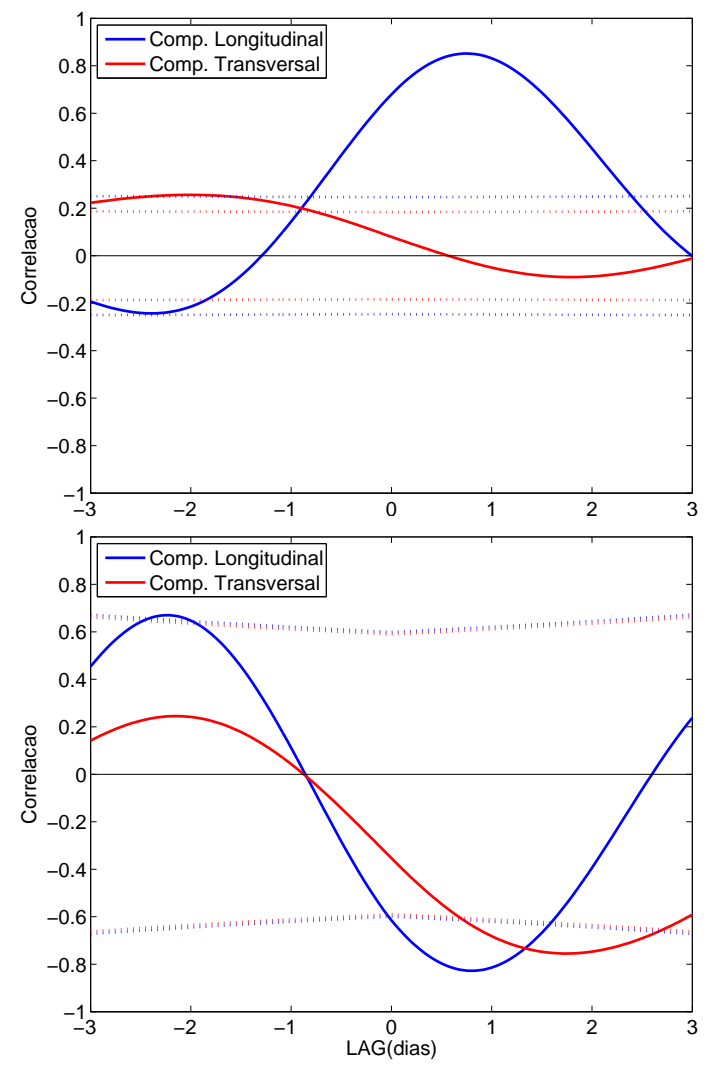

Figura 3.13: Correlações entre as séries de vento e corrente na superfície, VP $202 \times$ x 20 S no topo, e de vento e corrente no fundo, VP201 x P20F abaixo. As linhas pontilhadas indicam intervalos de confiança de $95 \%$. 


\section{Espectros}

Os autoespectros para as séries de correntes de superfície e fundo são apresentados na Figura 3.14. Em ambas profundidades, as componentes paralelas à batimetria são mais energéticas, apresentando picos com uma ordem de grandeza maiores que as componentes normais, e as correntes de superfícies são mais energéticas que as do fundo, chegando a quase uma ordem de grandeza maiores.

As componentes paralelas apresentam picos de energia bem evidentes nas bandas de freqüência próximas a $0,15 \mathrm{cpd}$, correspondendo a períodos entre 5 e $8 \mathrm{~d}$. As componentes normais à batimetria apresentam oscilações em freqüências mais altas, entre 0,3-0,4 cpd, correspondendo a períodos entre 2,5 e 3 d, e em freqüências mais baixas, na superfície por volta de $0,1 \mathrm{cpd}$, entre os períodos de 8 a 12 dias, e no fundo próximas a $0,15 \mathrm{cpd}$, correspondendo a períodos entre 5 e $8 \mathrm{~d}$.
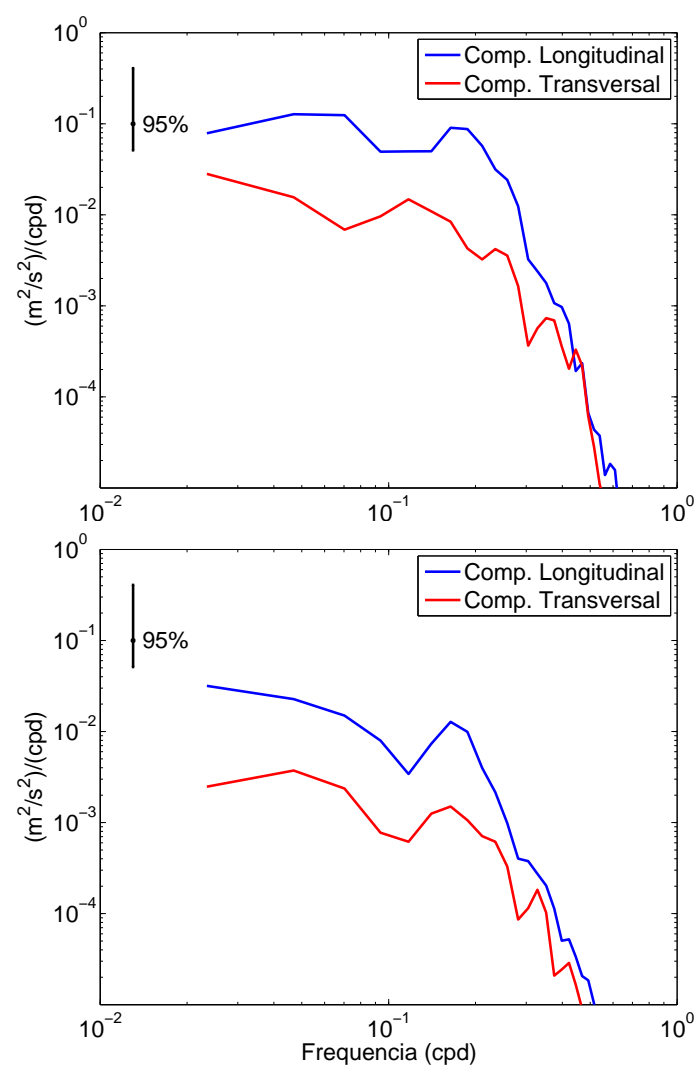

Figura 3.14: Autoespectros das séries de superfície P20S no topo, e de fundo P20F abaixo. 
Os espectros de coerência ao quadrado e fase, entre vento e corrente de superfície são apresentados na Figura 3.15. Espectros de coerência entre vento e corrente de fundo não foram calculados devido ao curto período disponível da série de vento. Tampouco foram calculados entre superfície e fundo, pois as medições disponíveis eram referentes a períodos distintos.

Alta coerência para as componentes paralelas, de 0,9 aproximadamente, pode ser observada em torno de $0,2 \mathrm{cpd}$, com período de aproximadamente $5 \mathrm{~d}$, sendo que o vento lidera a corrente em aproximadamente $50^{\circ}$ (16 horas). Há também a presença de coerência mais baixa, de 0,6, em 0,07 cpd, com período de aproximadamente 14 dias e fase $30^{\circ}$ (30 horas) e, de 0,55 em 0,33 cpd, com período de aproximadamente 3 dias, e fase $18^{\circ}(3,5$ horas), onde em ambos casos a liderança é do vento sobre a corrente.

Para a componente normal, há coerência de 0,7 aproximadamente em 0,14 cpd, com período de 7 dias, e fase de aproximadamente $-60^{\circ}$ (28 horas), sendo o vento liderado pela corrente. Há também a presença de coerência mais baixa, de 0,6, em 0,3 cpd, com período de aproximadamente 3,5 dias, e fase $40^{\circ}$ (9 horas), onde o vento lidera a corrente, e de 0,6 em 0,45 cpd, com período de 2,2 dias, e fase $0^{\circ}$, não havendo liderança, ou seja, ambos estão em fase. 


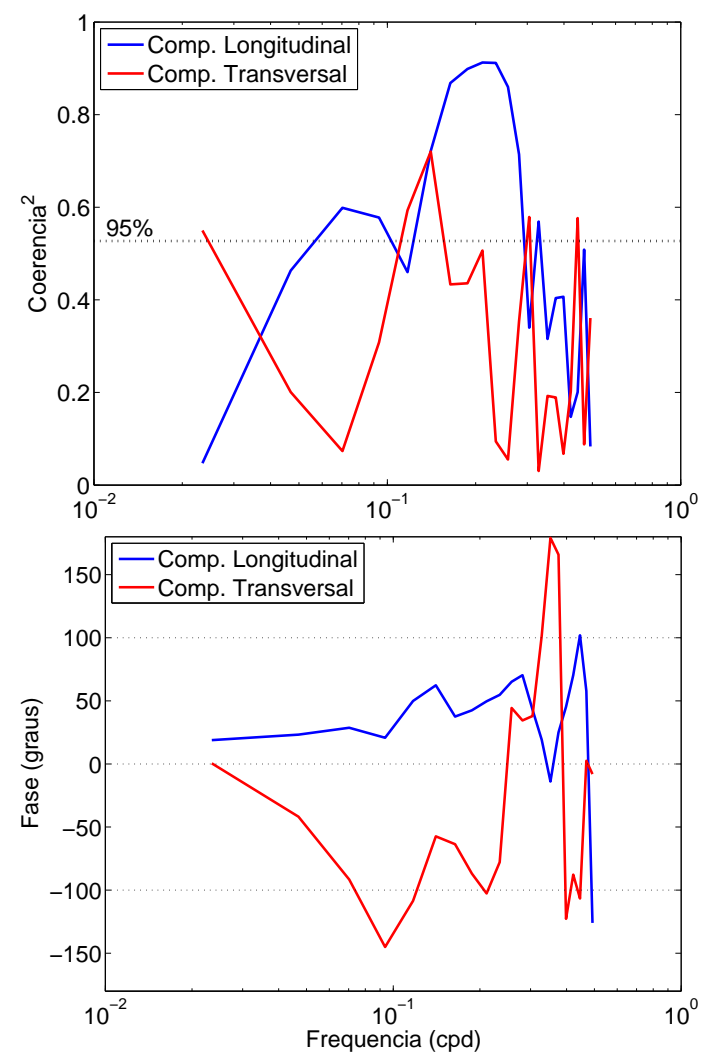

Figura 3.15: Espectros de coerência ao quadrado no topo e fase abaixo, entre vento e corrente de superfície, das séries VP202 x P20S 


\subsubsection{S20}

Os primeiros momentos estatísticos para as séries de corrente do fundeio S20 são apresentados na Tabela 3.3. Não há grande diferença entre as intensidades extremas e médias medidas em superfície e no fundo. Os valores máximos ocorreram nas componentes paralelas com módulo de 0,49 e $0,48 \mathrm{~m} / \mathrm{s}$, para a primeira parte dos dados, e de 0,72 e 0,65 $\mathrm{m} / \mathrm{s}$ respectivamente, para a segunda parte dos dados. Pode-se observar ainda, que as componentes paralelas à batimetria apresentam maior variância do que as componentes normais. Nota-se também que os desvios padrões são quase sempre maiores que as médias.

A filtragem dos dados causou uma maior redução da variância para as componentes normais à batimetria, chegando a $81 \%$ na superfície e $79 \%$ no fundo, para a primeira parte dos dados, e $89 \%$ na superfície e $94 \%$ no fundo para a segunda parte dos dados. Para as componentes paralelas às isóbatas, a redução foi de apenas $34 \%$ em superfície e no fundo, para a primeira parte dos dados, e $44 \%$ na superfície e $49 \%$ no fundo para a segunda parte dos dados.

\begin{tabular}{ccccccc}
\hline Série & Min & Max & Amp & M \pm D.Pad & Var & \% \\
\hline \hline US20S1 & $-0,01$ & 0,21 & 0,23 & $0,06 \pm 0,06$ & 0,0031 & 19 \\
VS20S1 & $-0,28$ & 0,49 & 0,77 & $0,02 \pm 0,21$ & 0,0444 & 66 \\
US20F1 & $-0,04$ & 0,19 & 0,22 & $0,04 \pm 0,06$ & 0,0031 & 21 \\
VS20F1 & $-0,26$ & 0,48 & 0,73 & $0,02 \pm 0,20$ & 0,0400 & 66 \\
US20S2 & $-0,01$ & 0,16 & 0,17 & $0,06 \pm 0,04$ & 0,0015 & 11 \\
VS20S2 & $-0,16$ & 0,72 & 0,88 & $0,15 \pm 0,20$ & 0,0396 & 56 \\
US20F2 & $-0,05$ & 0,13 & 0,17 & $0,03 \pm 0,03$ & 0,0008 & 6 \\
VS20F2 & $-0,17$ & 0,65 & 0,82 & $0,12 \pm 0,17$ & 0,0304 & 51 \\
\hline
\end{tabular}

Tabela 3.3: Primeiros momentos estatísticos para séries correntográficas filtradas para o fundeio S20. $\mathrm{U}$ e $\mathrm{V}$ correspondem às componentes transversais e paralelas às isóbatas locais, respectivamente. Min é o valor mínimo e Max é o valor máximo (em m/s); Amp é a diferença entre Max e Min (em m/s); M. é a média; D.Pad é o desvio padrão da média $(\mathrm{em} \mathrm{m} / \mathrm{s})$; Var é a variância $\left(\mathrm{m}^{2} / \mathrm{s}^{2}\right)$ e \% é a porcentagem que a variância da série filtrada representa com relação à variância da série original. 
A distribuição temporal dos vetores velocidade de corrente é apresentada na Figura 3.16 para a primeira parte dos dados e na Figura 3.17 para a segunda parte. As rosas de distribuição de correntes e diagramas vetorias progressivos são apresentados na Figura 3.18 para a primeira parte dos dados e na Figura 3.19 para a segunda parte.

É possível verificar que não há diferenças importantes entre as velocidades de superfíe e de fundo, tanto para a primeira quanto para a segunda parte dos dados. É importante ressaltar que em ambas partes dos dados, e em ambas profundidades, a direção predominante das correntes encontra-se no eixo NW-SE, ou seja, quase paralela à isóbata local.

Na primeira parte dos dados, são observadas mudanças na direção das correntes, embora o sentido SE predomine, conforme observado pelos diagramas vetoriais progressivos. Na segunda parte dos dados, são observadas mudanças menos duradouras na direção das correntes, mas há uma evidente predominância do sentido SE, observado tanto nos diagramas vetoriais progressivos quanto nas rosas de distribuição de correntes. 

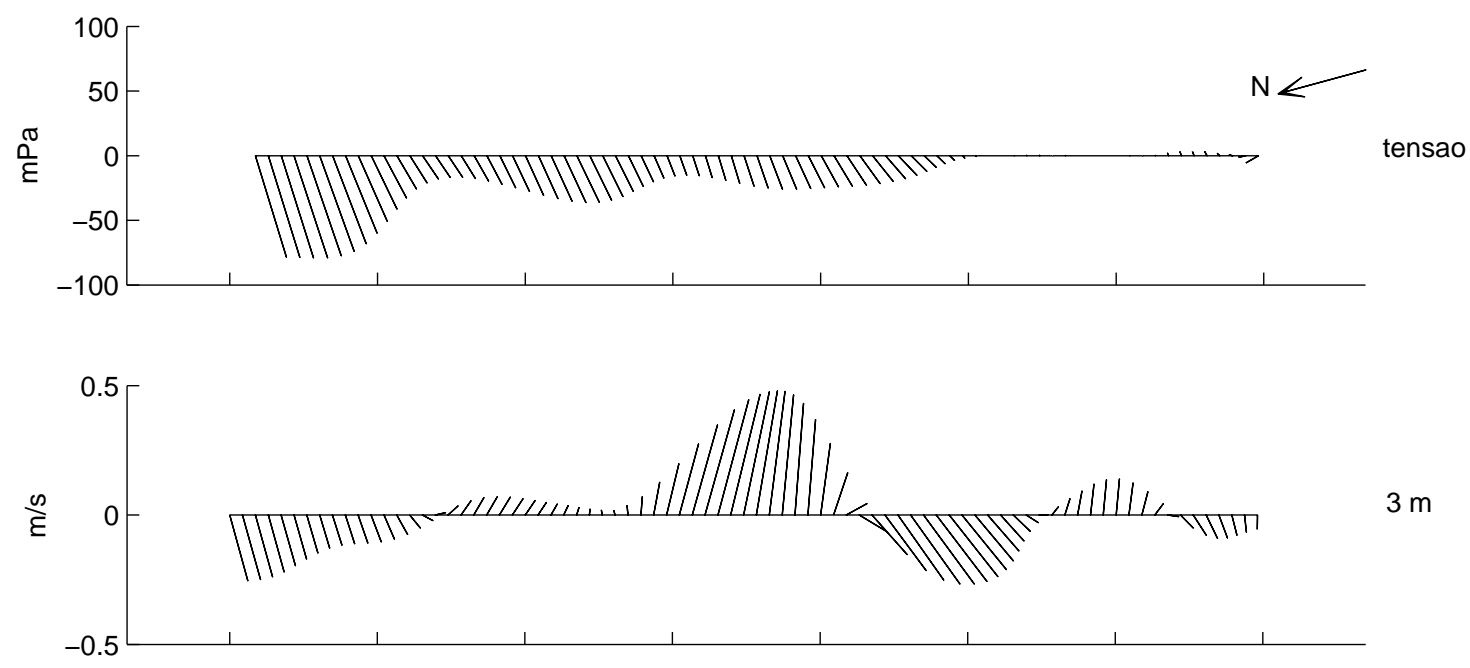

$3 \mathrm{~m}$

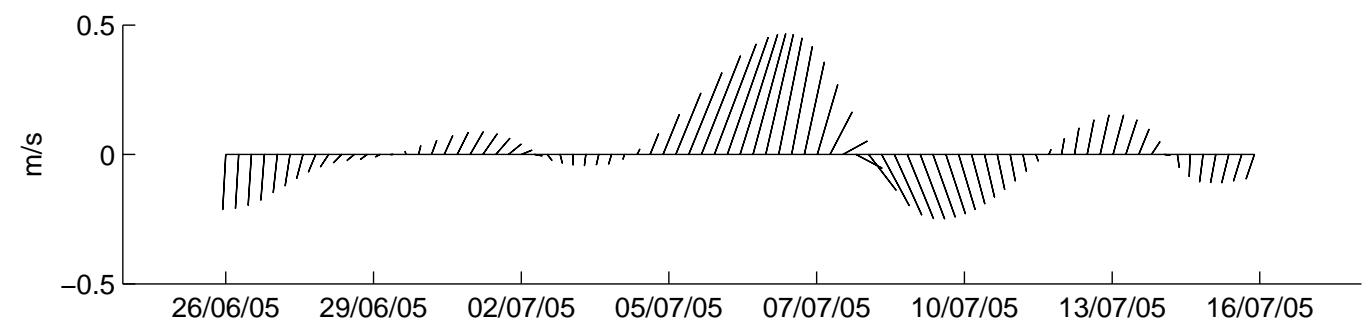

Figura 3.16: Distribuição temporal dos vetores tensão de cisalhamento do vento da série VL30 e de velocidade de corrente na superfície da série S20S1 e no fundo da série S20F1. As unidades de tensão estão em $\mathrm{mPa}$ e de velocidade $\mathrm{em} \mathrm{m} / \mathrm{s}$. O vetor $\mathrm{N}$ indica a orientação do Norte e os números à direita indicam a profundidade das séries obtidas (m) e dados de vento (tensão). 

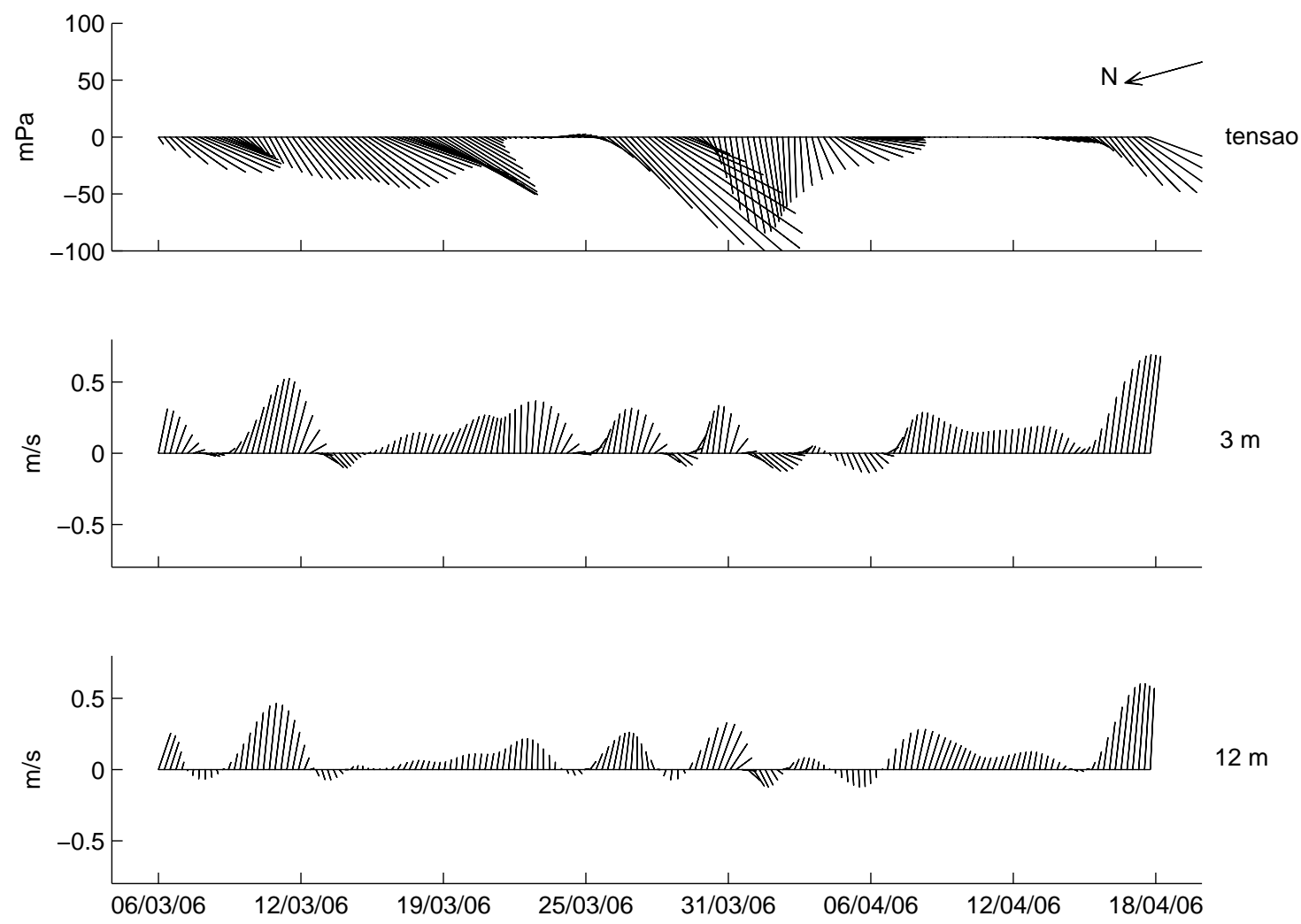

Figura 3.17: Distribuição temporal dos vetores tensão de cisalhamento do vento da série VL30 e de velocidade de corrente na superfície da série S20S2 e fundo da série S20F2. As unidades de tensão estão em $\mathrm{mPa}$ e de velocidade $\mathrm{em} \mathrm{m} / \mathrm{s}$. O vetor $\mathrm{N}$ indica a orientação do Norte e os números à direita indicam a profundidade das séries obtidas (m) e dados de vento (tensão). 


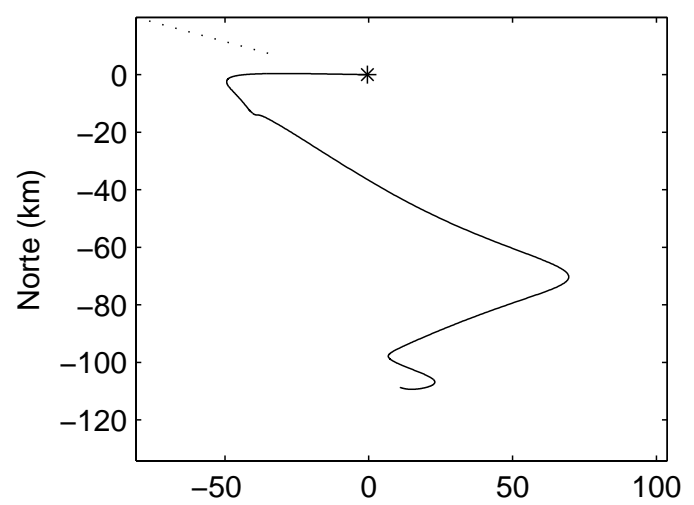

$3 m$

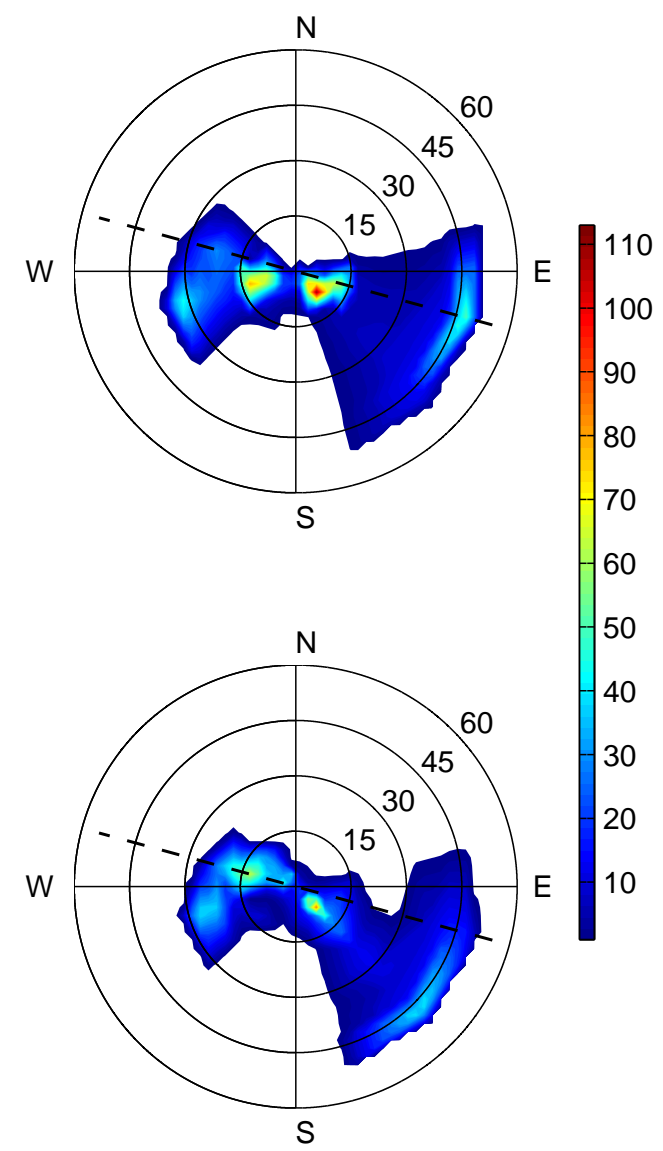

Figura 3.18: Diagramas vetoriais progressivos e rosas de distribuição de correntes $(\mathrm{em} \mathrm{cm} / \mathrm{s}$ ) das séries de superfície S20S1 no topo, e fundo S20F1 abaixo.Os asteríscos indicam o início das séries, as linhas pontilhadas ou tracejadas a orientação da isóbata local e a barra de cores o número de observações. 

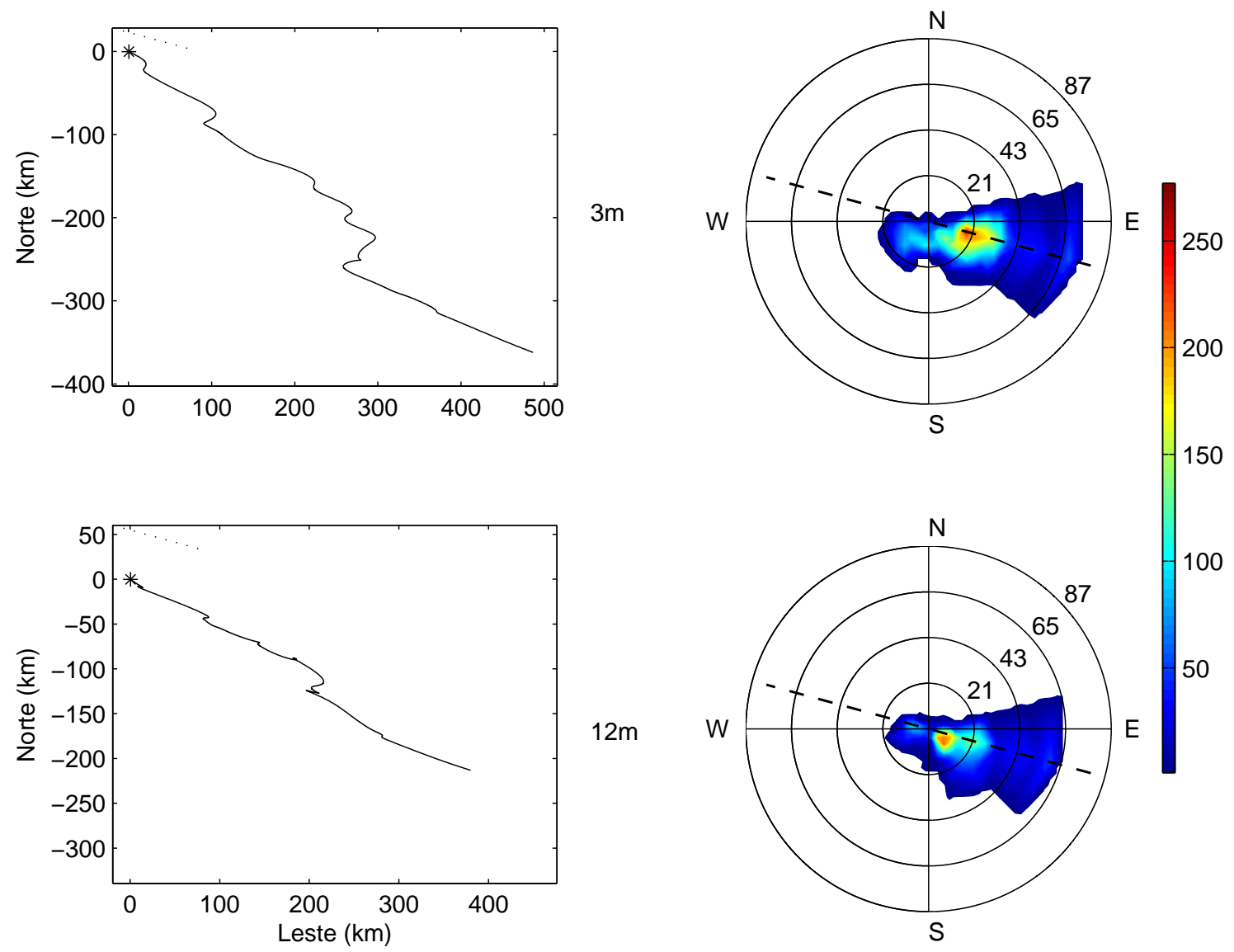

Figura 3.19: Diagramas vetoriais progressivos e rosas de distribuição de correntes $(\mathrm{em} \mathrm{cm} / \mathrm{s})$ das séries de superfície S20S2 no topo, e de fundo S20F2 abaixo. Os asteríscos indicam o início das séries, as linhas pontilhadas ou tracejadas a orientação da isóbata local e a barra de cores o número de observações. 


\section{Correlações}

As correlações entre as séries de superfície e fundo são apresentadas na Figura 3.20, para a primeira parte dos dados, e na Figura 3.21, para a segunda parte dos dados. Para ambas as partes, há correlação alta, próxima a um, em lag próximo a zero, para as componentes paralelas à batimetria. Para as componentes normais, a correlação é menor, em lag -0,3 dias para a primeira parte dos dados e marginalmente significativa, em lag -1,5 dias, para a segunda parte dos dados, sendo a corrente de superfície liderada pela de fundo.

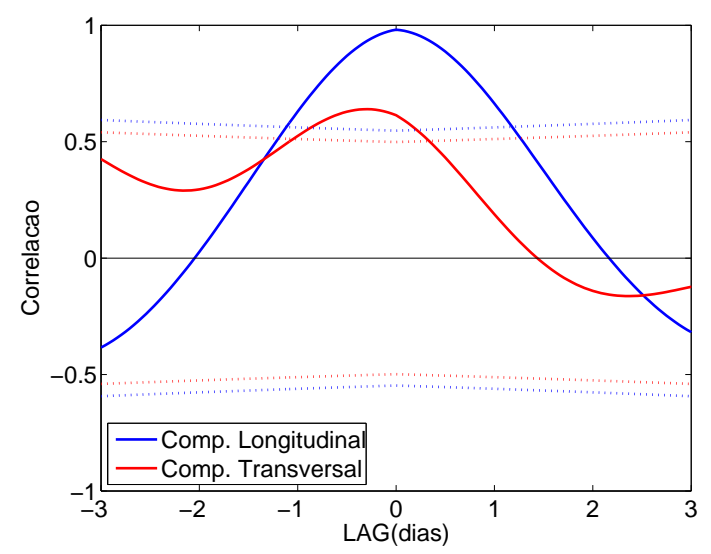

Figura 3.20: Correlações entre as séries de corrente de superfície e fundo, S20S1 x S20F1. As linhas pontilhadas indicam intervalos de confiança de $95 \%$.

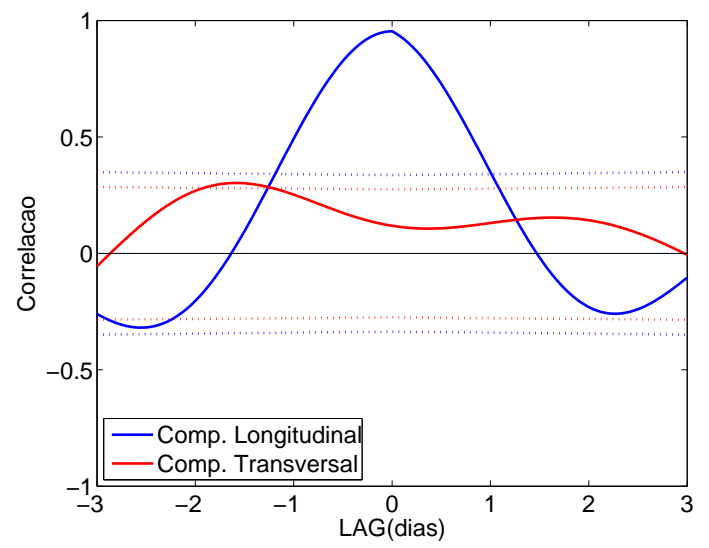

Figura 3.21: Correlações entre as séries de corrente de superfície e fundo, S20S2 x S20F2. As linhas pontilhadas indicam intervalos de confiança de $95 \%$. 
As correlações entre as séries de vento e corrente na superfície, e entre vento e corrente no fundo, são apresentadas na Figura 3.22, para a primeira parte dos dados, e na Figura 3.23, para a segunda parte dos dados. Na primeira parte, em ambas profundidades, são observadas correlações positivas significativas para as componentes paralelas à isóbata, em lag de 1,5 dias (36 horas), sendo a corrente liderada pelo vento. Para as componentes normais, apenas no fundo há correlação significativa, negativa, em lag 0,25 dias (6 horas), havendo liderança do vento sobre a corrente.

$\mathrm{Na}$ segunda parte dos dados, as componentes paralelas apresentam correlação significativa, tanto em superfície quanto no fundo, com lag de 1,8 dias (43 horas), sendo a corrente liderada pelo vento. Para as componentes normais, apenas no fundo há correlação significativa, negativa, em lag próximo a zero.

Devido ao pequeno comprimento das séries, não foram efetuadas análises no domínio da freqüência.

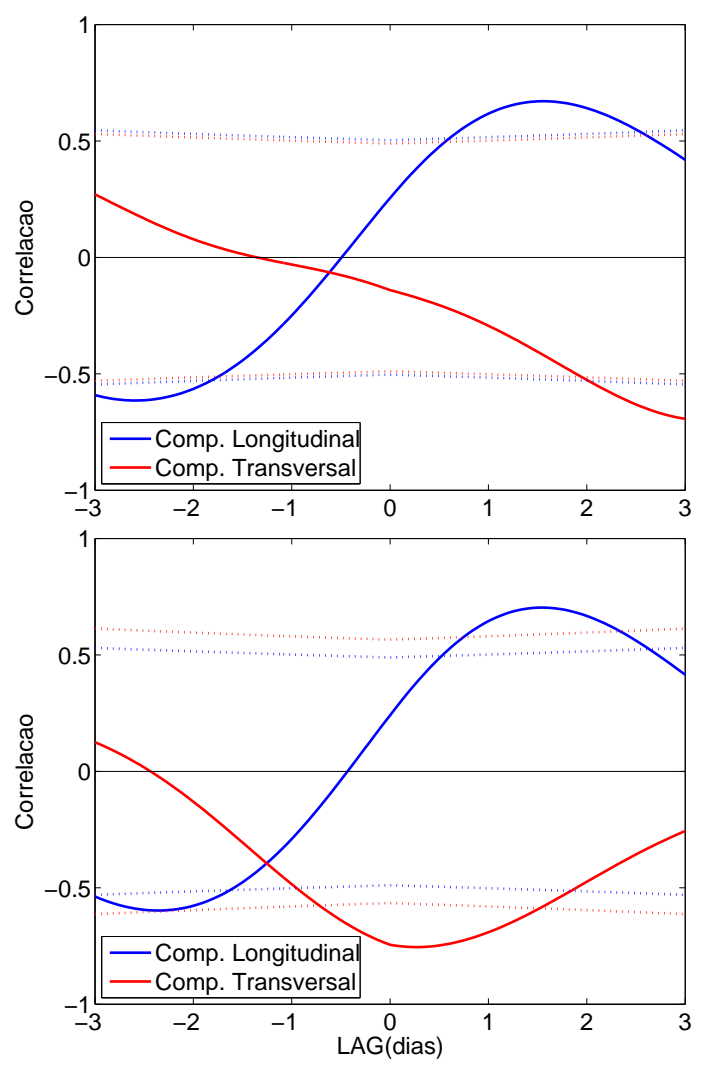

Figura 3.22: Correlações entre as séries de vento e corrente de superfície, VL30 x S20S1 acima, e de vento e corrente de fundo, VL30 x S20F1 abaixo. As linhas pontilhadas indicam intervalos de confiança de $95 \%$. 


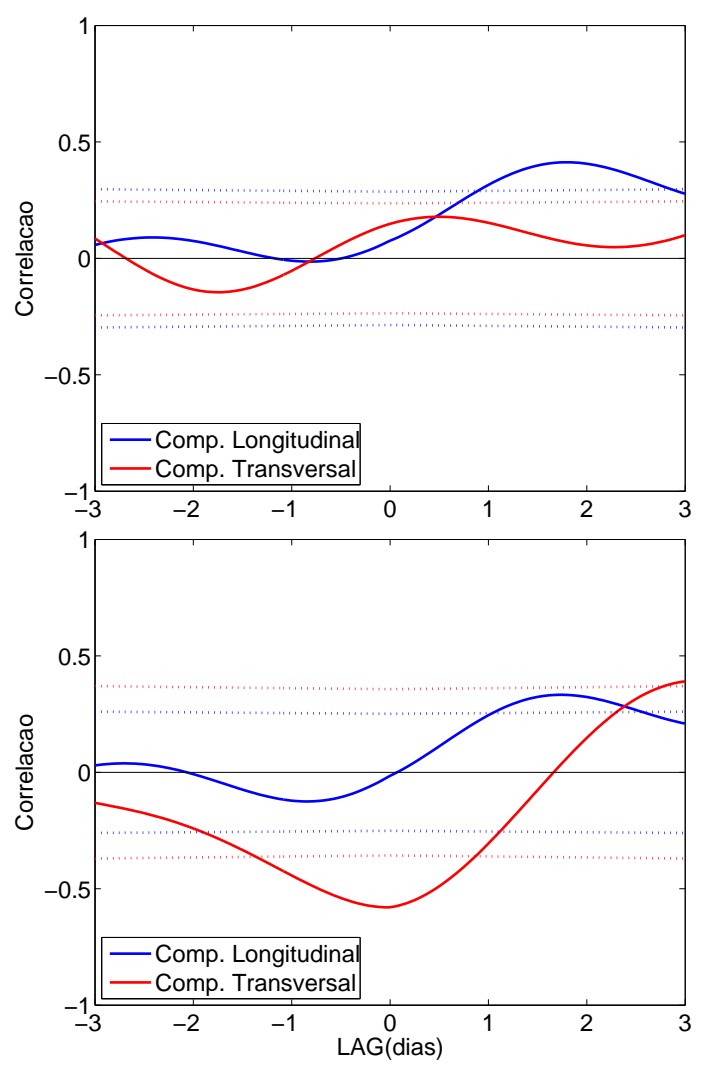

Figura 3.23: Correlações entre as séries de vento e corrente de superfície, VL30 x S20S2 acima, e de vento e corrente de fundo, VL30 x S20F2 abaixo. As linhas pontilhadas indicam intervalos de confiança de $95 \%$. 


\subsubsection{M20}

Os primeiros momentos estatísticos para as séries de corrente do fundeio M20 são apresentados na Tabela 3.4. Nesse fundeio os dados de corrente em superfície não serão analisados pois apresentaram problemas nos registros, assim todas as analises serão baseadas apenas nos dados de correntes no fundo.

As velocidades máximas em módulo são de $0,35 \mathrm{~m} / \mathrm{s}$ para a primeira parte dos dados e $0,52 \mathrm{~m} / \mathrm{s}$ para a segunda parte dos dados. As componentes paralelas à batimetria apresentam valores mais intensos que as componentes normais, aproximadamente uma ordem de grandeza, em ambas partes dos dados. Nota-se que as médias e desvios padrões apresentam valores similares, para ambas partes dos dados.

A filtragem dos dados causou uma redução da variância maior para as componentes normais que em relação as componentes paralelas, apresentando valores de $59 \%$ para a componente normal e $29 \%$ para a componente paralela, na primeira parte dos dados, e $82 \%$ para a componente normal e $39 \%$ para a componente paralela, na segunda parte dos dados.

\begin{tabular}{ccccccc}
\hline Série & Min & Max & Amp & M D.Pad & Var & $\%$ \\
\hline \hline UM20F1 & $-0,11$ & 0,08 & 0,19 & $-0,01 \pm 0,03$ & 0,0011 & 41 \\
VM20F1 & $-0,34$ & 0,35 & 0,69 & $0,09 \pm 0,12$ & 0,0153 & 71 \\
UM20F2 & $-0,09$ & 0,05 & 0,14 & $-0,01 \pm 0,03$ & 0,0008 & 18 \\
VM20F2 & 0,19 & 0,52 & 0,71 & $0,17 \pm 0,14$ & 0,0194 & 61 \\
\hline
\end{tabular}

Tabela 3.4: Primeiros momentos estatísticos para séries correntográficas filtradas para o fundeio M20. U e V correspondem às componentes transversais e paralelas às isóbatas locais, respectivamente. Min é o valor mínimo e Max é o valor máximo (em m/s); Amp é a diferença entre Max e Min (em m/s); M. é a média; D.Pad é o desvio padrão da média $(\mathrm{em} \mathrm{m} / \mathrm{s})$; Var é a variância $\left(\mathrm{m}^{2} / \mathrm{s}^{2}\right)$ e $\%$ é a porcentagem que a variância da série filtrada representa com relação à variância da série original. 
A distribuição temporal dos vetores velocidade de corrente é apresentada nas Figuras 3.24 e 3.24 para a primeira e para a segunda parte dos dados, respectivamente. As rosas de distribuição de correntes e diagramas vetorias progressivos são apresentados na Figura 3.26 para a primeira parte dos dados e na Figura 3.27 para a segunda parte dos dados.

É importante ressaltar que em ambas partes dos dados, as correntes são predominantemente paralelas à topografia, com sentido predominante Leste, apresentado diversas inversões.
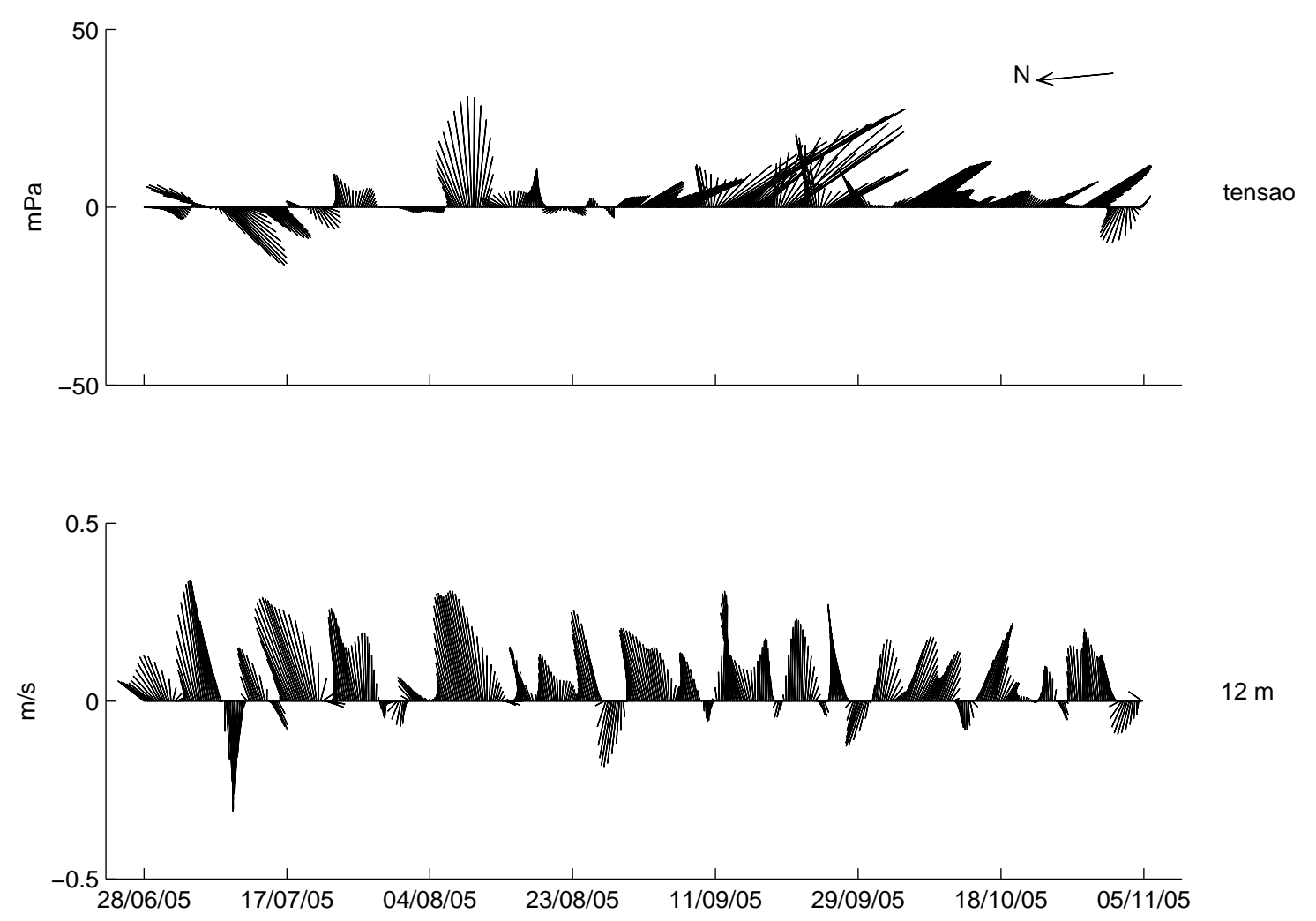

Figura 3.24: Distribuição temporal dos vetores tensão de cisalhamento do vento da série VM20 e de velocidade de corrente no fundo da série M20F1. As unidades de tensão estão em mPa e de velocidade $\mathrm{em} \mathrm{m} / \mathrm{s}$. O vetor $\mathrm{N}$ indica a orientação do Norte e os números à direita indicam a profundidade das séries obtidas (m) e dados de vento (tensão). 

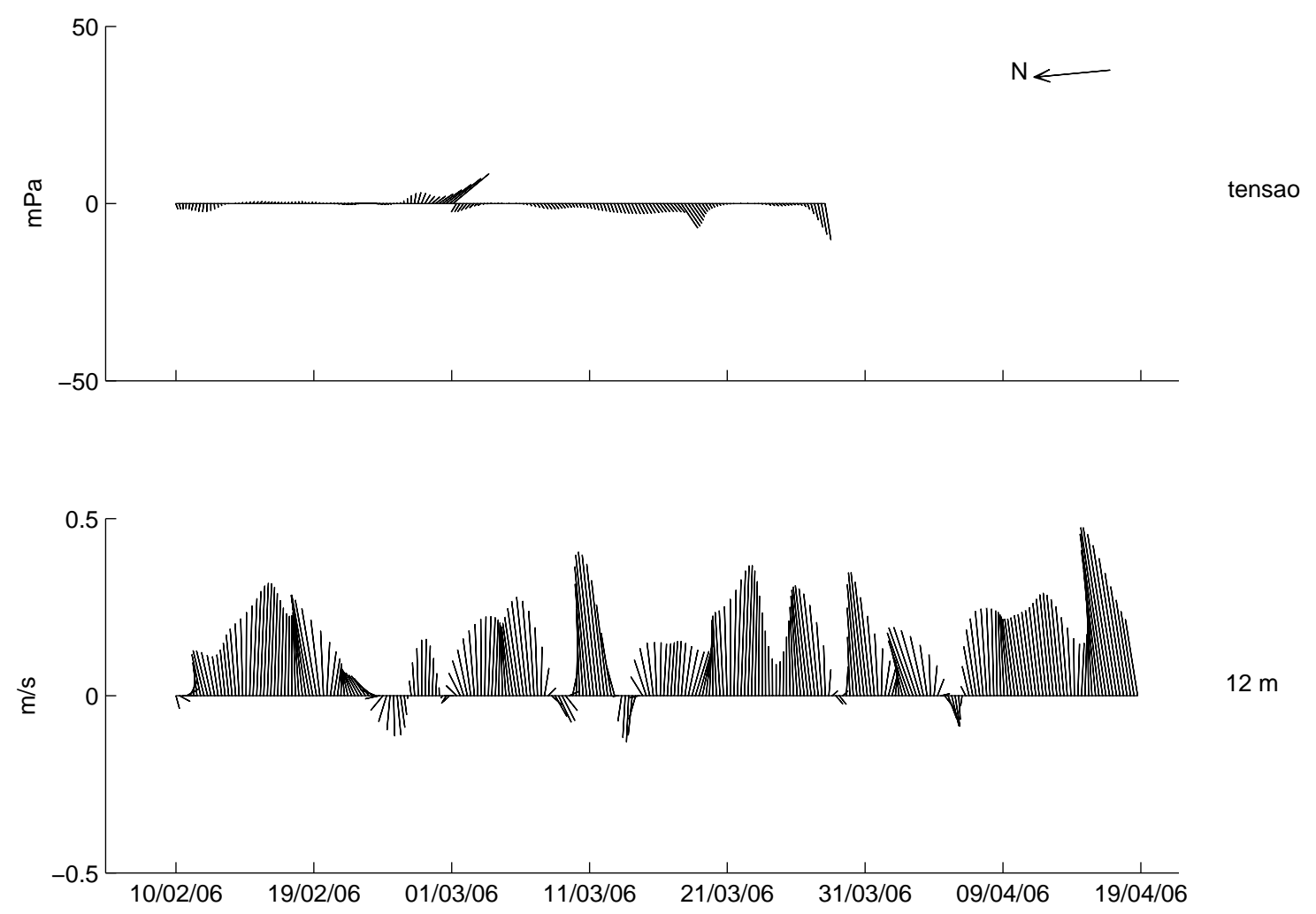

Figura 3.25: Distribuição temporal dos vetores tensão de cisalhamento do vento da série VM20 e de corrente no fundo da série M20F2. As unidades de tensão estão em $\mathrm{mPa}$ e de velocidade em $\mathrm{m} / \mathrm{s}$. O vetor $\mathrm{N}$ indica a orientação do Norte e os números à direita indicam a profundidade das séries obtidas (m) e dados de vento (tensão). 

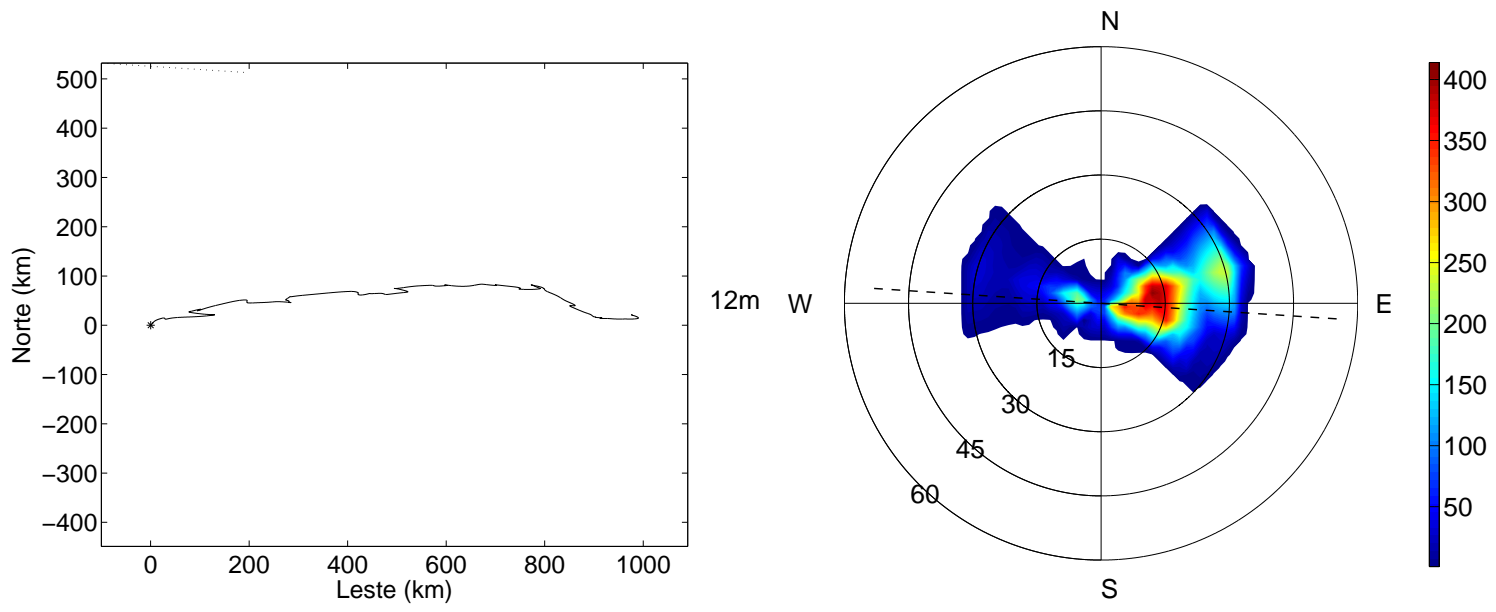

Figura 3.26: Diagrama vetorial progressivo e rosa de distribuição de correntes $(\mathrm{em} \mathrm{cm} / \mathrm{s}$ ) da série de fundo M20F1. Os asteríscos indicam o início das séries, as linhas pontilhadas ou tracejadas a orientação da isóbata local e a barra de cores o número de observações.
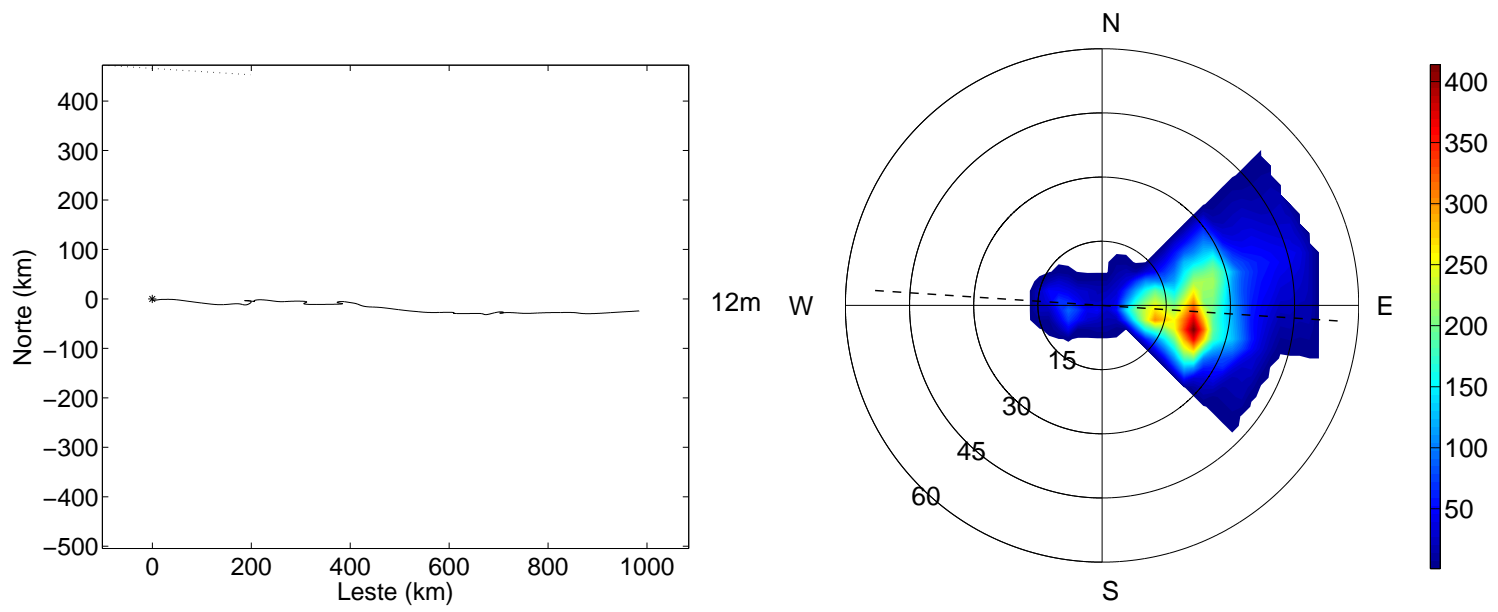

Figura 3.27: Diagrama vetorial progressivo e rosa de distribuição de correntes $(\mathrm{em} \mathrm{cm} / \mathrm{s}$ ) da série de fundo M20F2. Os asteríscos indicam o início das séries, as linhas pontilhadas ou tracejadas a orientação da isóbata local e a barra de cores o número de observações. 


\section{Correlações}

As correlações entre as séries de vento e corrente no fundo são apresentadas na Figura 3.28, para a primeira parte dos dados, e na Figura 3.29, para a segunda parte dos dados. Apenas na na primeira parte dos dados há correlações significativas, sendo positivas para ambas componentes, com máximo no lag de 0,4 dias para as componentes paralelas, e lag -0,3 dias para a componentes normais. Na primeira, a corrente é liderada pelo vento e, na segunda, o vento liderado pela corrente.

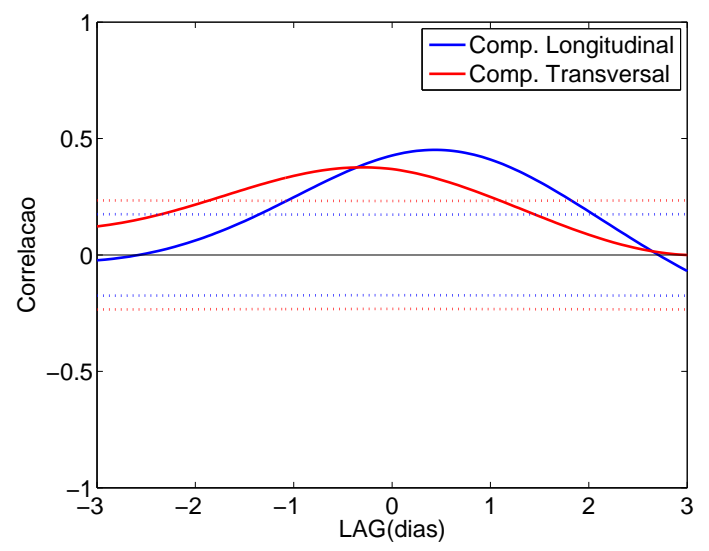

Figura 3.28: Correlação entre as séries de vento e corrente de fundo, VM20 x M20F1. As linhas pontilhadas indicam intervalos de confiança de $95 \%$.

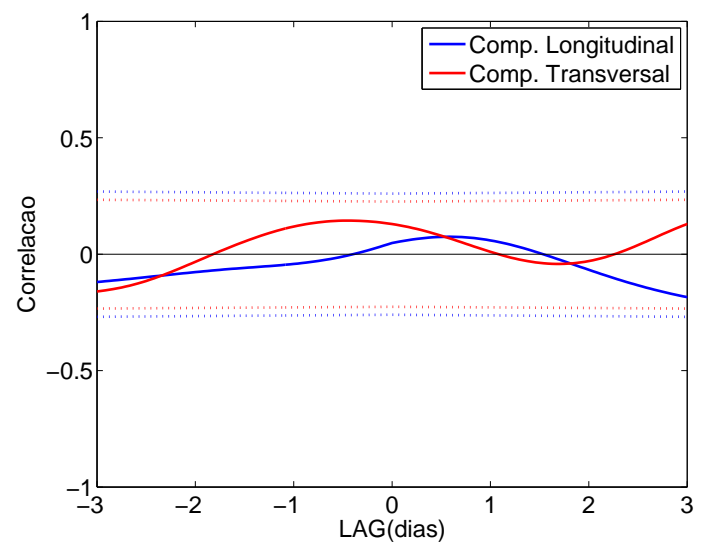

Figura 3.29: Correlações entre as séries de vento e corrente de fundo VM20 x M20F2. As linhas pontilhadas indicam intervalos de confiança de $95 \%$. 


\section{Espectros}

Os autoespectros para as séries de correntes de fundo são apresentados na Figura 3.30, para a primeira parte dos dados, e na Figura 3.31, para a segunda parte dos dados. Em ambas, as componentes paralelas à batimetria são muito mais energéticas, pelo menos uma ordem de grandeza maior. Na primeira parte dos dados a componente paralela apresenta picos nas bandas 0,1, 0,2 e 0,3 cpd, com períodos entre 3,5 e 10 dias, e a componente normal nas bandas 0,15 e 0,3 cpd, com períodos de 3,5 e 8 dias. Na segunda parte dos dados, dois picos são evidentes em ambas componentes, de 0,2 e 0,4 cpd, com períodos de 2,5 e 5 dias.

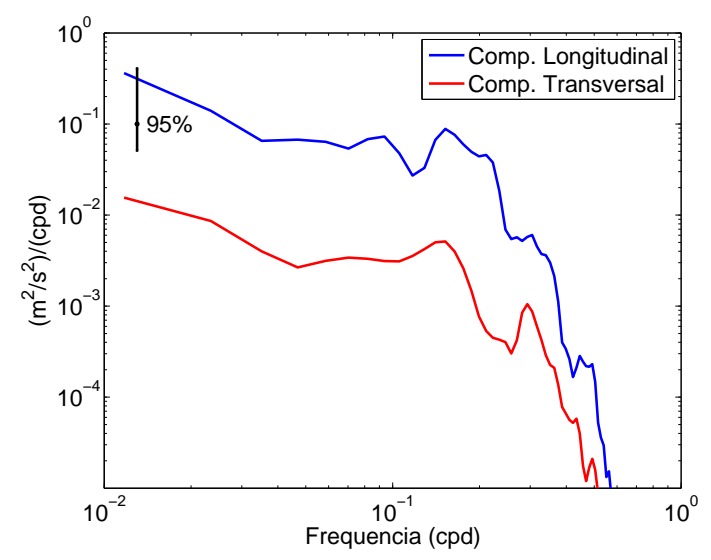

Figura 3.30: Autoespectros das séries de corrente de fundo M20F1.

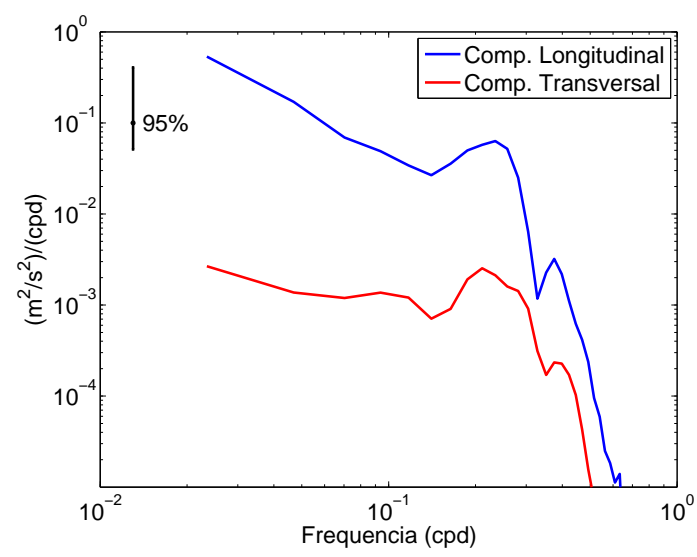

Figura 3.31: Autoespectros das séries de corrente de fundo M20F2. 
Os espectros de coerência ao quadrado e fase da primeira parte dos dados, entre vento e corrente de fundo, são apresentados na Figura 3.32. Para a segunda parte dos dados, a série de vento foi muito curta. Desta forma, não foram incluídas nas análises de coerência e fase.

Para a componente paralela à batimetria, há correlação significativa em 3 picos: na banda de 0,06 cpd, com período de 16 dias, e fase $-55^{\circ}$ (55 horas), sendo o vento liderado pela corrente; na banda próxima à 0,1, com período aproximado de 10 dias, e com fase de $10^{\circ}$ ( 5 horas), sendo a corrente liderada pelo vento; na banda de 0,3 cpd, com período de 3 dias, e fase $35^{\circ}$ ( 8 horas), novamente sendo a corrente liderada pelo vento. A componente normal não apresenta coerência significativa.
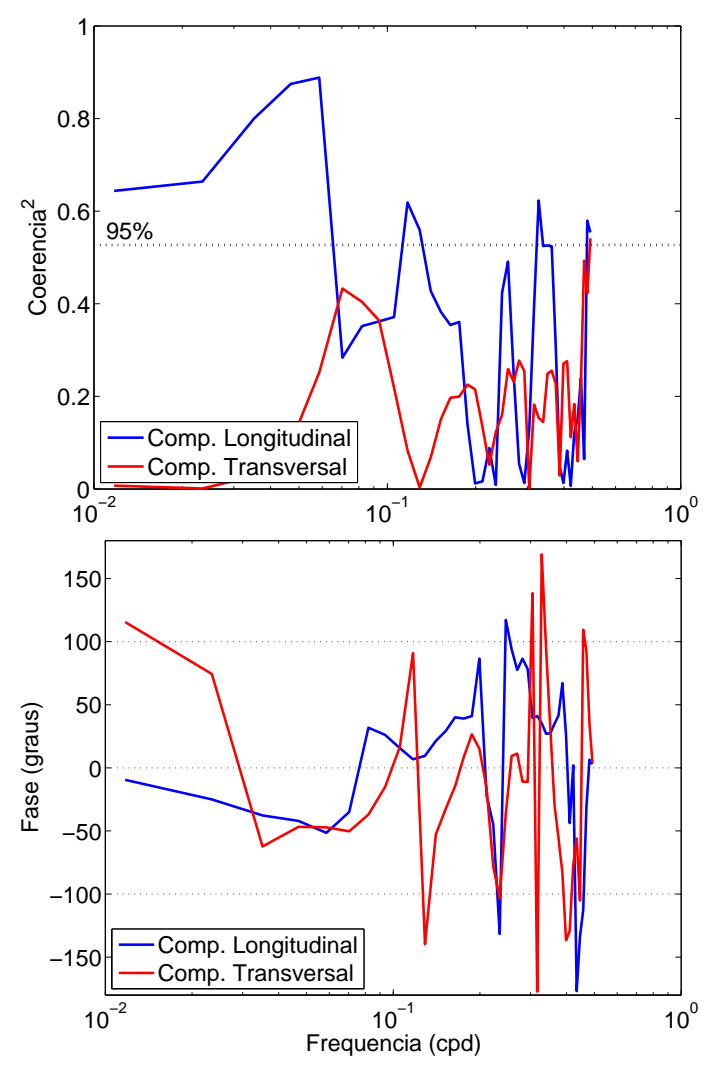

Figura 3.32: Espectros de coerência ao quadrado no topo e fase abaixo, entre vento e corrente de fundo, das séries VM20 x M20F1. 


\subsubsection{S100}

Os primeiros momentos estatísticos para as séries de corrente do fundeio S100 são apresentados na Tabela 3.5.

Pode-se observar um aumento nas intensidades com o aumento da profundidade. As velocidades máximas em módulo são $0,11 \mathrm{~m} / \mathrm{s}$ na superfície, $0,27 \mathrm{~m} / \mathrm{s}$ em meia-água e $0,31 \mathrm{~m} / \mathrm{s}$ no fundo. As componentes paralelas à topografia são pouco mais intensas em comparação às componentes normais e também aumentam com o aumento da profundidade. A diferença entre as velocidades máximas apresentadas pelas componentes foi de 0,02 m/s na superfície, 0,06 em meia-água, e 0,11 m/s no fundo. Nota-se também que os desvios padrões são maiores que as médias.

A filtragem dos dados causou uma maior redução da variância para as componentes normais à batimetria,crescentemente com o aumento da profundidade. Reduções: em $64 \%$ na superfície, $66 \%$ em meia-água, e $81 \%$ no fundo. Para as componentes paralelas às isóbatas, a redução foi mais homogênea ao longo da coluna de água: de $51 \%$ em superfície, $41 \%$ em meia-água, e $52 \%$ no fundo.

\begin{tabular}{ccccccc}
\hline Série & Min & Max & Amp & M \pm D.Pad & Var & $\%$ \\
\hline \hline US100S & $-0,09$ & 0,08 & 0,17 & $0,01 \pm 0,03$ & 0,0010 & 36 \\
VS100S & $-0,11$ & 0,08 & 0,19 & $-0,02 \pm 0,04$ & 0,0015 & 49 \\
US100M & $-0,21$ & 0,11 & 0,33 & $-0,02 \pm 0,05$ & 0,0027 & 34 \\
VS100M & $-0,23$ & 0,27 & 0,50 & $0,01 \pm 0,08$ & 0,0064 & 59 \\
US100F & $-0,20$ & 0,12 & 0,32 & $-0,02 \pm 0,05$ & 0,0030 & 19 \\
VS100F & $-0,23$ & 0,31 & 0,54 & $-0,02 \pm 0,08$ & 0,0057 & 48 \\
\hline
\end{tabular}

Tabela 3.5: Primeiros momentos estatísticos para séries correntográficas filtradas para o fundeio S100. $\mathrm{U}$ e $\mathrm{V}$ correspondem às componentes transversais e paralelas às isóbatas locais, respectivamente. Min é o valor mínimo e Max é o valor máximo (em m/s); Amp é a diferença entre Max e Min (em m/s); M. é a média; D.Pad é o desvio padrão da média $(\mathrm{em} \mathrm{m} / \mathrm{s})$; Var é a variância $\left(\mathrm{m}^{2} / \mathrm{s}^{2}\right)$ e \% é a porcentagem que a variância da série filtrada representa com relação à variância da série original. 
A distribuição temporal dos vetores velocidade de corrente é apresentada na Figura 3.33. As rosas de distribuição de correntes e diagramas vetorias progressivos são apresentados pela Figura 3.34 .

Novamente é possível verificar um pequeno aumento das intensidades com o aumento da profundidade. A direção predominante em superfície é SW, em meia-água varia entre NE e NW, e no fundo é W. A predominância das direções razoavelmente segue a direção da isóbata local, com exceção da corrente em meia-água, que durante boa parte das medições teve sentido normal à isóbata. Em todas as profundidades observam-se diversas inversoẽs de corrente.
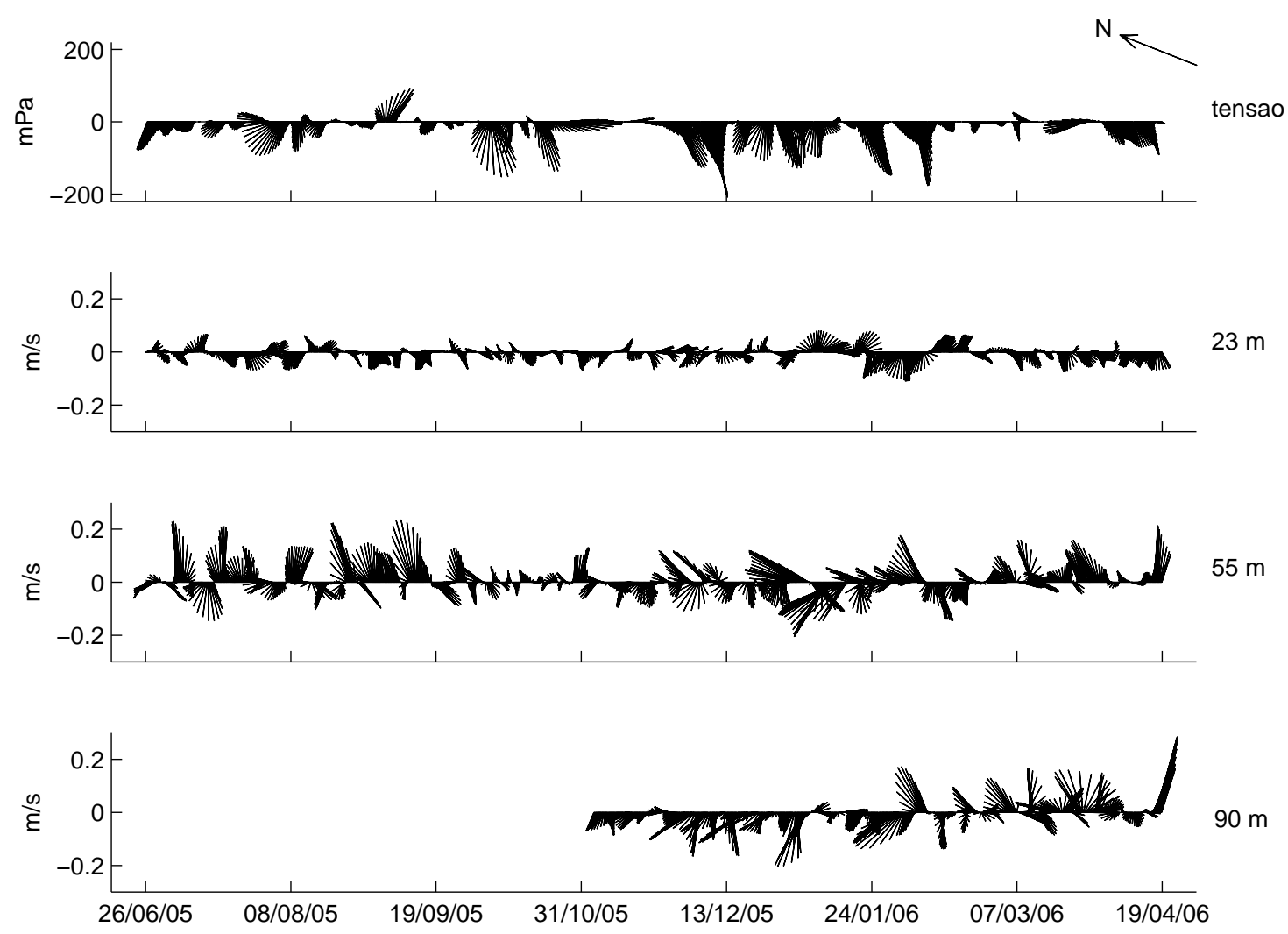

Figura 3.33: Distribuição temporal dos vetores tensão de cisalhamento do vento da série VL30 e de velocidade de corrente na superfície da série S100S, em meia-água da série S100M, e no fundo da série $\mathrm{S} 100 \mathrm{~F}$. As unidades de tensão estão em $\mathrm{mPa}$ e de velocidade em $\mathrm{m} / \mathrm{s}$. O vetor $\mathrm{N}$ indica a orientação do Norte e os números à direita indicam a profundidade das séries obtidas $(\mathrm{m})$ e dados de vento (tensão). 

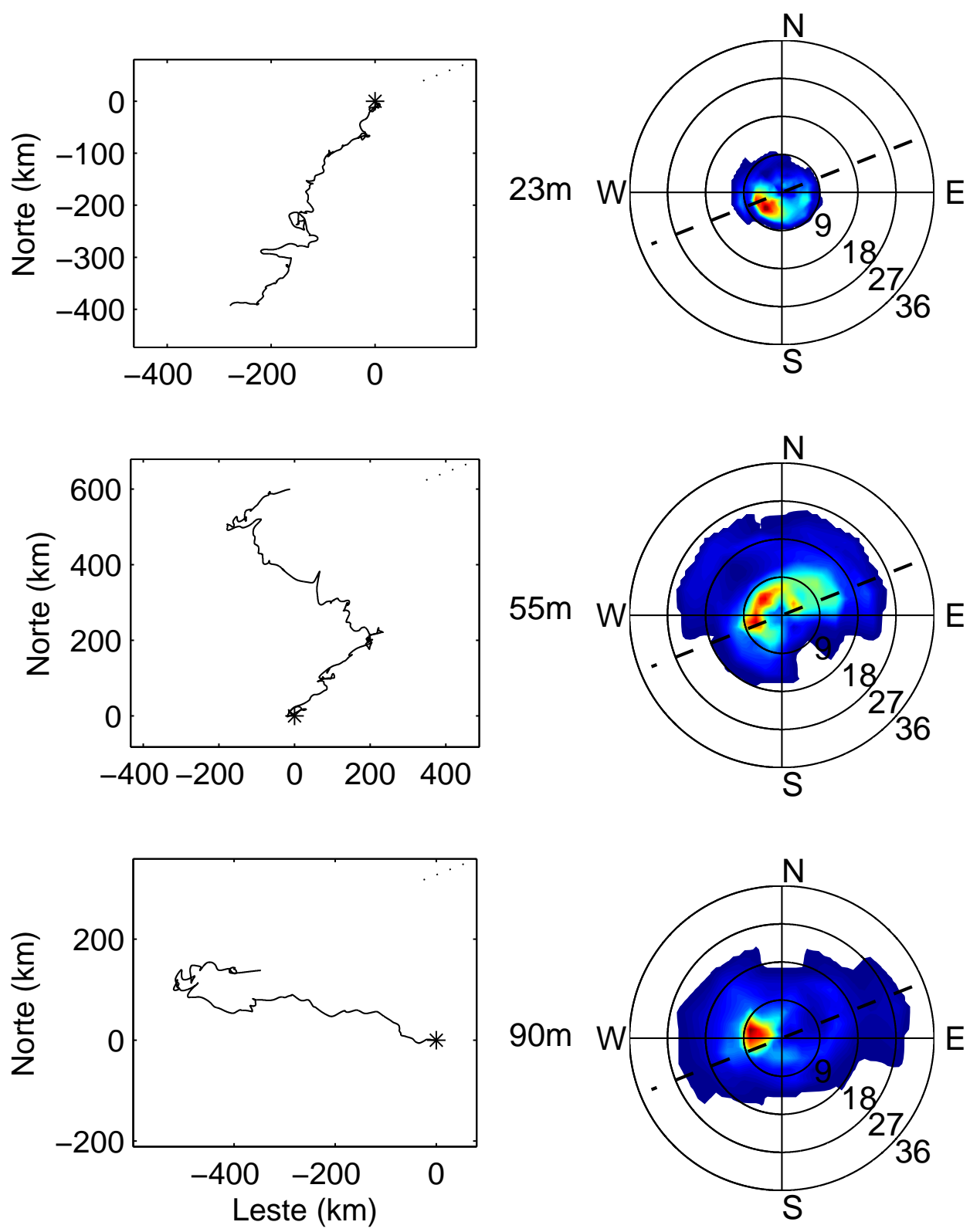

Figura 3.34: Diagramas vetoriais progressivos e rosas de distribuição de correntes $(\mathrm{em} \mathrm{cm} / \mathrm{s}$ ) das séries de corrente de superfície, S100S no topo, de meia-água, S100M no meio, e de fundo, S100F abaixo. Os asteríscos indicam o início das séries, as linhas pontilhadas ou tracejadas a orientação da isóbata local e a barra de cores o número de observações. 


\section{Correlações}

As correlações entre as séries de superfície e meia-água, superfície e fundo, e meiaágua e fundo são apresentadas na Figura 3.35. Em superfície e meia-água, a correlação é significativa e negativa para ambas componentes. A correlação é maior em módulo para as componentes paralelas, com valor de $-0,7$ aproximadamente, em lag zero. Para as componentes normais, a correlação é - 0,2 em lag de aproximadamente 2 dias, sendo a corrente em meia-água liderada pela corrente na superfície.

Na superfície e fundo, há correlações marginalmente significativas para ambas componentes: positiva para as componentes normais e negativa para as componentes paralelas, com valores máximos em módulo próximos ao lag zero. Para meia-água e fundo, ambas componentes apresentam valores próximos de correlação, positivos e com valores máximos próximos ao lag zero. 

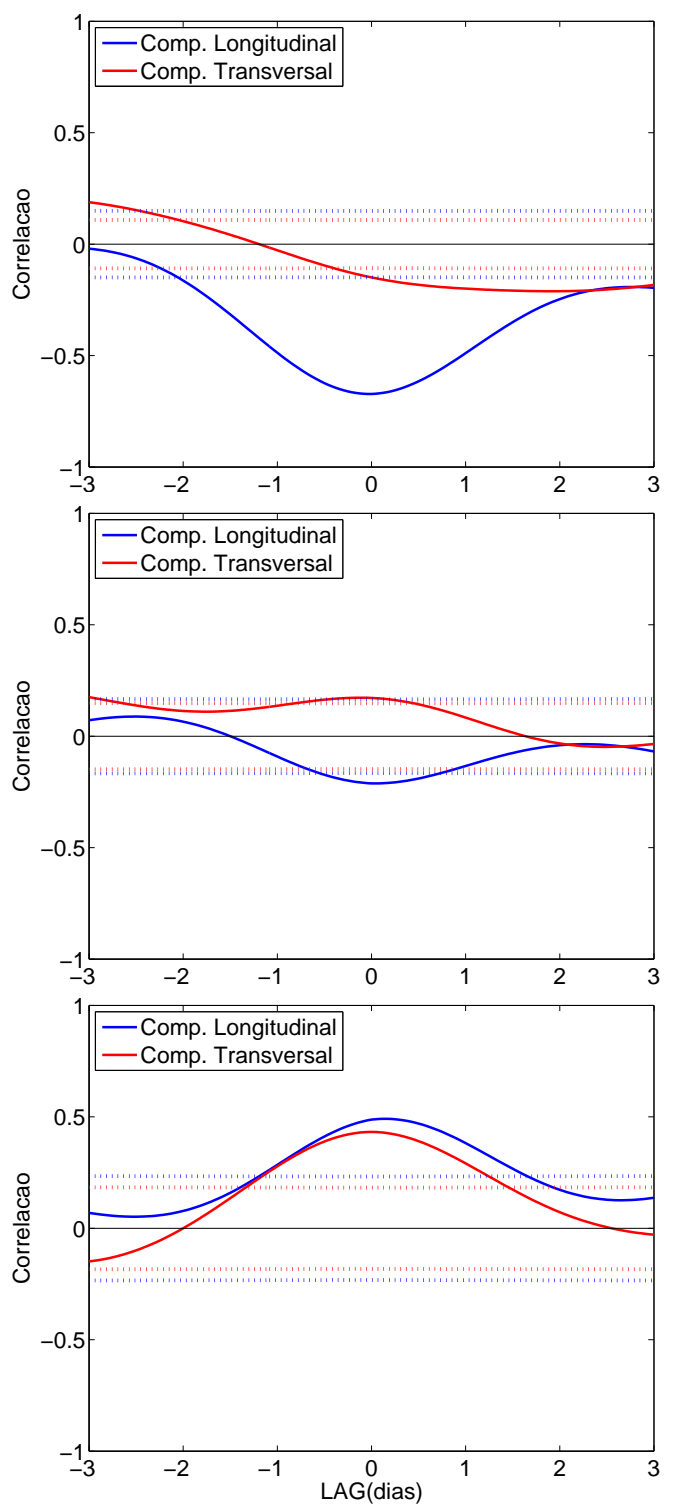

Figura 3.35: Correlações entre as séries de corrente de superfície e meia-água, S100S x S100M no topo, de superfície e fundo, S100S x S100F no meio, e de meia-água e fundo, S100M x S100F abaixo. As linhas pontilhadas indicam intervalos de confiança de $95 \%$. 
As correlações entre as séries de vento e corrente de superfície, vento e corrente de meia-água, e de vento e corrente de fundo são apresentadas na Figura 3.36. Em nenhuma profundidade há correlação significativa para as componentes normais à topografia. Para as componentes paralelas, em superfície a correlação é marginalmente significativa, negativa, e em meia-água a correlação é positiva, ambas com valores máximos em módulo com lag de um dia. No fundo não há correlação significativa.
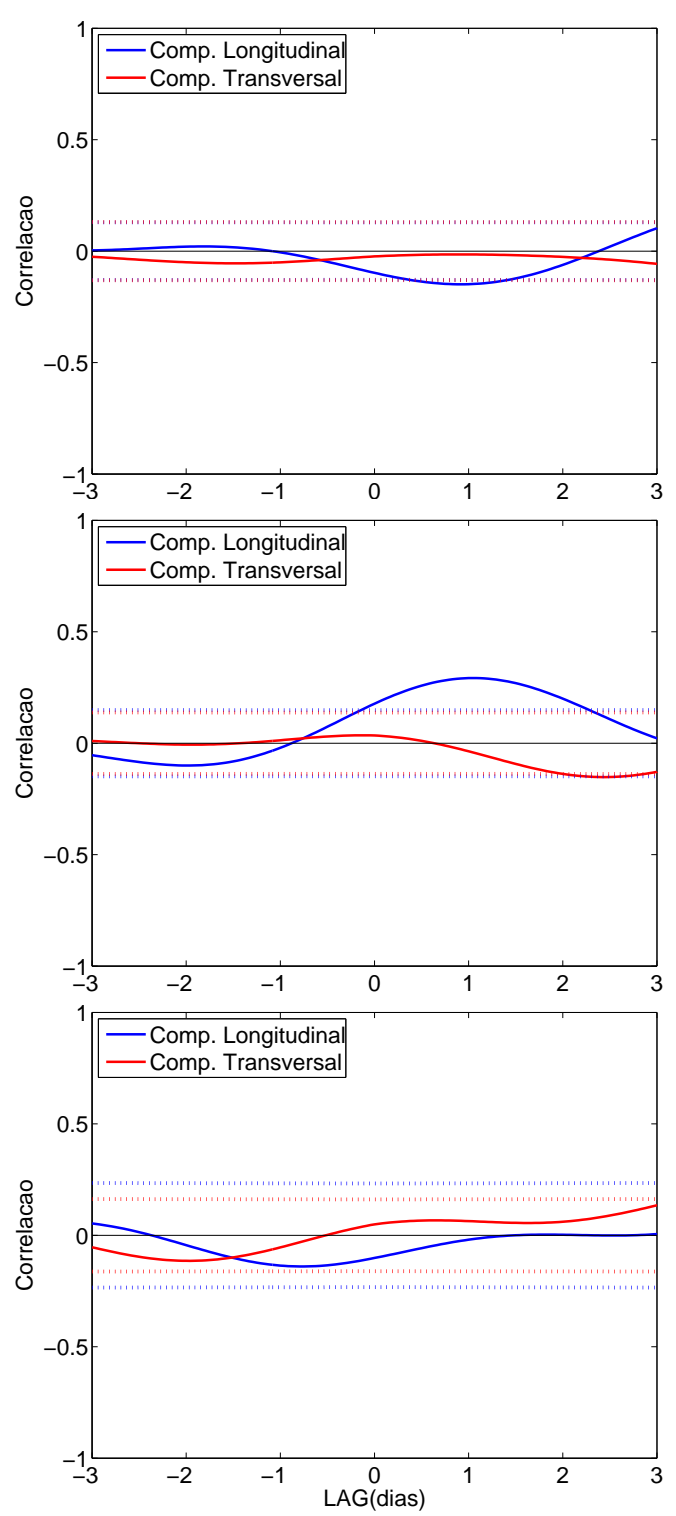

Figura 3.36: Correlações entre as séries de vento e corrente de superfície, VL30 x S100S no topo, de vento e corrente de meia-água, VL30 x S100M no meio, e de vento e corrente de fundo, VL30 x S100F abaixo. As linhas pontilhadas indicam intervalos de confiança de $95 \%$. 


\section{Espectros}

Os autoespectros para as séries de correntes de superfície, meia-água, e fundo são apresentado na Figura 3.37. Em todas profundidades, há maior energia associada às componentes paralelas à topografia, entretanto com pouca discrepância em relação às componentes normais.

Na superfície, ambas componentes apresentam um pico bem evidenciado na banda de 0,2 cpd, correspondendo a um período de 5 dias, e presença de oscilações de 0,07 cpd, correspondendo a um período de 14 dias . Em meia-água, ambas componentes apresentam um pico bem evidenciado na banda de $0,2 \mathrm{cpd}$, correspondendo a um período de 5 dias, e oscilações na banda de 0,1 cpd, correspondendo a um período de 10 dias. No fundo, ambas componentes apresentam energia nas bandas de 0,4,0,2 e 0,1 cpd, com período de $2,5,5$ e 10 dias. 

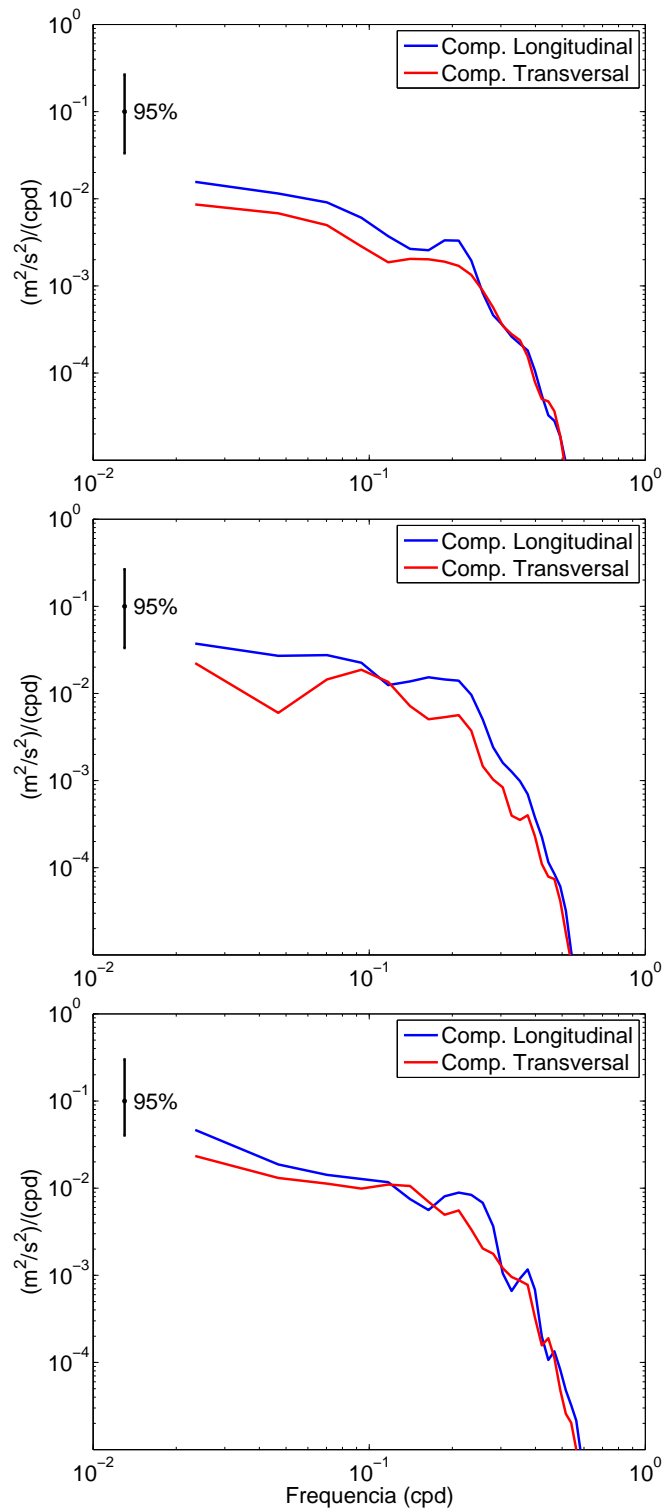

Figura 3.37: Autoespectros das séries de corrente de superfície, S100S no topo, de meia-água, S100M no meio, e de fundo, S100F abaixo. 
Os espectros de coerência ao quadrado e fase entre as séries de superfície e meiaágua, de superfície e fundo e meia-água e fundo são apresentados nas Figuras 3.38, 3.39, 3.40, respectivamente. Entre superfície e meia-água, há coerência em 3 bandas para as componentes paralelas: $0,05 \mathrm{cpd}$, período correspondente de 20 dias, e fase $-170^{\circ}(9,8$ dias), sendo superfície liderada por meia-água; $0,25 \mathrm{cpd}$, período correspondente de 4-5 dias, e fase $175^{\circ}$ (45 horas), sendo meia-água liderada pela superfície; e 0,35 cpd, período correspondente de 2,5-3 dias, e fase $-175^{\circ}$ (33 horas), sendo superfície liderada por meiaágua. As componentes normais, possuem coerência significativa menor que em relação às componentes paralelas, em 2 bandas: 0,07 cpd, período correspondente de 14 dias, e fase $-90^{\circ}$ (85 horas), sendo superfície liderada por meia-água; e 0,15, período correspondente de 8 dias $-160^{\circ}$ (70 horas), sendo novamente superfície liderada por meia-água.

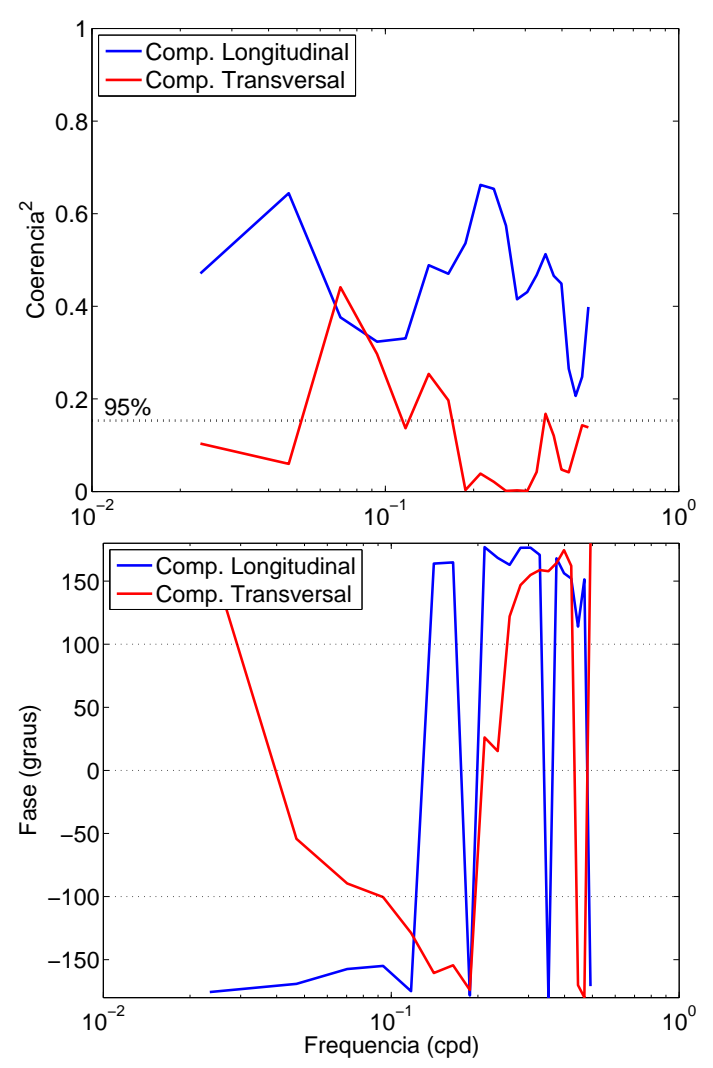

Figura 3.38: Espectros de coerência ao quadrado no topo e fase abaixo, entre corrente na superfíe e meia-água, das séries S100S x S100M. 
Entre superfície e fundo, as componentes paralelas possuem coerência em 2 bandas: $0,2 \mathrm{cpd}$, período correspondente de 5 dias, e fase $180^{\circ}$ (120 horas), sendo o fundo liderado pela superfície; $0,4 \mathrm{cpd}$, período correspondente de 2,5 dias, e fase $150^{\circ}$ (25 horas), sendo o fundo também liderado pela superfície. As componentes normais apresentam coerências mais baixas, marginalmente significativas, nas bandas: 0,2, período correspondente de 5 dias, e fase $10^{\circ}$ (3 horas), sendo o fundo liderado pela superfície; e 0,3 , período correspondente de 3 dias, e fase $25^{\circ}$ (6 horas), sendo novamente o fundo liderado pela superfície.

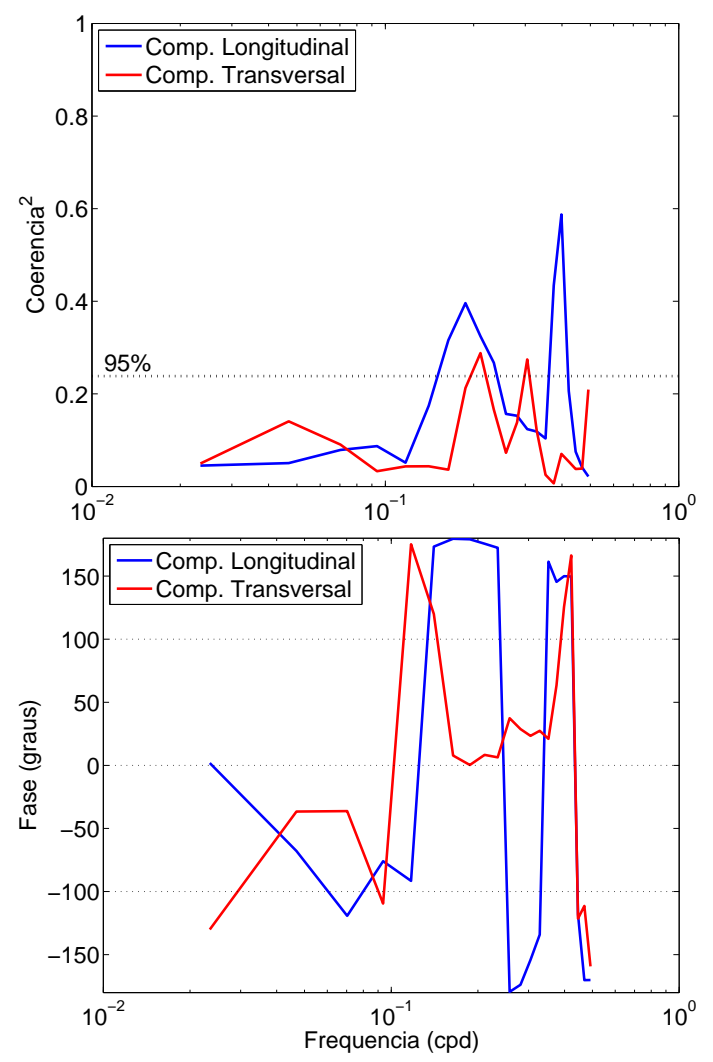

Figura 3.39: Espectros de coerência ao quadrado no topo e fase abaixo, entre corrente de superfíe e fundo, das séries S100S x S100F. 
Entre meia-água e fundo, as componentes paralelas possuem coerência em 2 bandas: 0,15 cpd, período correspondente de 5-8 dias, e fase $10^{\circ}$ (5 horas), sendo fundo liderado por meia-água; e 0,4 cpd, período correspondente de 2,5 dias, e fase $5^{\circ}$ (1 hora), sendo fundo também liderado por meia-água. As componentes normais possuem coerência em 2 bandas: entre 0,1 e 0,15 cpd, período correspondente de 8-10 dias, e fase $-5^{\circ}$ (2 horas), sendo meia-água liderada pelo fundo; $0,2 \mathrm{cpd}$, período correspondente de 5 dias, e fase $-5^{\circ}$ (3 horas), sendo novamente meia-água liderada pelo fundo.

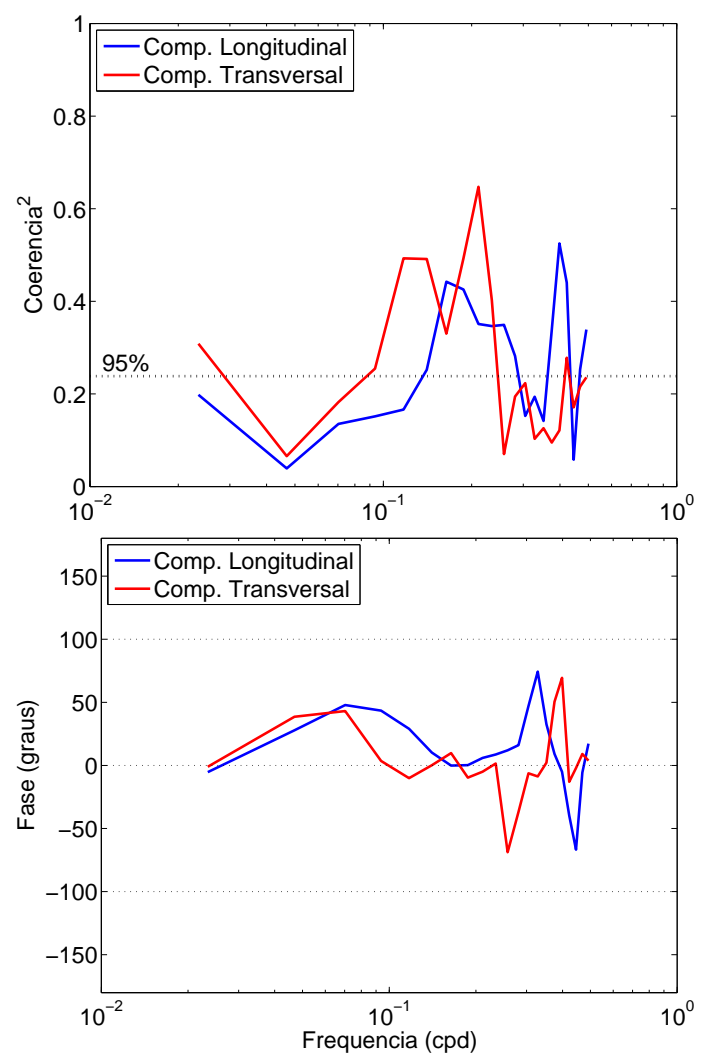

Figura 3.40: Espectros de coerência ao quadrado no topo e fase abaixo, entre corrente de meia-água e fundo, das séries S100M x S100F. 
Os espectros de coerência ao quadrado e fase entre as séries de vento e corrente na superfície, vento e corrente em meia-água, e vento e corrente no fundo são apresentados nas Figuras 3.41, 3.42, 3.43, respectivamente. Entre vento e superfície, apenas as componentes paralelas apresentam coerências significativas, em 2 bandas: 0,1 cpd, período correspondente de 10 dias, e fase $180^{\circ}$ (120 horas), sendo a corrente liderada pelo vento; e 0,2, período correspondente de 5 dias, e fase $-90^{\circ}$ (30 horas), sendo o vento liderado pela corrente.

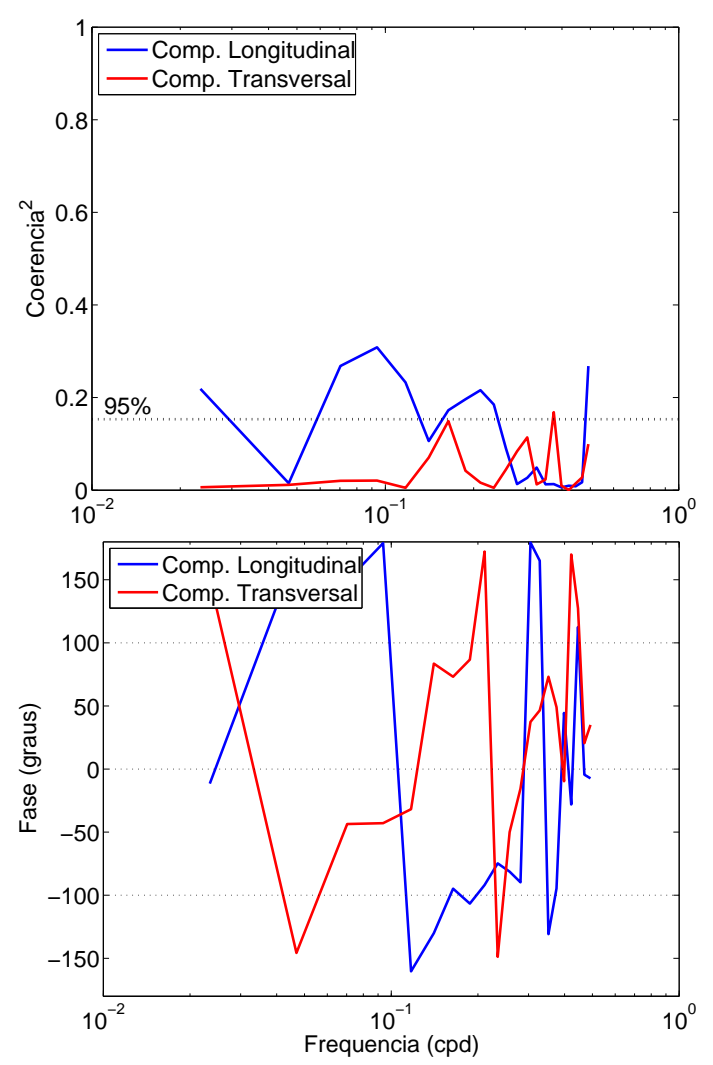

Figura 3.41: Espectros de coerência ao quadrado no topo e fase abaixo, entre vento e corrente de superfície, das séries VL30 x S100S. 
Entre vento e corrente em meia-água, há uma alta coerência entre as componentes paralelas, maior que 0,6, na banda 0,15 cpd, período de 5-7 dias, e fase 55 (22 horas), sendo a corrente liderada pelo vento. As componentes normais apresentam coerências menores, nas bandas: $0,15 \mathrm{cpd}$, com período entre 5-7 dias, e fase $-75^{\circ}$ (30 horas), sendo o vento liderado pela corrente; 0,25 e 0,3 cpd, com períodos de 4-5 dias e 3 dias respectivamente, e fases $30^{\circ}$ (10 horas) e $60^{\circ}$ (13 horas) respectivamente, sendo em ambos a corrente liderada pelo vento.

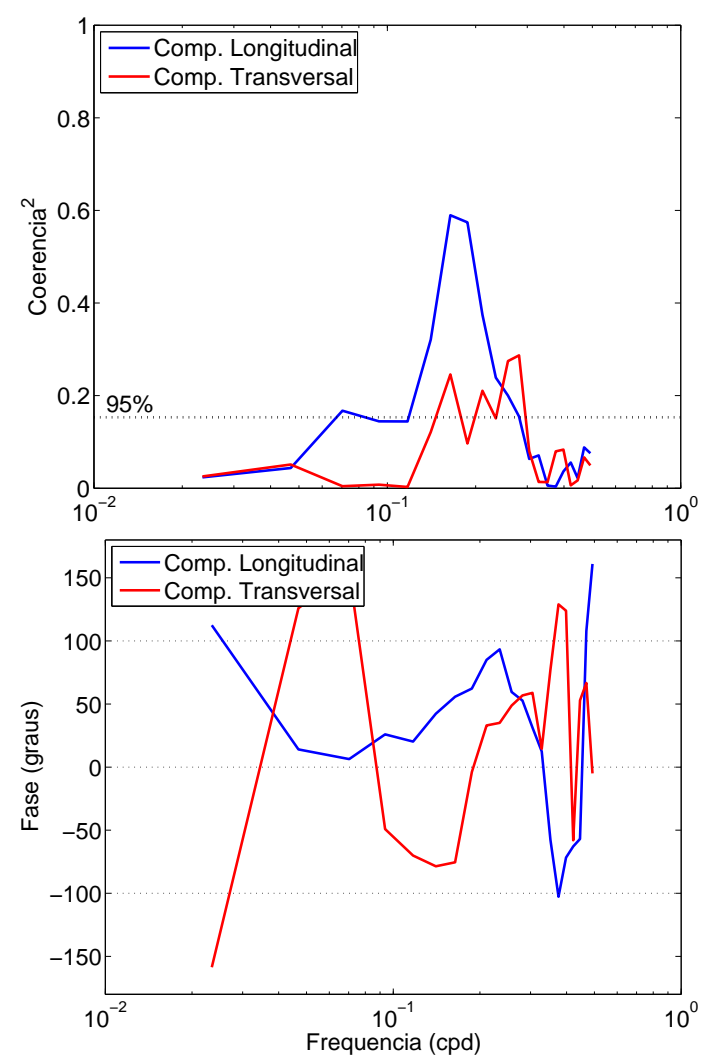

Figura 3.42: Espectros de coerência ao quadrado no topo e fase abaixo, entre vento e corrente de meia-água, das séries VL30 x S100M. 
Entre vento e corrente no fundo, as coerências entre as componentes apresentam valores similares entre 0,3 e 0,4 . As componentes normais apresentam dois picos: 0,2 cpd, período entre 4-5 dias, e fase $40^{\circ}$ (13 horas), sendo a corrente liderada pelo vento; 0,3 cpd, período de 3 dias, e fase $-3^{\circ}$ (1 horas), sendo o vento liderado pela corrente. As componentes paralelas apresentam 2 picos: $0,25 \mathrm{cpd}$, período de 4 dias, e fase $85^{\circ}(22$ horas), sendo a corrente liderada pelo vento; $0,35 \mathrm{cpd}$, período de 3 dias, e fase $45^{\circ}$ (10 horas), sendo novamente a corrente liderada pelo vento.

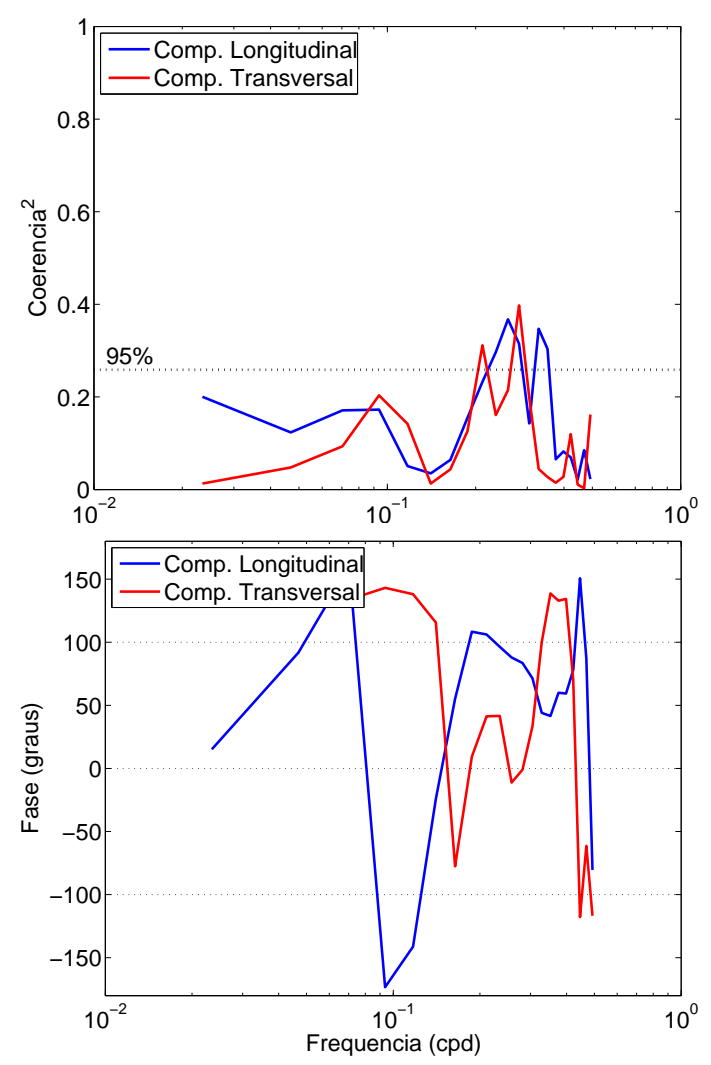

Figura 3.43: Espectros de coerência ao quadrado no topo e fase abaixo, entre vento e corrente de fundo, das séries VL30 x S100F. 


\subsubsection{Correlações entre Fundeios}

\section{P20 x S20}

Correlações entre as séries de corrente de fundo das estações P20 e S20 são apresentadas na Figura 3.44. A correlação entre as componentes paralelas é maior em módulo que entre as componentes normais. Entre as componentes paralelas a correlação é de -0,8 aproximadamente, em lag zero. Entre as componentes normais a correlação é de 0,6 aproximadamente, em lag $-1,3$ dias.

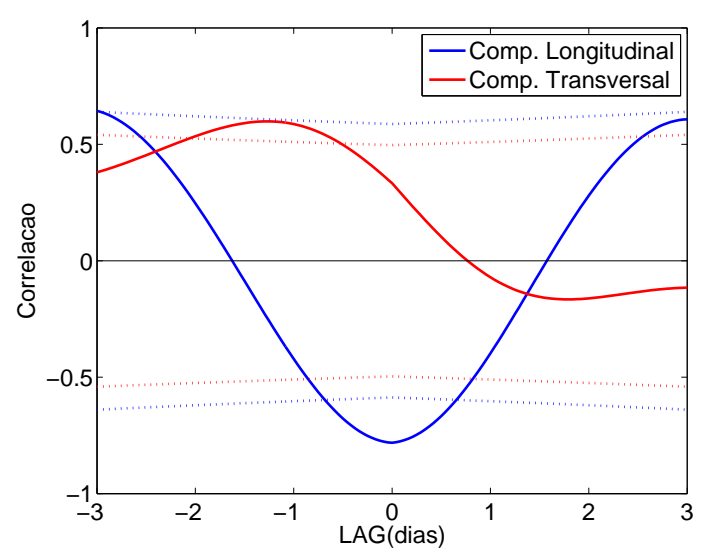

Figura 3.44: Correlação entre as séries de corrente de fundo P20F x S20F1. As linhas pontilhadas indicam intervalos de confiança de $95 \%$.

\section{P20 x M20}

Correlações entre as séries de corrente de fundo das estações P20 e M20 são apresentadas na Figura 3.45. A correlação entre as componentes paralelas é maior em módulo que entre as componentes normais. Entre as componentes paralelas a correlação é de -0,7 aproximadamente, em lag ligeiramente negativo, havendo liderança de M20 sobre P20. Entre as componentes normais a correlação é de 0,4 aproximadamente, em lag 0,4 dias, sendo M20 liderada por P20. 


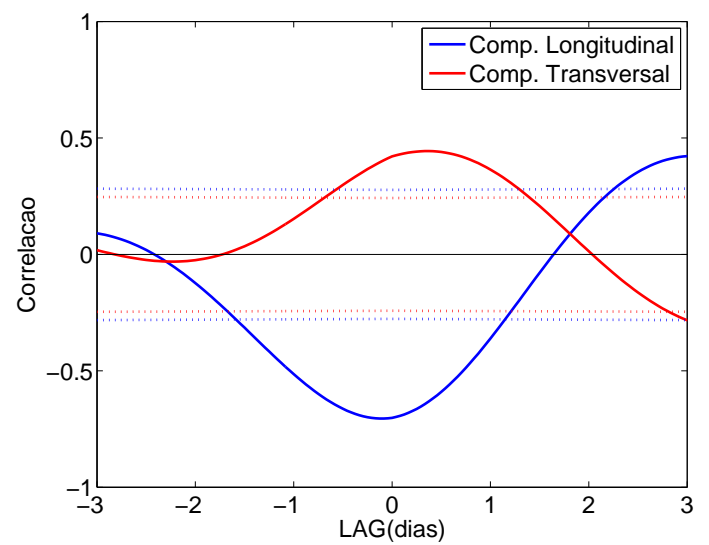

Figura 3.45: Correlação entre as séries de corrente de fundo P20F x M20F1. As linhas pontilhadas indicam intervalos de confiança de $95 \%$.

\section{P20 x S100}

Correlações entre as séries de corrente de superfície das estações P20 e S100 são apresentadas na Figura 3.46. Há correlação significativa apenas para as componentes paralelas, com valor -0,3 em lag ligeiramente menor que zero, sendo P20 liderada por S100.

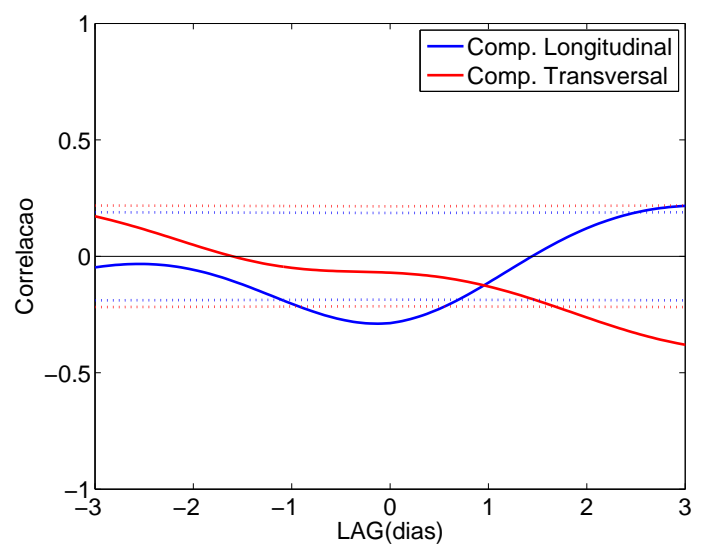

Figura 3.46: Correlação entre as séries de corrente de superfície P20S x S100S. As linhas pontilhadas indicam intervalos de confiança de $95 \%$.

\section{$\mathrm{S} 20 \times \mathrm{M} 20$}

Correlações entre as séries de corrente de fundo das estações S20 e M20 são apresentadas na Figura 3.47 para a primeira parte dos dados, e na Figura 3.48 para a 
segunda parte dos dados. As componentes paralelas apresentam correlações maiores que as componentes normais, com valores acima de 0,8 , em lag próximo a zero para a primeira parte dos dados, e lag ligeiramente maior que zero para a segunda parte dos dados. As componentes normais apresentam correlação significativa negativa em lag -0.9 dias para a primeira parte dos dados, e lag 0,4 para a segunda parte dos dados.

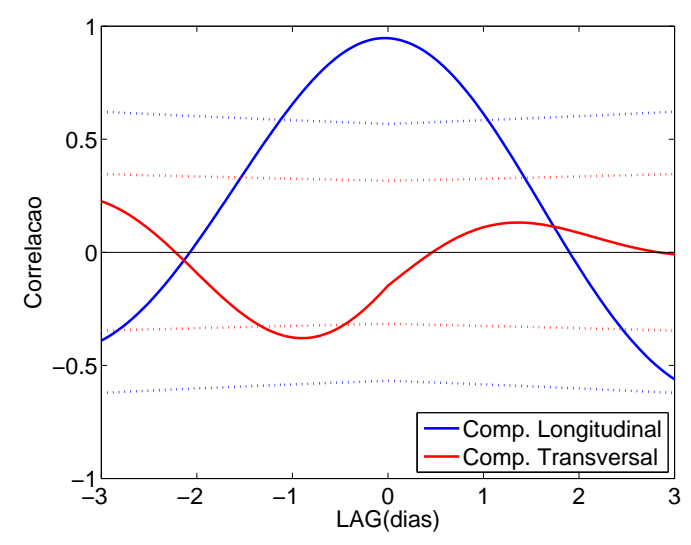

Figura 3.47: Correlação entre as séries de corrente de fundo S20F1 x M20F1. As linhas pontilhadas indicam intervalos de confiança de $95 \%$.

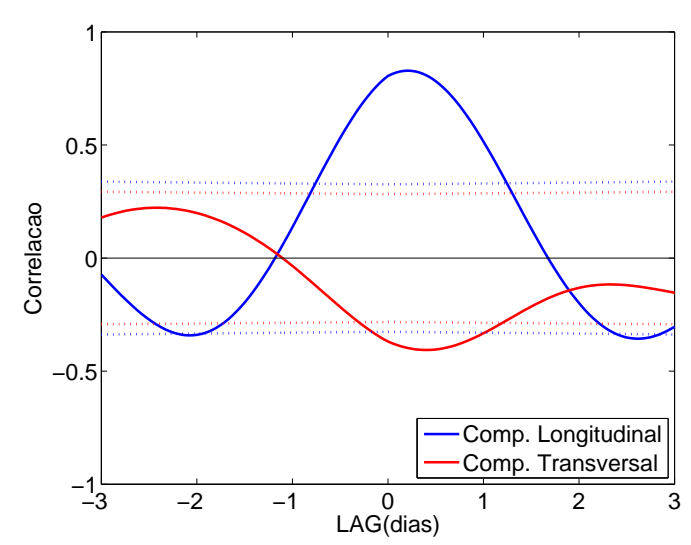

Figura 3.48: Correlação entre as séries de corrente de fundo S20F $2 \times$ M $20 \mathrm{~F} 2$. As linhas pontilhadas indicam intervalos de confiança de $95 \%$. 


\section{$\mathrm{S} 20 \times \mathrm{S} 100$}

Correlação entre as séries de corrente de superfície para a primeira parte dos dados de S20 e S100 está apresentada na Figura 3.49; e entre superfície e entre fundo para a segunda parte dos dados de S20 e S100 está apresentada na Figura 3.50.

Na superfície, há correlação marginalmente significativa para as componentes paralelas, apenas na primeira parte dos dados, sendo negativa, com valor máximo em módulo em lag de 1,3 dias, sendo S100 liderada por S20. Para as componentes normais, apenas na segunda parte dos dados há correlação significativa, em lag de 2 dias.

No fundo, na segunda parte dos dados, há alta correlação, acima de 0,8, para as componentes paralelas, em lag ligeiramente maior que zero, sendo S100 liderada por S20. Para as componentes normais, também há correlação significativa, com máximo em lag de -2 dias, sendo S20 liderada por S100.

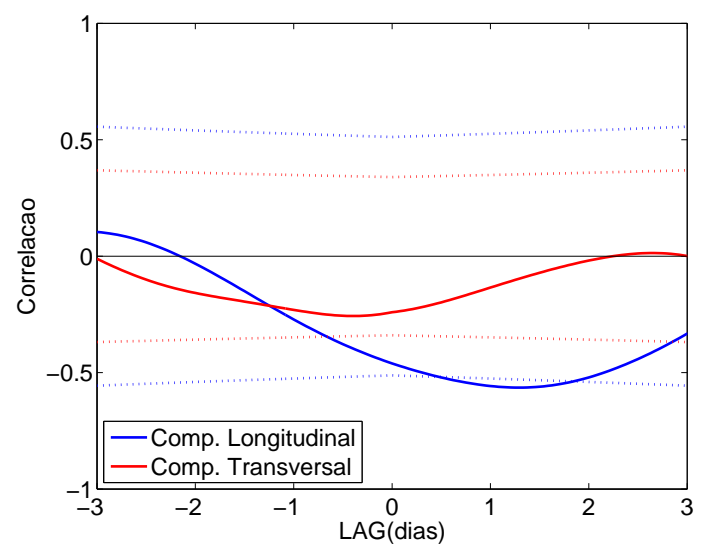

Figura 3.49: Correlação entre as séries de corrente de superfície S20S1 x S100S. As linhas pontilhadas indicam intervalos de confiança de $95 \%$. 


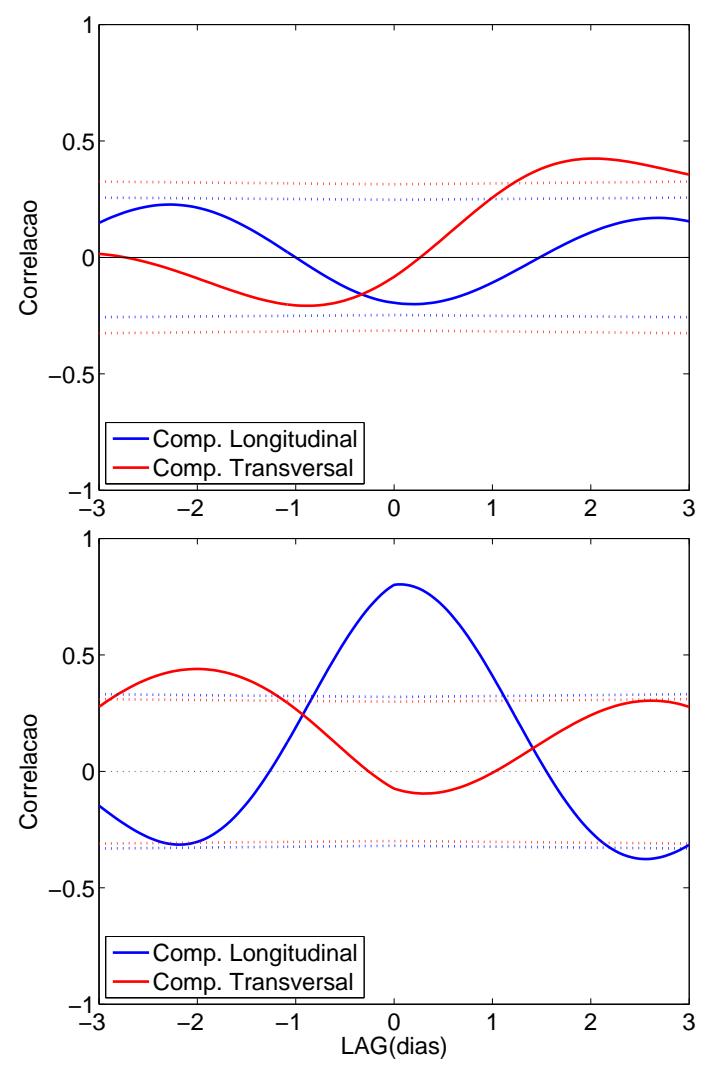

Figura 3.50: Correlação entre as séries corrente de superfície, S20S2 x S100S, e de fundo S20F 2 x S100F. As linhas pontilhadas indicam intervalos de confiança de $95 \%$.

\section{$\mathrm{M} 20 \times \mathrm{S} 100$}

Correlação entre as séries de corrente de fundo da segunda parte dos dados de M20 e S100 está apresentada na Figura 3.51. Há uma alta correlação, de aproximadamente 0,6 para as componentes paralelas, em lag ligeiramente maior que zero, sendo S100 liderada por M20. Para as componentes normais não há correlação significativa. 


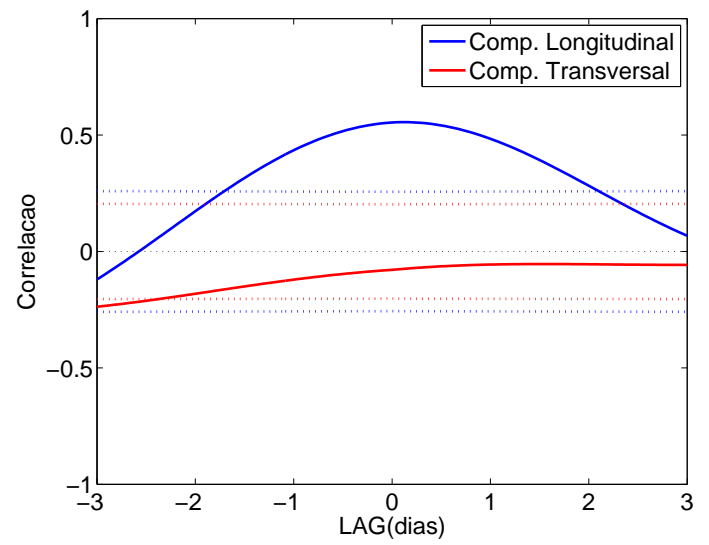

Figura 3.51: Correlação entre as séries de corrente de fundo M20F2 x S100F. As linhas pontilhadas indicam intervalos de confiança de $95 \%$. 


\subsubsection{Espectros Cruzados entre Fundeios}

\section{P20 x M20}

Espectros de coerência ao quadrado e fase entre as correntes de fundo de P20 e M20 são apresentados na Figura 3.52. As componentes paralelas apresentam alta coerência, de 0,9 para a banda 0,2 cpd, correspondendo a período de 5 dias, e fase de $-180^{\circ}$ (60 horas), e coerência mais baixa, de 0,65 aproximadamente para a banda 0,35 cpd, correspondendo a período de 3 dias, e fase $-170^{\circ}$ (32 horas). Em ambas freqüências P20 lidera M20. As componentes normais apresentam coerência mais baixa, na banda de 0,25 cpd, correspondendo a período de 4 dias, e fase $30^{\circ}$ (8 horas), sendo M20 liderada por P20.

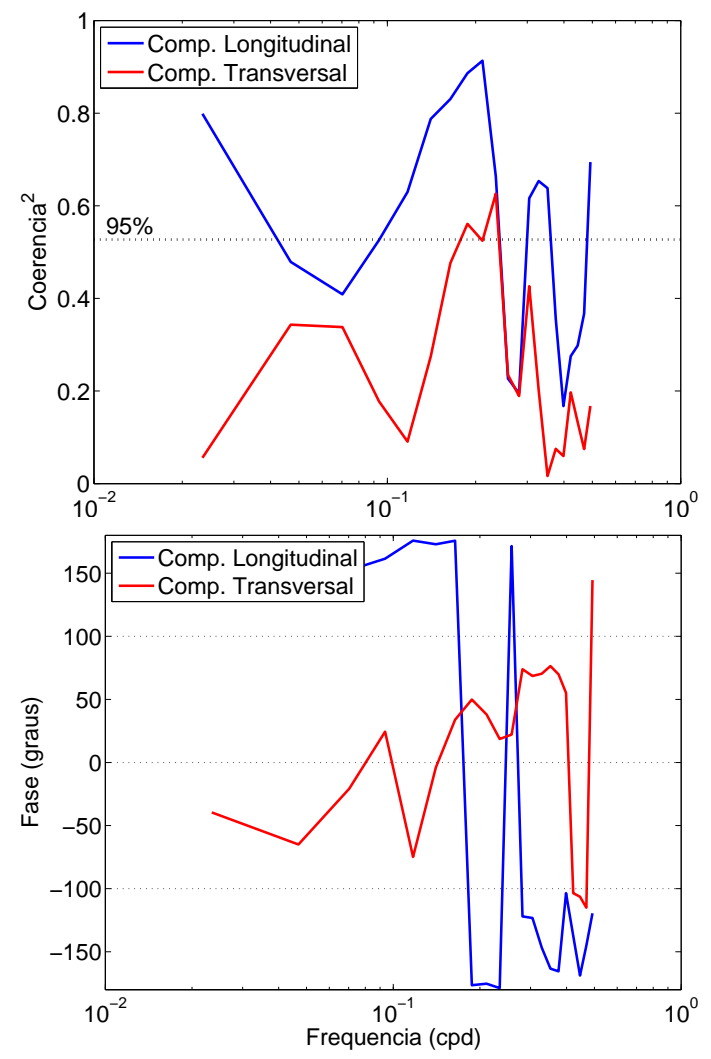

Figura 3.52: Espectros de coerência ao quadrado no topo e fase abaixo, entre corrente de fundo, das séries P20F X M20F. 


\section{P20 x S100}

Espectros de coerência ao quadrado e fase entre as correntes de superfície de P20 e S100 são apresentados na Figura 3.53.

As componentes paralelas apresentam coerência entre as bandas 0,3 e 0,4 cpd, correspondendo a período de 2,5-3 dias, e fase de $-160^{\circ}$ (35 horas), sendo P20 liderado por S100. As componentes normais apresentam coerência em 2 bandas: 0,05 cpd, correspondendo a período de 20 dias, e fase de $-100^{\circ}$ (130 horas), sendo P20 liderado por S100; e 0,2 cpd, correspondendo a período de 5-8 dias, e fase $35^{\circ}$ (12 horas), com S100 sendo liderado por P20.
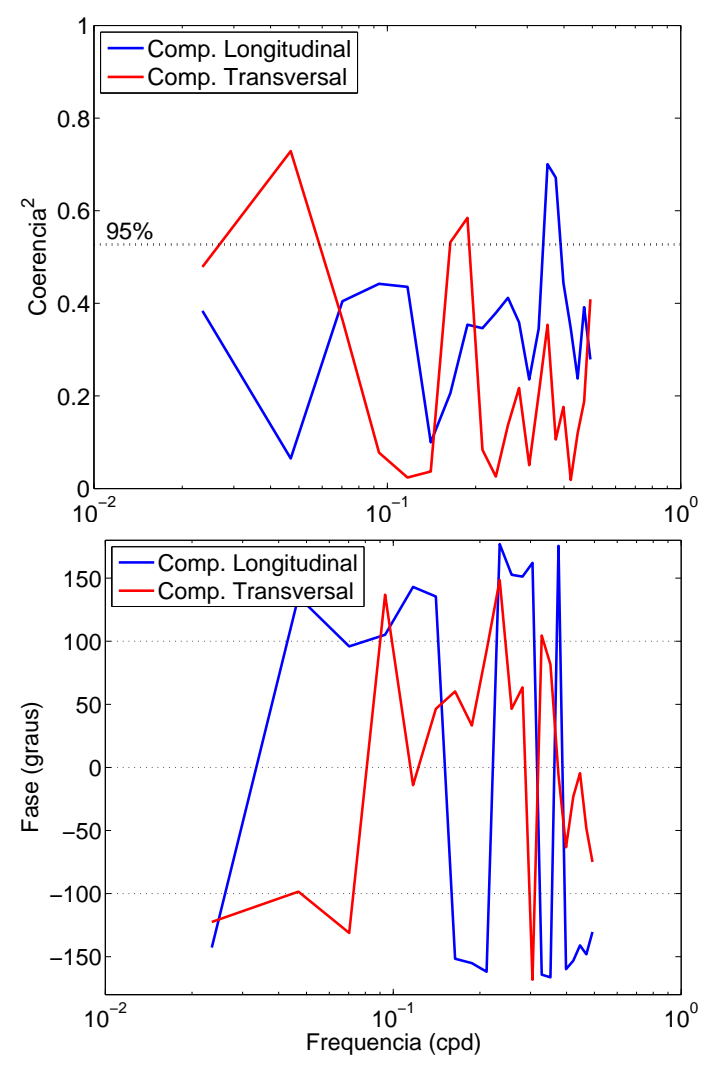

Figura 3.53: Espectros de coerência ao quadrado no topo e fase abaixo, entre corrente de superfície, das séries P20S X S100S. 


\section{$\mathrm{M} 20 \times \mathrm{S} 100$}

Espectros de coerência ao quadrado e fase entre as correntes de fundo da segunda parte de M20 e S100 são apresentados na Figura 3.54.

Para as componentes paralelas há uma alta coerência, de 0,95, em 0,1-0,15 cpd, correspondendo a período de 7-10 dias, e fase $-20^{\circ}$ (12 horas), sendo M20 liderada por S100, e entre 0,2-0,25 cpd, correspondendo a período de 4-5 dias, e fase 5-10 (2 horas), sendo S100 liderada por M20. Para as componentes normais não há coerência significativa.
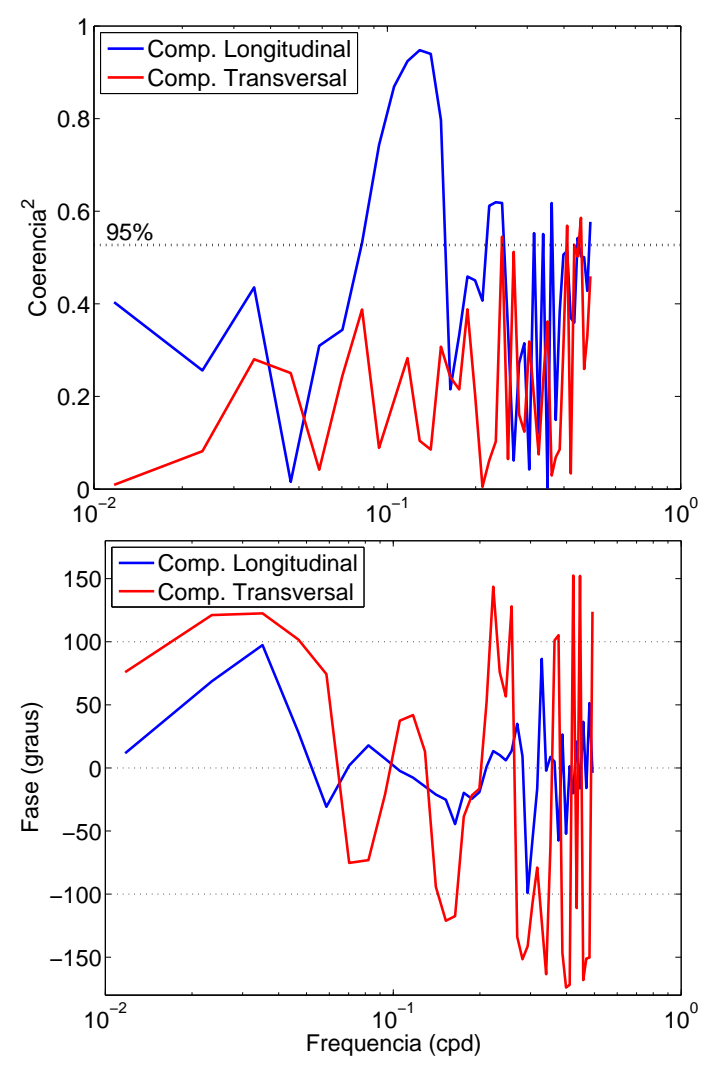

Figura 3.54: Espectros de coerência ao quadrado no topo e fase abaixo, entre corrente de fundo, das séries M20F2 X S100F. 


\section{Capítulo 4}

\section{Discussão}

\subsection{Ventos}

No sistema de coordenadas adotado, a direção de máxima variância é aproximadamente paralela à linha de costa e a direção de mínima variância aproximadamente normal à costa. Para facilitar a discussão, serão adotados os termos "componentes paralelas" e "componentes normais".

A filtragem dos dados demonstrou que ventos em escala suprainercial são responsáveis pela variância em: $81 \%$ das componentes paralelas e $92 \%$ das componentes normais de VM20, 63\% das componentes paralelas e $83 \%$ das componentes normais de VL30, 90\% das componentes paralelas e 96\% das componentes normais de VP20. Em todos os pontos observados, as componentes normais à costa apresentaram maior variância em freqüências suprainerciais, o que pode ser interpretado como um sinal típico de brisa marinha.

O fato de VL30 possuir menor redução da variância através da filtragem, pode ser devido à sua localização mais distante da costa, recebendo conseqüentemente menor influência da brisa marinha. Essa redução de intensidade da brisa marinha com o aumento da distância em relação à costa foi constatada por Franchito et al. (1998) através de experimentos de modelagem numérica aplicados à região de Cabo Frio. Os resultados obtidos pelo autor, modelando apenas a brisa marinha (sem a presença do vento médio proveniente de $\mathrm{NE}$ ), demonstraram que os ventos com maior intensidade ocorrem na região próxima à interface continente-oceano, podendo atingir até $50 \mathrm{~km}$ oceano adentro 
em períodos em que não há ressurgência na região (meses de abril, maio e junho), e além de $140 \mathrm{~km}$ quando há ressurgência (meses de outubro, novembro e dezembro). De qualquer forma, os resultados apresentados no Capítulo 3 mostram que a brisa marinha é a variabilidade mais energética nos três pontos de medição, sendo responsável por mais de $60 \%$ da variância total.

Em todas as séries de vento, a direção predominante observada foi para SW, demonstrando que a borda oeste da Alta Subtropical do Atlântico Sul agiu sobre a região neste período. A grosso modo, pode-se observar na Figura 3.1 entre 10 e 15 eventos onde há uma notável diminuição na intensidade dos ventos para SW. Essas perturbações no campo de ventos em latitudes médias são em geral causadas pela passagem de sistemas frontais (frentes frias). Segundo Climanálise (2004, 2005), houve ocorrência de 15 frentes frias passando por Santos durante o período estudado, portanto, em média as frentes ocorreram a cada 6 dias. É importante ressaltar que em apenas 3-6 desses eventos, houve inversão da direção dos ventos para NE, o que pode estar associado ao fato da época de observações ter sido entre primavera e verão (meses de novembro, dezembro e janeiro), quando há diminuição na intensidade dos ventos associados às frentes frias e, além disso há uma dependência da localização do centro de baixa pressão associado à frente. Stech (1990) observou para o período de inverno a ocorrência de frentes sobre a PCSE entre 6 e 11 dias, resultados bastante próximos às observações deste trabalho.

Essa mesma freqüencia da perturbação do campo de ventos também é traduzida pelos autoespectros, que apresentaram alta energia nas bandas 0,15-0,2 cpd, correspondendo a períodos de 5-6,7 dias, demonstrando que em escala sinótica o principal mecanismo de perturbação do estado básico da atmosfera são os sistemas frontais. Além disso, o fato das componentes paralelas possuirem maior energia demonstra que os ventos são em geral predominantemente paralelos à costa em freqüências subinerciais. Isso também é confirmado pela maior correlação (sempre acima de 0,8 ) e pela maior coerência na banda 0,15-0,2 cpd (sempre acima de 0,85) entre as componentes paralelas. Portanto, há homogeneidade do vento nas regiões observadas, como pode ser observado na Figura 3.1. Isso indica que em freqüências subinerciais o campo de ventos é controlado por fenômenos de meso e larga escala espacial.

As velocidade típicas dos ventos para SW são: 1,4 m/s em VM20, 4,5 m/s em 
VL30 e 2 m/s em VP20; para NE as velocidades típicas são menores em todas as estações meteorológicas: em torno de $0,7 \mathrm{~m} / \mathrm{s}$. Há discrepância entre os valores típicos para $\mathrm{SW}$ obtidos em VL30 em relação à VM20 e VP20, o que pode conduzir à duas hipóteses: primeira, a estação meteorológica VL30 estava localizada a uma maior altitude que as demais (38 metros acima do nível do mar), havendo menor dissipação de energia pelo atrito do vento com o oceano na camada de Ekman atmosférica, portanto apresentando maiores velocidades que VM20 e VP20; segunda, a orografia pode causar redução em direção à costa na intensidade dos ventos, já que a Serra do Mar forma uma barreira natural, assim VM20 e VP20 podem apresentar maior atenuação das velocidades. Com os dados obtidos não é possível determinar a espessura e perfil de velocidade da camada limite atmosférica e tampouco os efeitos orográficos.

Coelho (2008) através de 8 anos de dados de modelos do Serviço Meteorológico Alemão (DWD - Deutcher Wetterdienst) e do European Centre for Médium-Range Weather Forecasts (ECMF), obteve climatologia de tensão de cisalhamento do vento no período de verão (meses de janeiro, fevereiro e março), apresentada na Figura 4.1. Nota-se que há uma importante diminuição da tensão de cisalhamento do vento à partir da isóbata de 50 metros em direção à costa, o que de fato pode ser uma forte evidência da orografia influenciando o campo de ventos, sobretudo na PCI.

As análises de correlação, de coerência e de fase mostraram liderança das componentes paralelas de VP20 sobre VM20 e VL30, demonstrando assim que as frentes frias se deslocam de SW para NE, corroborando os trabalhos de Stech (1990), Stech \& Lorenzzetti (1992) e Coelho (2008). À partir da distância entre VP20 e VM20, de 140 km, e do lag onde a correlação é máxima entre essas estações, de 0,17 dias ou 4 horas, supondo deslocamento não acelerado das frentes frias entre VP20 e VM20, estima-se que em média as frentes se deslocam com velocidade de $35 \mathrm{~km} / \mathrm{h}$ ou $9,7 \mathrm{~m} / \mathrm{s}$ (840 km/dia). Essa velocidade de deslocamento está próxima daquelas obtidas por Castro $\&$ Lee (1995) para o período de inverno, que variaram entre $12 \mathrm{~m} / \mathrm{s}$ e $15 \mathrm{~m} / \mathrm{s}$. Nossa estimativa também é superior àquela do modelo de frente típica de inverno elaborado por Stech $\&$ Lorenzzetti (1992), com velocidade de $5,8 \mathrm{~m} / \mathrm{s}$. No entanto, os valores obtidos no presente estudo são bastante próximos ao modelo típico de verão de Coelho (2008), com velocidade de 9,1 m/s. Segundo Coelho (2008) a velocidade média de propagação das frentes frias é mais 
rápida no verão que no inverno, o que pode explicar as diferenças obtidas por Stech $\&$ Lorenzzetti (1992) com os resultados de Coelho (2008) e com o presente estudo.

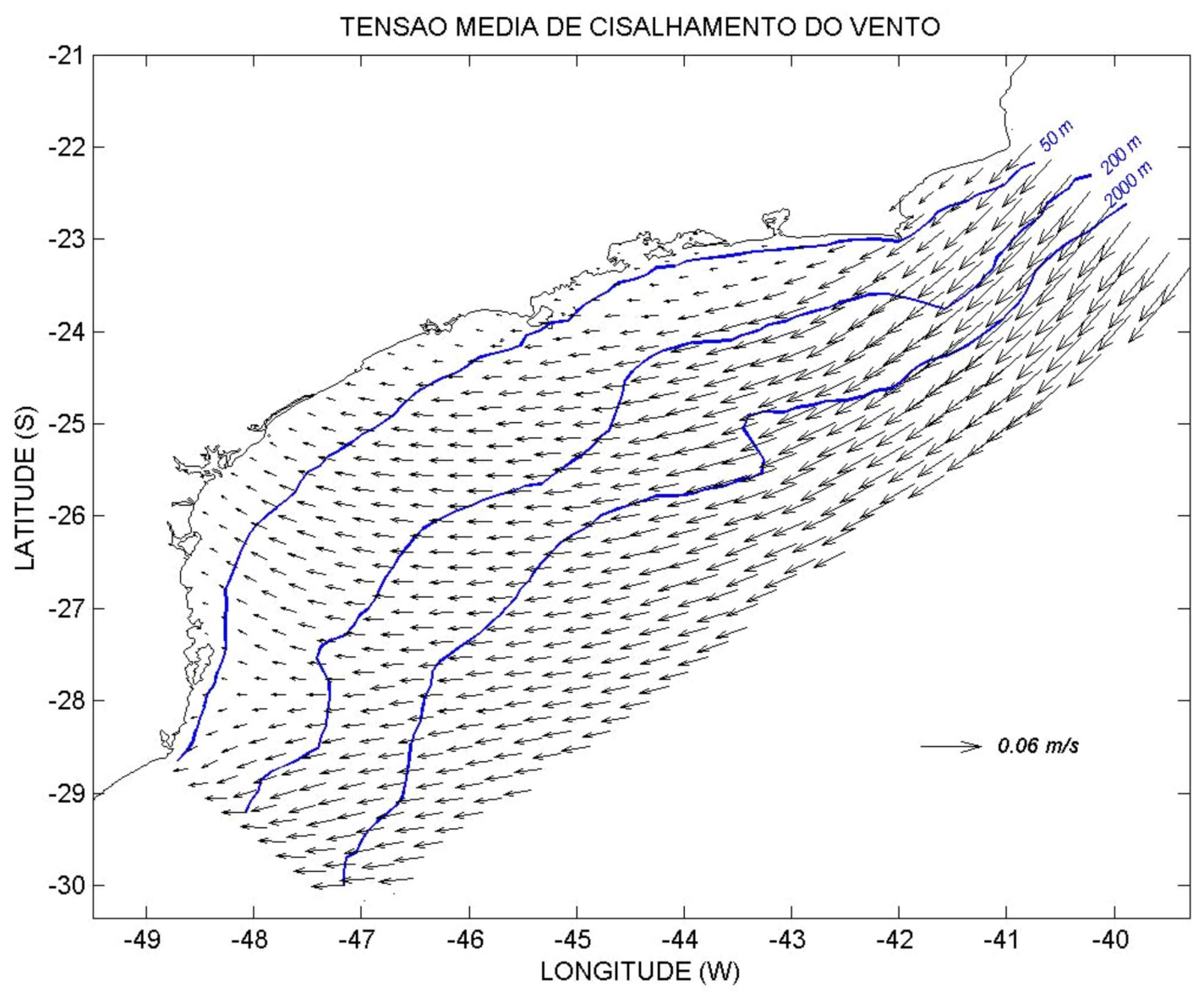

Figura 4.1: Climatologia da tensão de cisalhamento do vento sobre a PCSE para o período de verão, elaborada por Coelho (2008). 


\subsection{Correntes na PCI}

À partir da comparação da variância total com a variância dos dados filtrados (passa-baixa), pode-se verificar que as componentes normais à topografia são dominadas por freqüências suprainerciais, as quais são responsáveis por cerca de $69 \%$ da variância em P20, 85\% em S20 e 70\% em M20. Já as componentes paralelas à topografia possuem variabilidade muito menor em freqüências suprainerciais, sendo estas responsáveis por apenas 36\% da variância em P20, 40\% da variância em S20 e 34\% da variância em M20. A principal forçante em freqüências suprainerciais no oceano são as marés, portanto na região de estudo (PCI) pelo menos $70 \%$ da variância das componentes normais e apenas 40\% das componentes paralelas são regidas pela maré. Nesta última, a variabilidade mais energética está presente em freqüências subinerciais. Nessa faixa do espectro (subinercial), as principais forçantes das plataformas continentais são os ventos e gradientes de densidade.

Esse comportamento também foi constatado para a PCSE por Alves (1992), demonstrando que as freqüências suprainerciais são responsáveis por 40-50\% da variância das componentes normais e apenas $20 \%$ das componentes paralelas e por Castro (1996), que estimou que cerca de $43 \%$ da variância das componentes normais e $12 \%$ das componentes paralelas está presente em freqüências suprainerciais. As pequenas diferenças dos valores obtidos pelos autores podem ser devidas à alta variabilidade espacial das correntes causadas pela topografia e linha de costa irregulares.

Estudos anteriores também demonstram a polarização das elipses de maré no sentido perpendicular às isóbatas e linha de costa: através de observações na plataforma e talude entre Ubatuba e Cabo Frio (Ruffato, 2007), na PCI em Ubatuba e Montão de Trigo (Moreira, 1998), na quebra da plataforma e talude ao largo de Santos (Moreira, 1997) e também através de modelagem numérica em toda a PCSE (Pereira et al., 2007).

Em todos os fundeios e profundidades amostradas, as correntes subinerciais tiveram direção predominante paralela à isóbata local. Os autoespectros de P20 e M20, demonstram que as componentes paralelas à topografia são mais energéticas que as componentes normais (cerca de uma ordem de grandeza maiores). Além disso, em todos as correlações obtidas entre P20, S20 e M20, tanto em superfície quanto fundo, sempre há maior correlação entre as componentes paralelas. Essas análises demonstram que em escala subin- 
ercial as correntes são predominantemente paralelas à costa, apontando para um possível balanço geostrófico na direção perpendicular à costa, em primeira ordem. Os termos da equação do movimento integradas verticalmente foram calculados por Castro (1985) utilizando resultados de modelos numéricos, Castro (1996) à partir de dados observacionais na PCI em frente à Ubatuba e por Coelho (2008) através de resultado de simulações numéricas na PCSE: ambos autores obtiveram equilíbrio essencialmente geostrófico na direção perpendicular à topografia.

Velocidades típicas observadas na superfície em P20 são de $0,12 \mathrm{~m} / \mathrm{s}$ para NE e $0,11 \mathrm{~m} / \mathrm{s}$ para $\mathrm{SW}$; em S20 entre 0,16-0,21 m/s para E-SE e entre 0,06-0,13 m/s para W-NW. No fundo em P20 de $0,04 \mathrm{~m} / \mathrm{s}$ para $\mathrm{NE}$ e $0,05 \mathrm{~m} / \mathrm{s}$ para $\mathrm{SW}$; em $\mathrm{S} 20$ entre 0,16-0,18 m/s para E-SE e entre $0,05-0,11 \mathrm{~m} / \mathrm{s}$ para $\mathrm{W}-\mathrm{NW}$; e em M20 entre 0,13-0,20 $\mathrm{m} / \mathrm{s}$ para E e de 0,05-0,07 m/s para W. Portanto, em geral, as velocidades na PCI são tipicamente da ordem de 0,10-0,20 m/s para NE, e inferiores a $0,10 \mathrm{~m} / \mathrm{s}$ para $\mathrm{SW}$. Esses resultados apresentam concordância com aqueles de Coelho (2008), que obteve através de modelagem numérica na PCI em frente à Santos correntes para NE com valores típicos de $0,15 \mathrm{~m} / \mathrm{s}$, utilizando como forçantes em seu modelo gradientes de densidade e vento climatológico médio de verão (Figura 4.1).

Castro (1996) analisou correntes na PCI ao largo de Ubatuba e encontrou velocidades de cerca de $0,20 \mathrm{~m} / \mathrm{s}$ para $\mathrm{SW}$ e $0,10 \mathrm{~m} / \mathrm{s}$ para $\mathrm{NE}$, o oposto ao encontrado neste trabalho onde as maiores velocidades típicas são para NE. Os resultados aqui obtidos corroboram análises anteriores de Moreira (1998) e Castro et al. (2008) que mostram que a região de São Sebastião é uma zona natural de convergência do campo de correntes subinerciais.

Em S20, a grande discrepância de velocidades típicas observadas entre a primeira e segunda parte dos dados demonstra que as séries foram curtas demais para determinação das médias, desvios padrões, variâncias, máximos e mínimos reais representativos da população. À partir da comparação entre as magnitudes e sentidos das correntes, nota-se pouco cisalhamento vertical das componentes horizontais de velocidades, evidenciando que o modo barotrópico é dominante. Além disso, reforçando essa afirmação, a correlação entre superfície e fundo é positiva e elevada, principalmente entre as componentes paralelas, com valores próximo a um, em lag próximo a zero. Segundo Castro (1996) na 
PCI em frente à Ubatuba as correntes paralelas à costa são essencialmente barotrópicas, pois o primeiro modo ortogonal empírico explica mais de $95 \%$ da variância em qualquer profundidade amostrada. A característica barotrópica das correntes na PCI pode ser explicada pela grande homogeneidade vertical das características hidrográficas nessa região, causada principalmente pela turbulência imposta pela tensão de cisalhamento do vento na superfície e pelo cisalhamento das correntes de maré no fundo. 


\subsection{Correntes na PCM}

Assim como na PCI, as componentes normais à topografia são principalmente regidas pela maré, a qual é responsável por cerca de $64 \%$ da variância na superfície, $66 \%$ da variância em meia-água, e $81 \%$ da variância no fundo, sendo sua importância visivelmente crescente com a profundidade. Já para as componentes paralelas, a maré possui uma menor contribuição, sendo responsável por cerca de $51 \%$ da variância na superfície, $41 \%$ da variância em meia-água, e 52\% da variância no fundo. Castro (1996) analisando correntes na PCM (70 metros) em frente à Ubatuba observou também que as correntes de maré são mais importantes para as componentes normais, responsáveis por cerca de 52-54\% da variância, já para as componentes paralelas a contribuição foi de apenas $7-8 \%$.

As direções das correntes foram aproximadamente paralelas à isóbata local, com exceção das correntes em meia-água, que durante algum tempo apresentaram-se normais à topografia. No entanto, a presença da geostrofia é marcante, confirmada também pelo fato das componentes paralelas apresentarem maior energia que as componentes normais, característica essa também obtida por Castro (1996), Moreira (1997) e Souza (2000). Assim como na PCI, os termos da equação do movimento integrados verticalmente foram calculados por Castro (1996) à partir de dados observacionais na PCM (70 metros) em frente à Ubatuba e por Coelho (2008) através de resultado de simulações numéricas na PCSE: ambos autores obtiveram equilíbrio essencialmente geostrófico na direção perpendicular à topografia.

As correntes em superfície apresentaram sentido predominate para SW, resultado esse também obtido através de observações na PCM ao largo de Santos por Moreira (1997) e Souza (2000), ao largo de Ubatuba por Castro (1996) e através de modelagem numérica por Coelho (2008) e Rezende (2003), utilizando ventos típicos de NE e campo termohalino climatológico de verão como forçantes. Segundo esses autores, em toda a coluna de água foi observada a direção predominante SW.

Próximo ao fundo, as correntes observadas apresentaram sentido predominante para W; o desvio à esquerda da tensão de cisalhamento imposta pelo fundo já era esperado devido à presença da camada limite. Todavia, há uma importante componente paralela á topografia. No período final das observações houve predominância das correntes para 
E-NE.

As correntes em meia-água durante grande parte das observações apresentaram sentido NE e NW (perpendiculares à isóbata local), contrariando o padrão geral observado pelos trabalhos citados anteriormente. Souza (2000), durante o período de inverno, também observou predominância das correntes para NE. Segundo a autora, isso pode ter sido causado pela grande freqüência de passagens de frentes frias nessa época do ano. De qualquer forma, o comportamento dinâmico obtido, distinto de trabalhos anteriores, indica a necessidade de realização de fundeios de longa duração nesse local, tentando avaliar melhor as variações sazonais e interanuais.

O papel do vento como forçante na PCM foi constatado principalmente em meiaágua, observado através da correlação entre as componentes paralelas com o vento liderando a corrente em aproximadamente um dia e, também, da coerência elevada entre as componentes paralelas, maior que 0,6 na banda $0,15 \mathrm{cpd}$, período de 6,7 dias e fase $55^{\circ}$, com a corrente liderada pelo vento em 22 horas. Já em superfície e fundo, as coerências entre vento e corrente foram inferiores. Além disso, as correlações foram apenas marginalmente significativas e negativas em superfície; no fundo não houve correlação significativa, provavelmente devido à presença da camada limite.

O fato das correntes em meia-água e fundo apresentarem sentido NE durante uma boa parte do experimento revela a presença de forçantes baroclínicas, indicadas também na superfície pela correlação negativa entre vento e corrente. Os trabalhos de Moreira (1997) e Souza (2000) revelam que a região sobre a isóbata de 100 metros em frente à Santos apresenta regime típico de plataforma, com a dinâmica controlada pelo vento, sendo a presença da Corrente do Brasil apenas esporádica. A forçante baroclínica presente nas observações em S100 também foi observada em P20, e será discutida em maiores detalhes na próxima seção.

O comportamento barotrópico das correntes na PCM, constatado por Castro (1996) e Souza (2000), foi evidenciado neste trabalho apenas entre meia-água e fundo, onde há uma alta correlação entre ambas componentes em lag próximo a zero.

As correntes observadas em S100 possuem velocidades médias de 0,03 m/s para NE e 0,04 para SW em superfície, $0,07 \mathrm{~m} / \mathrm{s}$ para NE e 0,05 para $\mathrm{SW}$ em meia-água, e $0,06 \mathrm{~m} / \mathrm{s}$ para NE e 0,07 para SW no fundo. Portanto as correntes médias calculadas 
são tipicamente menores que $0,1 \mathrm{~m} / \mathrm{s}$ e não apresentam diferenças significativas nas intensidades para SW e NE. Em geral, as correntes observadas foram menos intensas que aquelas observadas por Moreira (1997) e Souza (2000), tipicamente entre 0,1 e 0,2 m/s, e por Castro (1996) entre 0,2-0,3 m/s. 


\subsection{Resposta da PCI às forçantes}

Segundo as observações obtidas neste trabalho, há uma tendência das correntes em S20 e M20 fluirem em direção à parte norte da PCSE, ou seja, o sentido predominante das correntes é em média para NE. Esse mesmo padrão foi obtido através de observações por Moreira (1998) em Montão de Trigo e, em toda a região da PCI entre Cananéia e a Ilha de São Sebastião, através de simulações numéricas por Rezende (2003) e Coelho (2008) utilizando apenas forçantes baroclínicas (campo de salinidade e temperatura climatológico médio de verão). O fato das correntes predominantes com sentido NE serem contrárias ao vento predominante, com sentido SW, revela que o estado médio dessas correntes é forçado por gradientes de densidade, e que o vento médio ou mais freqüente, não possui intensidade suficiente para inverter o sentido das correntes agindo apenas como atenuante das correntes para NE.

Essa evidência de forçantes baroclínicas também pode ser observada através da climatologia de temperatura e salinidade superficiais de verão na PCSE confeccionadas por Rezende (2003), apresentadas na Figura 4.2. Nos limites da PCI entre Praia Grande e São Sebastião ocorre uma zona de alta temperatura e baixa salinidade, provavelmente devido à influência que o estuário de Santos exerce sobre a região. Nessa área há um gradiente de densidade importante em direção à PCM e PCE, causando uma força de gradiente de pressão baroclínica provavelmente balanceada pela força de Coriolis, causando um fluxo geostrófico para direção NE da PCSE. 

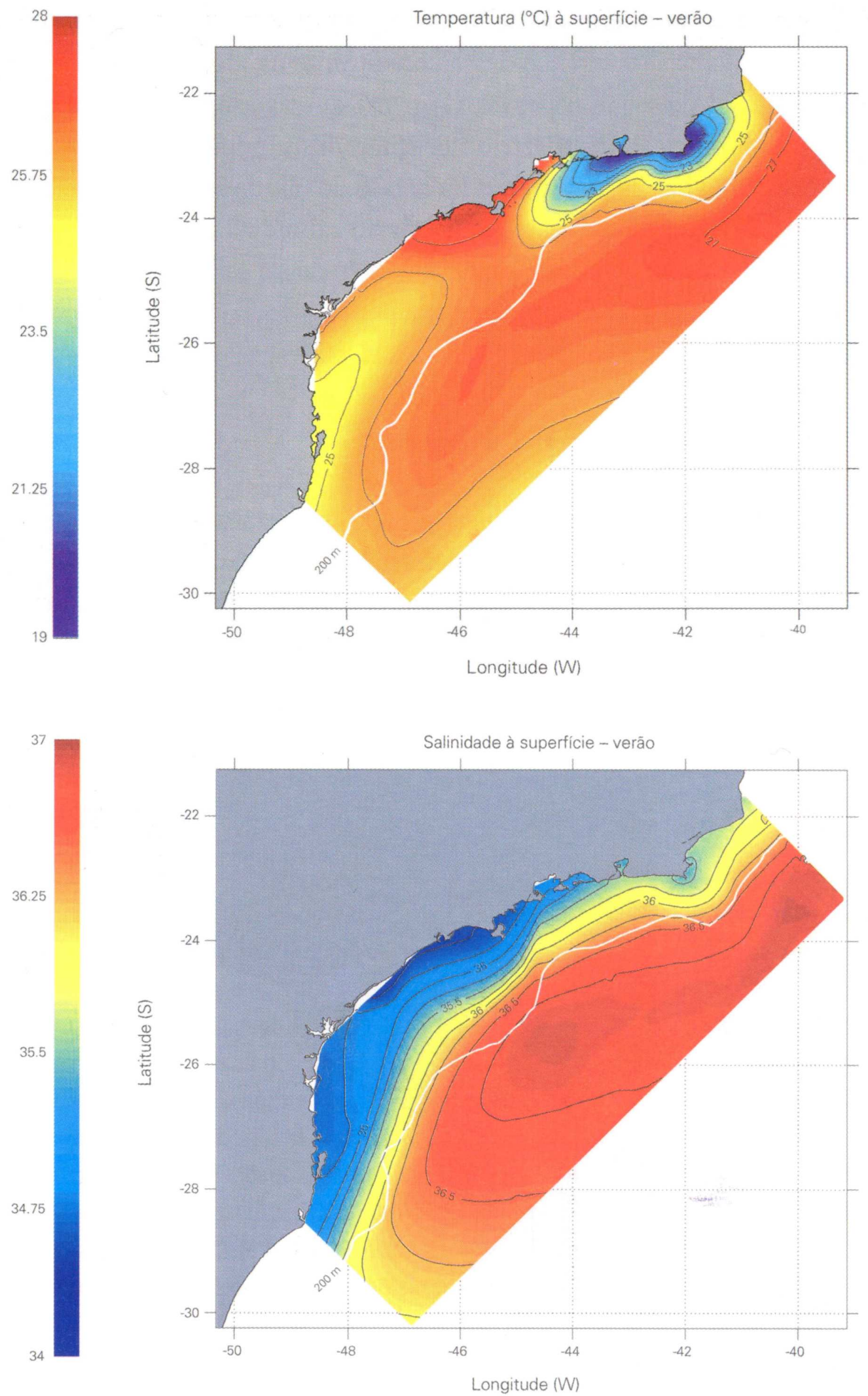

Figura 4.2: Distribuição superficial de temperatura (em cima) e salinidade (embaixo) climatológica de verão na plataforma continental e talude sudeste, obtida com dados históricos (Rezende, 2003). 
Em P20 as correntes apresentaram características distintas entre superfície e fundo. Entretanto, é importante ressaltar que as medições não foram simultâneas, sendo que cada série corresponde a períodos distintos, na superfície principalmente durante o verão e no fundo principalmente durante o inverno. Na superfície houve alta variabilidade das correntes, não apresentando um sentido predominante; já no fundo há predominância das correntes para SW, correspondendo ao sentido predominante do vento. Entretanto, a correlação entre vento e corrente no fundo é negativa, demonstrando que a forçante não foi o vento, mas sim gradientes de densidade, estes também observados em S100 na PCM. É importante ressaltar que a correlação entre o vento e corrente corresponde a um período curto, de aproximadamente 15 dias, com predominância das correntes para NE, padrão oposto ao observado durante maior parte do tempo nesse local, o que sugere que em outros instantes o efeito do vento possa eventualmente suprir o forçamento baroclínico.

Uma vez que não há grandes estuários próximos à essa região capazes de modificar significativamente a estrutura termohalina na PCI, há indícios de que essas águas possam ter sido advectadas do sul, possivelmente com influência do Rio da Prata. Segundo o trabalho de Piola et al. (2005) e Mello (2007), a influência das águas do Rio da Prata pode se estender até a PCSE, dependendo da descarga fluvial e principalmente do campo de ventos. Essa evidência também pode ser notada através da climatologia de inverno segundo Castro $\& 3$ Miranda (1998), apresentada na Figura 4.3, onde se observa claramente no campo de temperatura águas mais frias provenientes de sul englobando grande parte da PCSE. 

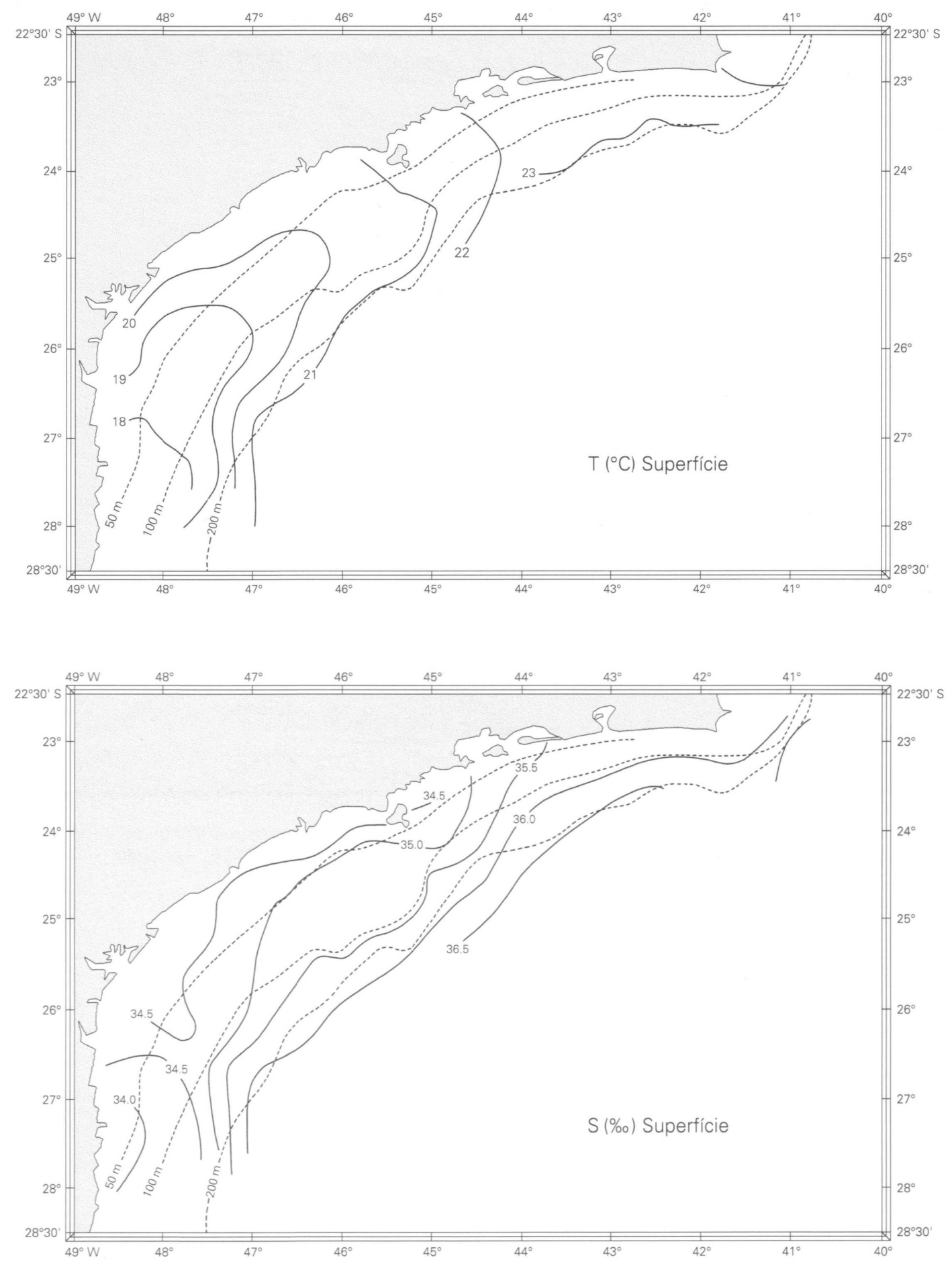

Figura 4.3: Distribuição superficial de temperatura (em cima) e salinidade (embaixo) climatológica de inverno na plataforma continental e talude sudeste, obtida com dados históricos (Castro $\&$ Miranda, 1998). 
Em S20 as correlações obtidas entre vento e corrente para as componentes paralelas apresentam máximos em lags entre 1,5 e 1,8 dias (entre 36 e 46 horas), o que sugere que a corrente não é forçada pelo vento local, neste caso as forçantes baroclínicas devidas à descarga do Estuário de Santos aparentemente tornam-se mais importantes que vento. Exatamente em frente à Santos podem-se verficar mínimos de densidade através da climatologia de Rezende (2003), apresentada na Figura 4.2. É importante ressaltar que essas análises referem-se à observações realizadas durante curtos períodos, cerca de 20 dias durante o inverno e 40 dias entre verão e outono, podendo haver comportamentos distintos ao longo do ano, através de variações espaciais e temporais do campo termohalino assim como intensidade dos ventos associados às frentes sinóticas.

Em P20 na superfície a resposta ao vento sinótico pode ser constatada através da correlação, que apresenta tempo de resposta de 18 horas. O autoespectros mostram energia em oscilações de períodos médios, entre 5-8 dias, coerentes à passagem de sistemas frontais, com maior energia associada às componentes paralelas. Nessa mesma banda de períodos médios, o vento lidera a corrente em $50^{\circ}$ (16 horas). Portanto o papel do vento como forçante é notável, sendo que a resposta das correntes ao vento pode variar entre 16 e 18 horas.

Na primeira parte dos dados de M20 as correlações indicam liderança do vento em 10 horas. Analisando-se os autoespectros nota-se a presença de energia associada a oscilações em períodos curtos, entre 3,5 e 5 dias, e médios, entre 5 e 10 dias, ambos também encontradas por Moreira (1998). Coerências significativas entre vento e corrente, também ocorrem em períodos médios e curtos, equivalentes à 10 e 3 dias, com fases de $10^{\circ}$ ( 5 horas) e $35^{\circ}$ (8 horas) respectivamente, com liderança do vento sobre a corrente. Portanto nesse período a corrente foi efetivamente forçada pelo vento sinótico, com tempo de resposta entre 5 e 10 horas. Já na segunda parte dos dados não houve correlação significativa entre vento e corrente. Analisando a Figura 3.25, nota-se que os ventos nesse período apresentaram intensidades bastante fracas, portanto não foram capazes de suplantar as forçantes baroclínicas associadas à descarga do Sistema Estuarino Santos-Bertioga.

Assim, nota-se que os gradientes de densidade na PCI apresentam um importante papel, sobretudo em S20, onde há o estuário de Santos, cuja descarga domina as caracterísiticas hidrográficas da região, como pode ser observado através de climatologias. O 
papel do vento sinótico aparentemente não é capaz de suplantar os efeitos baroclínicos em S20, mas foi constatado em M20 e P20, sobretudo no verão. 


\subsection{Influência da PCM na PCI}

Em todos as correlações obtidas entre S100 (PCM) e P20, S20 e M20 (PCI), tanto em superfície quanto no fundo, sempre há maiores valores entre as componentes paralelas. Além disso, em períodos curtos (2,5 a 3,5 dias) e médios (4 a 10 dias), sempre foi obtida maior coerência entre as componentes paralelas, o que demonstra que em escala subinercial as correntes são predominantemente paralelas à costa.

Em superfície a correlação de S100 com a primeira parte dos dados de S20 é apenas marginalmente siginificativa em lag muito elevado (1,3 dias) e com a segunda parte dos dados não há correlação significativa. Portanto, aparentemente S100 não possui qualquer influência em S20 e vice-versa.

As correlações em superfície entre entre P20 e S100 são negativas em lag ligeiramente menor que zero, porém muito pequenas. De qualquer modo, aparentemente essas regiões possuem sentidos opostos de corrente com resposta quase instantânea.

As maiores correlações foram obtidas entre as correntes paralelas no fundo, entre S20 e M20, sendo essas positivas e em lag ligeiramente maior que zero. Em ambos os casos a liderança é da PCI sobre a PCM, demonstrando que as perturbações ocorrem primeiro na PCI.

De qualquer forma, com os dados disponíveis torna-se difícil a caracterização da influência da PCM na PCI, uma vez que as comparações foram realizadas em distintas épocas do ano devido à grande ocorrência de gaps nas séries temporais. 


\section{Capítulo 5}

\section{Conclusão}

1. A brisa marinha é o fenômeno responsável pela variabilidade mais energética do campo de ventos na PCI.

2. Em escala sinótica, o campo de ventos sobre a região mais costeira da PCI é menos intenso que o campo de ventos da região mais distal, havendo indícios de que isso possa ser causado pelo efeito orográfico.

3. As frentes frias observadas no verão ocorreram a cada 6,5-10 dias, com velocidade média de propagação de $9,7 \mathrm{~m} / \mathrm{s}$.

4. Tanto na PCI quanto na PCM, as componentes normais de correntes são regidas principalmente pelas marés, enquanto que as componentes paralelas são dominadas por forçantes em escalas subinerciais, como os ventos e gradientes de densidade. As correntes subinerciais observadas na PCI e PCM são essencialmente geostróficas.

5. Correntes forçadas pelo vento na PCI foram observadas em P20, durante o verão, e em M20. Já em S20, o vento não foi capaz de suplantar os efeitos baroclínicos causados pela descarga fluvial do Sistema Estuarino de Santos. Em períodos de ventos fracos M20, é forçada por efeitos baroclínicos, aparentemente sofrendo também influência do sistema estuarino de Santos. Em P20 durante o inverno foi constatado a presença de forçantes baroclínicas, sendo estas atribuídas às águas provenientes do sul, talvez com influência do Rio da Prata, possivelmente influenciando também a dinâmica da PCM. 
6. Durante o período amostrado não foi verificado nenhuma influência direta da Corrente do Brasil sobre a PCM e, tampouco, sobre a PCI, demonstrando que essas regiões possuem dinâmica distinta da $\mathrm{PCE}$, onde a presença de meandros e vórtices da Corrente do Brasil é marcante.

7. A circulação na regiao estudada não é homogênea, apresentando um sistema complexo de fluxos e contra-fluxos, havendo tendência das correntes sobre a PCM e a PCI apresentarem sentidos opostos. Há também tendência das correntes na PCI apresentarem sentido predominante para NE, sobretudo entre Santos e São Sebastião, enquanto que na PCM a direção predominante é para SW.

8. Não foi possível determinar as características sazonais das correntes na PCI devido ao comprimento insuficiente das séries temporais obtidas. 


\section{Referências Bibliográficas}

Alves, M. A., 1992: Correntes de Maré e Inerciais na Plataforma Continental ao Largo de Ubatuba (sp). Dissertação de Mestrado, Universidade de São Paulo, São Paulo, 162 pp.

Amante, C. \& B. W. Eakins, 2008: ETOPO1 1 Arc-Minute Global Relief Model: Procedures, Data Sources and Analysis, National Geophysical Data Center, NESDIS, NOAA. U.S. Department of Commerce, Boulder, CO.

Caldas, M. J., 1978: Características da Estrutura e da Circulação das Águas da Plataforma Continental entre Cabo Frio e Ilha de Santa Catarina em Janeiro de 1968. Dissertação de Mestrado, Universidade de São Paulo, São Paulo, 94 pp.

Campos, E. J. D., J. E. Gonçalves, \& Y. Ikeda, 1995: Water mass structure and geostrophic circulation in the South Brazil Bight - summer of 1991. J. Geophys. Res., $100(C 9), 18.537-18.550$.

Castro, B. M., 1985: Subtidal response to wind forcing in the south Brazil bight during winter. Tese de Doutorado, University of Miami, Florida, 211 pp.

Castro, B. M., 1990: Wind driven currents in the Channel of São Sebastião: winter, 1979. Bolm. Inst. Oceanogr., 38(2), 111-132.

Castro, B. M., 1996: Correntes e Massas de Água da Plataforma Continental Norte de São Paulo. Tese de Livre Docência. Universidade de São Paulo, São Paulo, 248 pp.

Castro, B. M. \& T. Lee, 1995: Wind Forced Sea Level Variability On The Southeast Brazilian Shelf. J. Geophys. Res., 100 (8), 16.045-16.056. 
Castro, B. M. \& L. B. Miranda, 1998: Physical oceanography of the western atlantic continental shelf located between $4^{\circ} \mathrm{N}$ and $34^{\circ} \mathrm{S}$. The Sea, 11, 209-251.

Castro, B. M., L. B. Miranda, \& S. Miyao, 1987: Condições Hidrográficas na Plataforma Continental ao Largo de Ubatuba: Variações Sazonais e em Média Escala. Bolm. Inst. Oceanogr., 35 (2), 135-151.

Castro, B. M., L. B. Miranda, L. S. Silva, R. F. C. Fontes, A. F. Pereira, \& A. L. Coelho, 2008: Processos físicos: hidrografia, circulação e transporte. In: Pires-Vannin, A.M.S. (org), Oceanografia de um Ecossistema Subtropical. EDUSP, São Paulo, 59-121 pp.

Castro Filho, B. M., J. R. G. B. Moreira, A. L. Coelho, L. S. Silva, \& R. F. C. Fontes, 1995: "relatório 3". In Levantamento Oceanográfico da Área Diretamente Afetada por Efluentes dos Emissários Submarinos entre os Municípios de São Sebastião e Mongaguá, Estado de São Paulo - Subprojeto Oceanografia Física. São Paulo, Fundespa, 1-135.

Climanálise, 2004, 2005: Boletim de Monitoramento e Análise Climática. Centro de Previsão de Tempo e Estudos Climáticos - INPE.

Coelho, A. L., 2008: Resposta da Plataforma Continental Sudeste a ventos sazonais e sinóticos de verão: estudos numéricos. Tese de Doutorado, Universidade de São Paulo, São Paulo, 188 pp.

DHN, 2008: Cartas Náuticas Raster - CENTRO DE HIDROGRAFIA DA MARINHA DO BRASIL. https://www.mar.mil.br/dhn/chm/cartas/download/cartasbsb.

Emery, W. J. \& R. E. Thomson, 1998: Data analysis methods in physical oceanography. Pergamon, Great Britain, 634 pp.

Emílson, I., 1961: The shelf and coastal waters off Sourthern Brazil. Bolm. Inst. Oceanogr., 17 (2), 101-112.

Emílson, I., 1962: As correntes marítimas no Canal de São Sebastião. Cien. Cult., 14(4), $269-270$.

Fontes, R. F. C., 1995: As Correntes no Canal de São Sebastião. Dissertação de Mestrado, Universidade de São Paulo, São Paulo, 159 pp. 
Franchito, S. H., V. B. Rao, J. L. Stech, \& J. A. Lorenzzetti, 1998: The effect of coastal upwelling on the sea-breeze circulation at Cabo Frio, Brazil: a numerical experiment. Ann. Geophys., 16, 866-881.

Hellerman, S. \& M. Rosenstein, 1983: Normal monthly wind stress over the World Ocean with error estimates. J. Phys. Oceanogr., 13, 1093-1104.

Jenkins, G. M. \& D. G. Watts, 1968: Spectral Analysis and Its Applications. HD, 525 pp.

Kvinge, T., 1967: On the special current and water level variations in the channel of São Sebastião. Bolm. Inst. Oceanogr., 16(1), 23-28.

Luedemann, E. F., 1991: Contribuição ao Estudo das Correntes de Superfície sobre a Plataforma Continental do Estado de São Paulo, Brasil (Lat. 24-2501'S até Long. $\left.45^{\circ} 40^{\prime} \mathrm{W}\right)$. Bol. Inst. Oceanogr., 28, 47-53.

Matsuura, Y., 1975: A Study of Surface Currents in the Spawaning Area of Brazilian Sardine. Bolm. Inst. Oceanogr., 24, 31-44.

Mello, R. L., 2007: Estudo Numérico do Transporte de Sedimentos pela Pluma do Rio da Prata. Tese de Doutorado, Universidade de São Paulo, São Paulo, 169 pp.

Miranda, L. B., 1982: Análise de Massas de Água de Plataforma Continental e da Região Oceânica Adjacente: Cabo de S. Tomé (RJ) à Ilha de São Sebastião (SP). Tese de Livre Docência. Universidade de São Paulo, São Paulo, 194 pp.

Miranda, L. B., 1985: Forma da correlação T-S de massas de água das regiões costeira e oceânica entre o Cabe de São Tomé (RJ) e a Ilha de São Sebastião (SP). Bolm. Inst. Oceanogr., 33 (2), 105-119.

Miranda, L. B. \& B. M. Castro, 1995: Variabilidade da circulação e do transporte de volume no Canal de São Sebastião (SP): outono de 1980. Pub. Esp. Inst. Oceanogr., $11,1-9$.

Miranda, L. B. \& M. Katsuragawa, 1991: Estrutura Térmica na Região Sudeste do Brasil (Outubro/Novembro de 1988). Pub. Esp. Inst. Oceanogr., 8, 1-14. 
Moreira, J. R. G. B., 1997: Correntes na Plataforma Externa e Talude ao Largo de Santos: Observações no Verão de 1993. Dissertação de Mestrado, Universidade de São Paulo, São Paulo, 214 pp.

Moreira, M. H. R., 1998: Circulação na Plataforma Interna do Litoral Norte do Estado de São Paulo. Dissertação de Mestrado, Universidade de São Paulo, São Paulo, 153 pp.

Pereira, A. F., B. M. Castro, L. Calado, \& I. C. A. da Silveira, 2007: Numerical simulations of $\mathrm{M}_{2}$ internal tides in the South Brazil Bight and their interaction with the Brazil Current. J. Geophys. Res., 102(C04009), 1-17.

Piola, A. R., R. P. Matano, E. D. Palma, O. O. Möller Jr., \& E. J. D. Campos, 2005: The influence of the Plata River discharge on the western South Atlantic Shelf. Geophys. Res. Lett., 32 (L01603), 1-4.

Rezende, J. H. M., 2003: Intrusões da Água Central do Atlântico Sul na Plataforma Continental Sudeste durante o verão. Tese de Doutorado, Universidade de São Paulo, São Paulo.

Ruffato, D. G., 2007: Marés barotrópica e baroclínica na porção norte da Plataforma Continental Sudeste. Monografia de Graduação. Universidade de São Paulo. São Paulo, 109 pp.

Samuels, B. \& M. Cox, 1987: Data set atlas for ocean modeling. Ocean Modeling, 75, $1-3$.

Sciremammano, F. J., 1979: A suggestion for the presentation of correlations and their significance levels. J. Phys. Oceanogr., 09, 1273-1276.

Souza, M. C. A., 2000: A Corrente do Brasil ao Largo de Santos: Medições Diretas. Dissertação de Mestrado, Universidade de São Paulo, São Paulo, 169 pp.

Stech, J. L., 1990: Um estudo comparativo da dinâmica da circulação de inverno entre as plataformas continentais das costas sudeste do Brasil e dos Estados Unidos utilizando um modelo numérico. Tese de Doutorado, Universidade de São Paulo, São Paulo.

Stech, J. L. \& J. A. Lorenzzetti, 1992: The response of the South Brazil Bight to the passage of wintertime cold fronts. J. Geophys. Res., 97(C6), 9507-9520. 
Walters, R. \& C. Heston, 1982: Removing Tidal-Period Variations from Time-Series Data Using Low-Pass Digital Filters. J. Phys. Oceanogr., 12, 112-115.

Zembruscki, S., 1979: Geomorfologia da margem continental sul brasileira e das bacias oceânicas adjacentes. In PROJETO REMAC. Geomorfologia da margem continental brasileira e das áreas oceânicas adjacentes. PETROBRAS. CENPES. DINTEP (Série REMAC no. 7), Rio de Janeiro, 129-177. 